\title{
Uma proposta de protocolo Token Ring sem fio
}

\author{
Adroaldo Lazouriano Moreira Borges
}

\author{
DisSERTAÇÃO APRESENTADA \\ $\mathrm{AO}$ \\ Instituto de Matemática e Estatística \\ DA \\ Universidade DE SÃo Paulo \\ PARA \\ OBTENÇÃO DO TÍTULO \\ DE \\ Mestre em CiÊnCIAS
}

Programa: Mestrado em Ciência da Computação

Orientador: Prof. Dr. Marco Dimas Gubitoso

Durante o desenvolvimento deste trabalho o autor recebeu auxílio financeiro da CNPq

São Paulo, 7 de Março de 2014 


\section{Uma proposta de protocolo \\ Token Ring sem fio}

Esta versão da dissertação contém as correções e alterações sugeridas pela Comissão Julgadora durante a defesa da versão original do trabalho, realizada em 23/01/2014. Uma cópia da versão original está disponível no

Instituto de Matemática e Estatística da Universidade de São Paulo.

Comissão Julgadora:

- Prof. Dr. Marco Dimas Gubitoso (orientador) - IME-USP

- Prof. Dr. Francisco Carlos da Rocha Reverbel - IME-USP

- Prof. Dr. Markus Endler - PUC-Rio 
Dedico este trabalho a meus avós Brígida Pereira, Saudo Puti, Martina Fernandes e Agostinho Lopes (in memoriam). 


\section{Agradecimentos}

Agradeço a Deus pela fé e força, aos meus pais e meus irmãos pelos ensinamentos, apoios incondicionais e por serem a minha inspiração. Agradeço também a toda a minha família. Agradeço ao Professor Marco Gubitoso pela amizade, ajuda, ensinamentos, paciência despendida e conselhos. Aos professores Markus Endler, Francisco Reverbel e Daniel Batista pelas riquíssimas contribuições. Às empresas que me deram experiência profissional, em especial a LG Electronics de São Paulo. Ao IME-USP e em especial aos professores do departamento da Ciência da Computação. Ao Dr. Chih-Heng Ke pelo apoio com o simulador. Agradeço também, aos meus amigos que fiz ao longo da vida, e a todos aqueles que não citei - podem não caber nestas páginas, mas cabem na minha mente. 


\section{Resumo}

BORGES, A. L. M. Uma proposta de protocolo token ring sem fio. 2013. 120 f. Tese (Mestrado) - Instituto de Matemática e Estatística, Universidade de São Paulo, São Paulo, 2013.

O protocolo Token Ring sem fio (WTRP) é um protocolo distribuído de controle de acesso ao meio que provê qualidade de serviço em termos de uso de largura de banda e latência limitada [Erg02]. WTRP consiste de nós (estações) que formam topologicamente um anel. Contudo, quando o número de nós em um anel aumenta a latência aumenta e o tempo de reuso de token por parte de um nó em anel também aumenta. Neste trabalho, apresentamos uma versão extendida de WTRP com foco em reduzir a latência, tempo de reuso de token e permitir encaminhamento de dados entre anéis sem aumentar significativamente o consumo de energia. Para provar o conceito que propomos, implementamos e testamos a nossa versão de WTRP usando simulador de rede - NS.

Keywords: Token Ring sem fio, MANet, protocolo de controle de acesso ao meio, anel de anéis. 


\section{Abstract}

BORGES, A. L. M. A Proposal Wireless Token Ring Protocol. 2013. 120 f. Tese (Mestrado)

- Instituto de Matemática e Estatística, Universidade de São Paulo, São Paulo, 2013.

Wireless Token Ring Protocol (WTRP) is a distributed Medium Access Control protocol that provides quality of service in terms of reserved bandwidth and limited latency [Erg02]. It consists of nodes or stations structured in ring topology. However, when the number of nodes in a ring increases latency and time of a node reuse token increases. In this work, we present an extended version WTRP that focus on reducing latency, time of token reuse and data forwarding among the rings in a MANet ${ }^{1}$, without suggestive increasing of energy consumption. We have implemented and tested our version of WTRP in network simulator - NS.

Keywords: Wireless Token Ring, MANet, Medium Access Control protocol, Ring of rings.

${ }^{1}$ Rede sem fio móvel 


\section{Sumário}

Lista de abreviaturas $\quad$ xi

Lista de símbolos e constantes $\quad$ xiii

Lista de Figuras $\quad$ xv

Lista de Tabelas $\quad$ xvii

1 Introdução $\quad 1$

1.1 Motivação . . . . . . . . . . . . . . . . . . . . . . . . . 3

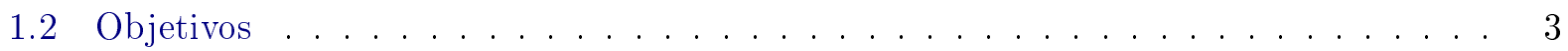

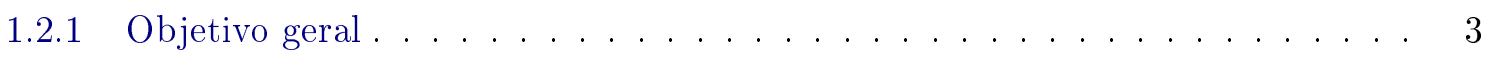

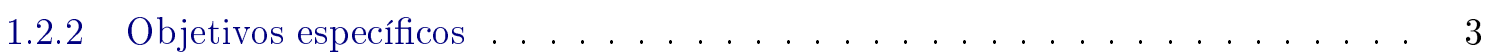

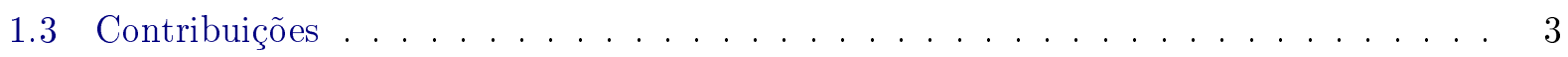

1.4 Organização do Trabalho . . . . . . . . . . . . . . . . . . . . 3

2 Conceitos básicos $\quad 5$

2.1 Redes Ad hoc móveis - MANets . . . . . . . . . . . . . . . . . 5

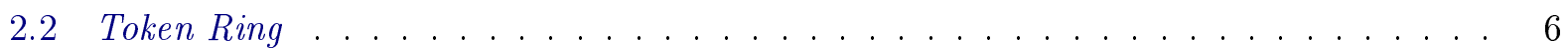

2.3 Algoritmo de eleição em anel: O algoritmo de Chang \& Roberts . . . . . . . . . . . 7

2.3 .1 Eleição de coordenador . . . . . . . . . . . . . . . . . 8

3 Protocolo Token Ring sem fio $\quad 9$

3.1 Definições . . . . . . . . . . . . . . . . . . . . . . . . 9

3.2 Revisão de arquitetura de sistema . . . . . . . . . . . . . . . . . . . . . 10

3.2 .1 Controle de acesso ao meio f . . . . . . . . . . . . . . . . 10

3.2 .2 Alocador de canal . . . . . . . . . . . . . . . . . . . . . 10

3.2 .3 Gerenciador de mobilidade . . . . . . . . . . . . . . . . . . . . . . 10

3.2 .4 Controle de admissão . . . . . . . . . . . . . . . . . . . . . . 10

3.3 O protocolo Token Ring sem fio . . . . . . . . . . . . . . . . . . . . 10

3.3 .1 Descrição . . . . . . . . . . . . . . . . . . . . . 10

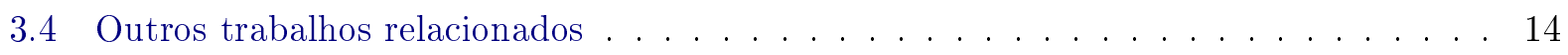

4 O protocolo $\quad 15$

4.1 A descrição do protocolo . . . . . . . . . . . . . . . . . . 15

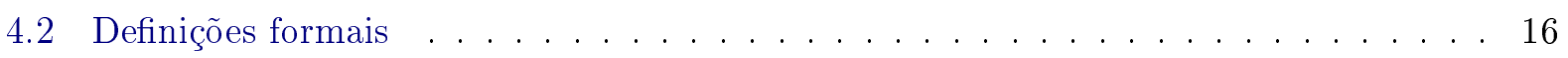


4.3 Estrutura de token ............................ 17

4.4 Comunicação entre anéis . . . . . . . . . . . . . . . . . . . . 18

4.5 Gerenciamento de conectividade . . . . . . . . . . . . . . . . . 18

4.6 Tratamento de falhas . . . . . . . . . . . . . . . . . . . 20

4.7 Procedimentos de entrada e saída . . . . . . . . . . . . . . . . . . . 21

4.7.1 Procedimento de entrada ....................... 21

4.7.2 Procedimento de saída ....................... 23

$\begin{array}{llr}5 & \text { Implementação } & \mathbf{2 7}\end{array}$

5.1 Descrição dos pacotes do projeto . . . . . . . . . . . . . . . . . . 27

5.2 Definições e constantes . . . . . . . . . . . . . . . . . . . . . . . . . . 29

5.3 Transmissão de Token . . . . . . . . . . . . . . . . . . 29

5.4 Relação entre módulos . . . . . . . . . . . . . . . . . . . . . . . . 30

6 Resultados experimentais $\quad 33$

6.1 Ambiente de experimentos . . . . . . . . . . . . . . . . . . 33

6.2 Ambiente de simulação . . . . . . . . . . . . . . . . . . . . . . 33

6.3 Experimentos e resultados ........................... 34

6.3.1 Tempo de rotação de token . . . . . . . . . . . . . . . . . . . . . . 34

6.3.2 Resultado de experimento de taxa de transferência de dados . . . . . . . . 35

6.3.3 Atraso médio ponto a ponto . . . . . . . . . . . . . . . . 36

6.3.4 Configuração para simulação com posicionamento aleatório . . . . . . . . . 37

6.3.5 Resultados de teste de configuração . . . . . . . . . . . . . . . . . . . 38

6.3.6 Experimento do consumo de energia . . . . . . . . . . . . . . . . 40

7 Conclusões $\quad \mathbf{4 3}$

7.1 Considerações Finais . . . . . . . . . . . . . . . . . . . . . . . . . . . . . 44

7.2 Sugestões para Pesquisas Futuras . . . . . . . . . . . . . . . . . . . . . . 44

7.2.1 Alcançabilidade ............................ . . 44

7.2.2 Consumo de energia .......................... . . 45

$\begin{array}{lll}\text { A Especificação } & \mathbf{4 7}\end{array}$

A.1 Especificação dos quadros de tokens . . . . . . . . . . . . . . . . . . . . . . 47

B Alguns detalhes da implementação do protocolo 51

B.1 Descrição dos arquivos criados . . . . . . . . . . . . . . . . . . . . . . 51

B.1.1 wtrp.h ......................... 51

B.1.2 wtrp.cc ............................ 52

B.1.3 wtrp_packet.h ......................... 55

B.1.4 node.h............................ 55

B.1.5 ringutils.h e ringutils.cc . . . . . . . . . . . . . . . . . . 56

B.1.6 utils-constants.h .........................56

B.2 Arquivos alterados . . . . . . . . . . . . . . . . . . 56

B.2.1 Arquivos em $\mathrm{C}++$ e o Makefile .................... . 56

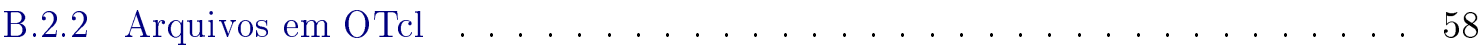


B.3 Simulador de rede . . . . . . . . . . . . . . . . . . . . . 59

B.3.1 Exemplo de um arquivo TCL . . . . . . . . . . . . . . . 59

B.3.2 Revisão do conceito . . . . . . . . . . . . . . . . . 60

B.3.3 Estrutura do diretório NS . . . . . . . . . . . . . . . . 60

$\begin{array}{lll}\text { C Os problemas de terminal oculto e terminal exposto } & 61\end{array}$

$\begin{array}{lll}\text { D Implementação de energia recebida com um pacote no NS } & 63\end{array}$

$\begin{array}{lll}\text { E As configurações } & \mathbf{6 5}\end{array}$

E.1 Amostra do Resultado de simulações pelo critério conexão com primeira resposta . . 65

E.2 Resultado de simulações pelo critério número de nós $\ldots \ldots$. . . . . . . . . 66

E.3 Resultado de simulações pelo critério sinal de recebimento de pacote . . . . . . . 67

$\begin{array}{ll}\text { Referências Bibliográficas } & 71\end{array}$ 


\title{
Lista de abreviaturas
}

\author{
ACK Acknowledge \\ AckI Implicit Acknowledge \\ AODV Ad-hoc On Demand Distance Vector
}

AP Access Point

AWK Alfred V. Aho, Peter J. Weinberger e Brian W. Kernighan

BS Base Station

bps bits per second

CBR Constant Bit Rate

CTS Clear To Send

DA Destine Address

DARPA Defense Advanced Research Projects Agency

DCF Distributed Coordination Function

evWTRP extended version of Wireless Token Ring Protocol

FC Frame Control

GSM Global System for Mobile communications

IBM International Business Machine

IEEE Institute of Electrical and Electronics Engineers

Kbps Kilobits per second

LAN Local Area Network

MAC Medium Access Control

MAN Metropolitan Area Network

MANet Mobile Ad-hoc Network

Mbps Megabits per second 
MIB Management Information Base

NAM Network Animator

NoN Number of node

NS Network Simulator

OTcl Object-oriented Tool command language

PCF Point Coordination Function

PDU Protocol Data Unit

PRPC Primeira Resposta Primeiro Contato

QoS Quality of Service

RA Ring Address

RTS Request To Send

RTR NS routing layer

SA Source Address

Seq Sequence

Tcl Tool command language

TclCL Tool command language with Classes

THT Token Holding Time

TRT Token Rotation Time

TTL Time To Live

UDP User Datagram Protocol

UMTS Universal Mobile Telecommunications System

WMAN Wireless Metropolitan Area Network

WLAN Wireless Local Area Network

WTRP Wireless Token Ring Protocol

WWAN Wireless Wide Area Network 


\section{Lista de símbolos e constantes}

$\varepsilon$

$\Theta$

$\Delta$ tev

$\Delta \mathrm{t}$

$\theta \mathrm{r}$

$\theta \mathrm{e}$

npacote

$R n$

NnVm

INITIALVALUE

ENERGYMODEL
Energia restante.

Tempo de eleição.

Diferença de tempo entre enviar e receber token.

Diferença de tempo (atraso) entre o tempo que uma estação emissora envia pacote de dados e o tempo que uma estação receptora recebe o pacote de dados enviado.

Tempo de recepção de token.

Tempo de envio de token.

Quantidade de pacotes de dados recebidos.

Estrutura em Anel de $n$ nós. Ex. R12, anel de 12 nós.

Estrutura em Varal de $n$ nós e $m$ nós no varal.

Ex. $N 12 V 4$, Varal de 4 nós e os demais espalhados pelos sub-anéis.

Parâmetro energia inicial de um nó no NS.

Parâmetro modelo de energia em cada nó no NS. 


\section{Lista de Figuras}

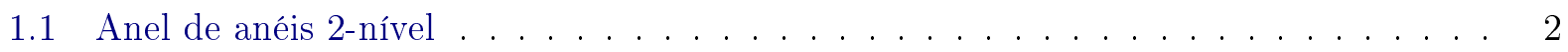

2.1 Duas redes com estruturas diferentes . . . . . . . . . . . . . . . . 5

2.2 Uma rede Token Ring . . . . . . . . . . . . . . . . . . . . 7

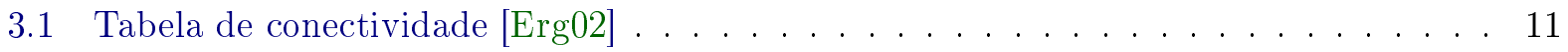

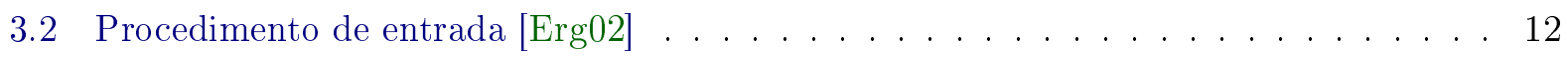

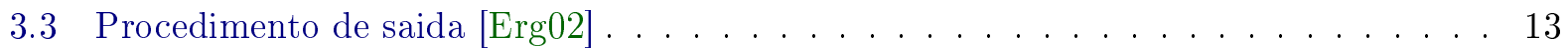

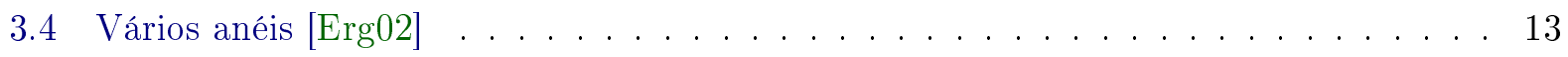

4.1 Anel de anéis . . . . . . . . . . . . . . . . . . . 15

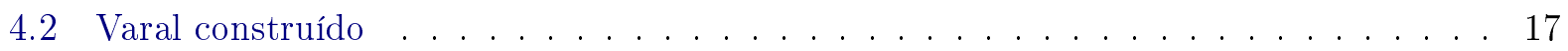

4.3 Anel $\mathrm{R}$ pendurado no varal . . . . . . . . . . . . . . . 17

4.4 Anel unitário R . . . . . . . . . . . . . . . . . . . . 17

4.5 Lista de ids em C . . . . . . . . . . . . . . . . . . 19

4.6 Alcance de sinal e tabelas de conectividade do $\mathrm{H} \ldots \ldots \ldots \ldots$

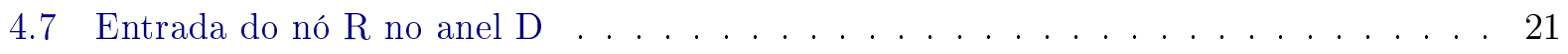

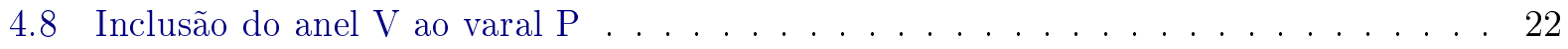

4.9 Saída do nó A do anel $\mathrm{R}$ e coordenador $\mathrm{T} \ldots \ldots \ldots \ldots$. . . . . . . . . . . . . . . . . . . . . . . . . .

4.10 Saída do coordenador E . . . . . . . . . . . . . . . . . . . 24

4.11 Reconexão do anel após a saída do nó E . . . . . . . . . . . . . . 25

5.1 union com cabeçalho de todas as mensagens . . . . . . . . . . . . . 27

5.2 Representação de transmissão de token por broadcast . . . . . . . . . . . . . . 30

5.3 estrutura dos arquivos incluídos . . . . . . . . . . . . . . 30

6.1 Gráfico de TRT . . . . . . . . . . . . . . . . . . 35

6.2 Gráficos de taxa de transferência média em redes com 10, 30 e 50 nós . . . . . . . . 36

6.3 Gráficos de atraso médio ponto a ponto . . . . . . . . . . . . 37

6.4 Exemplo de cenário e a sua configuração . . . . . . . . . . . . . . . . 38

6.5 Configurações e ocorrências pelo critério PRPC . . . . . . . . . . . . . . . 39

6.6 Configurações e ocorrências pelo critério número de nós $\ldots \ldots \ldots$. . . . . . . . 39

6.7 Configurações e ocorrências pelo critério sinal de recebimento de pacote . . . . . . 40

6.8 Cenário para o teste do consumo de energia . . . . . . . . . . . . . . . 40

6.9 Resultados do consumo de energia nos 100 segundos iniciais . . . . . . . . . . . . 41

6.10 Resultados do consumo de energia nos 10 segundos finais . . . . . . . . . . . . . . 41 
7.1 Exemplo de uma estrutura para maior alcançabilidade . . . . . . . . . . . . . . . 44

7.2 Transformação de anel em varal . . . . . . . . . . . . . . . . . . . 45

B.1 Exemplo de um arquivo TCL . . . . . . . . . . . . . . . . . 59

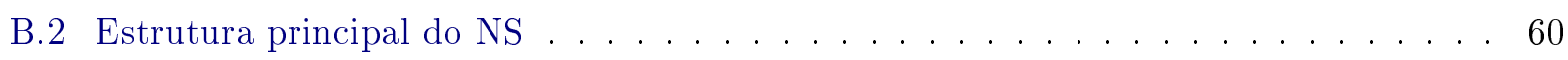

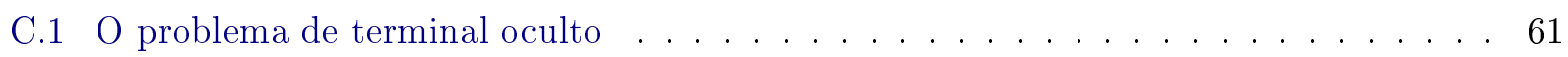

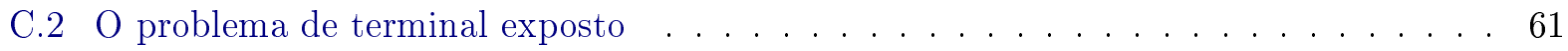




\section{Lista de Tabelas}

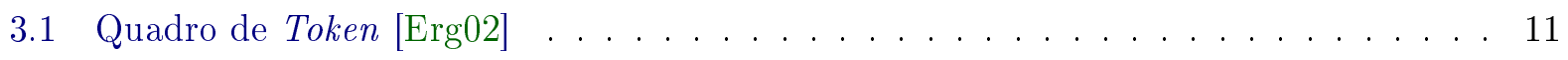

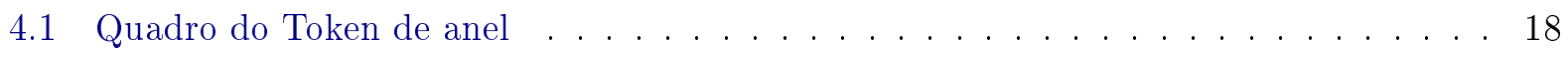

5.1 Tabela de tokens . . . . . . . . . . . . . . . . . . . . . 28

6.1 Tabela de parâmetros de simulação . . . . . . . . . . . . . . . . 34 


\section{Capítulo 1}

\section{Introdução}

A computação móvel voltada às telecomunicações é uma das áreas de pesquisa em evidência. Do passado relativamente recente aos dias de hoje, temos tido: comunicações entre estações bases (BS) na terra e os foguetes em viagem além do planeta terra; aparelhos de telefonia móvel e smartphones cada vez mais inteligentes; tablets, e computadores portáveis com capacidades de processamento e armazenamento melhoradas dia após dias. Para poder executar comunicação à distância, todas essas tecnologias são equipadas com dispositivos que permitem comunicações em ambientes de redes sem fio.

De uma forma breve, dizemos que uma rede sem fio é formada por um conjunto de dispositivos com a capacidade de se conectarem, e transmitirem e/ou receberem dados entre si, sem cabeamento. Diariamente utilizamos algumas redes sem fio. Por exemplo, rede WWAN (Wireless Wide Area Network) de telecomunicações móvel ou WLAN (Wireless Local Area Network) wi-fi, ou mesmo uma rede formada por dispositivos móveis equipados com tecnologia bluetooth.

A arquitetura de uma rede sem fio pode ser infraestruturada (por exemplo, telecomunicações móvel) ou ad-hoc (por exemplo, rede de dispositivos móveis com bluetooth). Normalmente, redes com infraestrutura são compostas por satélites, antenas de transmissão e recepção, estações base BS, pontos de acesso AP e terminais móveis (nós), dentre outros componentes. Se algum dos componentes não-terminais falhar comprometerá funcionamento da rede. Já uma rede $a d$-hoc sem fio é composta exclusivamente por dispositivos móveis em uma área local. Uma rede desta natureza pode ser descentralizada e homogênea. Se um terminal cair não comprometerá o funcionamento da rede. Aliás, nesta abordagem, os terminais funcionam como intermediários (roteadores) com finalidade de encaminhar dados de um terminal origem para um terminal destino. Essas redes ad-hoc são adequadas em situações de emergência e em caso de desastres naturais onde não haja redes infraestruturadas (por exemplo, redes de telefonia celular) [HMDD04]. Porém, ainda existem desafios a serem superados.

Os fatores queda de nós (devido a alcance de sinal curto e a bateria com pouca carga, por exemplo), eficiência em uso de largura de banda, controle de interferência entre os nós, e a limitação de latência, são alguns dos desafios em uma rede $a d-h o c$ sem fio móvel.

Pesquisadores têm trabalhado no sentido de apresentar soluções cada vez melhores para superar problemas em redes sem fio, em especial MANets (Redes ad-hoc móveis sem fio). Consequentemente, WTRP (Wireless Token Ring Protocol) foi apresentado.

WTRP é um protocolo distribuído de controle de acesso ao meio [Erg02]. Nesse protocolo, as estações (neste trabalho, estação, nó, nó, terminal são sinônimos) assumem uma topologia em forma 
de anel. A estação atual recebe token da estação anterior a ele no anel e passa token para estação posterior a ele no anel. O trabalho inicial foi desenvolvido pelo Dr. Duke Lee e subsequentemente gerou vários outros trabalhos dentre eles a dissertação de mestrado do Dr. Mustafa Ergen.

Enquanto especificações de tecnologia 802.11 resolvem problema de controle de acesso ao meio implementando DCF (Distributed Coordination Function) e/ou PCF (Point Coordination Function) [IEE07], e problema de colisões de pacotes (introduzido por problema de terminal oculto C) implentando mecanismos de RTS (Request-To-Send) e CTS (Clear-To-Send); WTRP, naturalmente evita esses problemas através de uso de token [Erg02]. Este protocolo provê qualidade de serviço em termos de uso reservado de largura de banda e latência limitada. Essas QoS são benéficas aos aplicativos que rodam em ambiente $a d-h o c$ sem fio. WTRP é robusto contra queda de um nó e dá suporte às topologias flexíveis através de fato de cada nó ser parcialmente conectado (nem todos os nós precisam estar conectados entre si) [Erg02]. Porém, a medida que o diâmetro do anel cresce o tempo que um determinado nó leva para reutilizar token também cresce, e a latência pode aumentar. Para lidar com esses problemas apresentamos evWTRP (extended version of Wireless Token Ring Protocol).

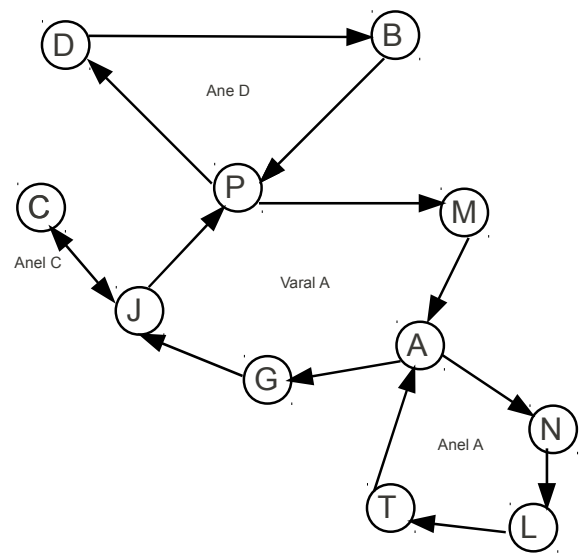

Figura 1.1: Anel de anéis 2-nível

O protocolo evWTRP é um protocolo de controle de acesso ao meio que se baseia em WTRP com foco em encaminhamento de dados entre nós em diferentes anéis, e em não aumentar o tempo de reutilização de token e a latência, à medida que o número de nós em anel cresce. Sem aumentar significativamente o consumo de energia quando comparado a WTRP. Este protocolo é formado por anel de anéis em 2-nível ${ }^{1}$ (figura 1.1). Para testar a nossa proposta, implementamos o evWTRP no simulador, testamos e apresentamos os resultados.

\footnotetext{
${ }^{1}$ Anel 2-nível é uma estrutura em que os anéis estão pendurados a um anel que não está pendurado
} 


\subsection{Motivação}

Prover um protocolo de roteamento que facilite o desenvolvimento de aplicativos para troca de dados entre usuários participantes co-localizados em uma sala de conferência e aeronaves não tripuladas, por exemplo, que requerem um controle rígido de largura de banda, latência limitada e rapidez na cobertura de falha.

\subsection{Objetivos}

\subsubsection{Objetivo geral}

O nosso objetivo é desenvolver um protocolo de controle de acesso ao meio alternativo a WTRP para redes ad-hoc móveis.

\subsubsection{Objetivos específicos}

Prover uma alternativa a WTRP, que permita:

- menos tempo para reuso de meio de comunicação através de token

- reduzir latência de acesso ao meio

- adicionar procedimentos para encaminhamento de dados entre estações de anéis diferentes.

Sem aumentar significativamente o consumo de energia.

\subsection{Contribuições}

A principal contribuição deste trabalho é:

- Proposta e implementação de software para encaminhamento de dados em uma rede com topologia de anel de anéis.

\subsection{Organização do Trabalho}

O resto do trabalho está organizado da seguinte forma: no capítulo 2, apresentamos os conceitos de redes ad-hoc móveis - MANets. As suas características e benefícios em relação às redes infraestruturadas; apresentamos de uma forma sucinta o conceito Token Ring, entre especificações [trs98] e adaptações $\left[\mathrm{LAP}^{+} 01\right]$; e finalmente, apresentamos também algoritmo de eleição de líder de Chang \& Roberts [TS02] (uma adaptação para eleição de proprietário de anel). O capítulo 3 é dedicado aos trabalhos relacionados. No nosso caso, o trabalho altamente relacionado é o trabalho de dissertação de mestrado do Dr. Ergen [Erg02]. Apresentamos os principais procedimentos de WTRP e alguns pontos de outros trabalhos relacionados. No capítulo 4, apresentamos o nosso protocolo evWTRP. No capítulo 5, descrevemos de forma breve as mensagens "tokens" do protocolo, explicamos como foi implementada a transmissão de token de permissão, e apresentamos diagrama de arquivos do protocolo. No capítulo 6, discutimos os resultados alcançados após testes. E, finalmente, no capítulo 7, tecemos as considerações finais e sugerimos possível direção para trabalhos futuros relacionados a 
Token Ring sem fio. Ainda, no apêndice A, apresentamos as especificações de quadros de tokens (de permissão e adicionais), e também apresentamos estruturas de como foi feita a implementação. No apêndice B, apresentamos alguns detalhes da nossa implementação e algumas informações sobre o simulador, assim como alguns conceitos complementares. No apêndice C, apresentamos os problemas de terminais (nós) ocultos e terminais expostos. No apêndice D, descrevemos as alterações feitas no NS para poder ter acesso a energia recebida com cada pacote recebido. E, finalmente no apêndice E, apresentamos as tabelas com as configurações resultantes dos testes de configuração. 


\section{Capítulo 2}

\section{Conceitos básicos}

Neste capítulo apresentamos os conceitos fundamentais para concepção do nosso protocolo. Esses conceitos são: redes ad-hoc móveis, Token Ring e um algoritmo alternativo de eleição em anel.

Redes $a d$-hoc móveis são redes móveis em que os terminais não precisam ter infraestruturas (exemplo, estações bases) para comunicarem e cooperarem entre si.

É importante mencionar a origem e algumas especificações básicas de Token Ring. Por exemplo, estrutura física e estrutura lógica, e o funcionamento.

Para que possamos atribuir responsabilidade a nós em um anel, escolhemos implementar um critério justo baseado em algoritmos de eleição.

A seguir, apresentamos mais informações para cada tópico.

\subsection{Redes Ad hoc móveis - MANets}

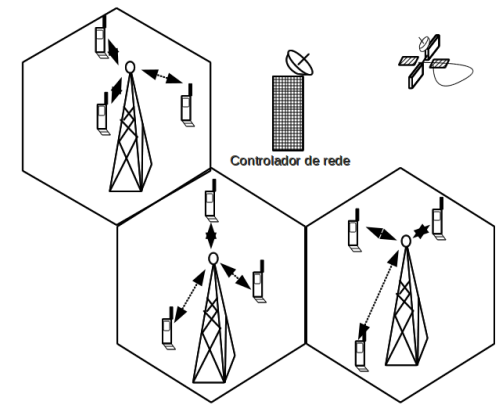

(a) Uma rede com infraestrutura fixa

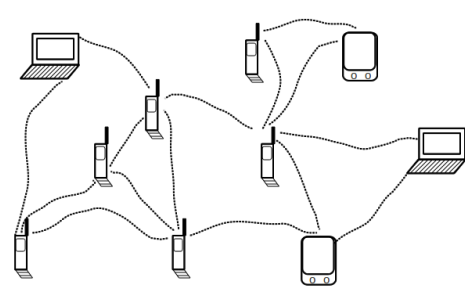

(b) Uma rede ad hoc móve

Figura 2.1: Duas redes com estruturas diferentes

Rede celular ou rede de sistema celular (a) é atualmente a topologia de comunicação sem fio dominante. Ela tem sido a base de todos os sistemas de comunicação móvel pessoal tais como UMTS (sistema universal de telecomunicações móvel), GSM (Sistema Global Para Comunicações Móvel), etc [TT06]. Como mostramos na figura (2.1 a), em uma rede celular somente o último salto (ligação a satélite e controlador da rede, e ligação a uma estação base e aparelhos móveis) é sem fio, todo aparelho móvel remetente precisa contactar uma estação base para poder alcançar um aparelho móvel destino, e um controlador de rede é o operador das principais funções do sistema. Em redes dessa natureza (arquitetura centralizada), se o controlador de rede falhar está última fica 
inoperante. Uma alternativa (distribuída e descentralizada) à rede de sistema celular é rede $a d$ hoc móvel.

Uma rede ad hoc móvel 2.1 (b) é uma coleção autônoma de dispositivos móveis (não necessariamente homogenêos) que se comunicam através de enlaces sem fio, e colaboram entre si de modo distribuído de forma a prover funcionalidades necessárias na ausência de infraestrutura fixa [HMDD04]. Ao contrário de redes sem fio com infraestruturas 2.1 (a), onde cada estação se comunica diretamente com alguma estação base ou ponto de acesso, uma MANet, não depende de infraestrutura fixa para executar as operações inerentes.

O conceito MANet começou em 1972 com o projeto Packet Radio Network da DARPA [HMDD04]. As suas vantagens suscitaram interesses em organizações de resgate e instituições militares para uso em situações de desastre e ambientes hostís. Somente em meados dos anos 1990 com a comercialização de tecnologia de rádio é que a comunidade de pesquisa em tecnologias sem fio ficou ciente da grande potencialidade que redes desta natureza possuem.

Em uma rede dessa natureza, quando um dispositivo deseja se comunicar ou usufruir de algum serviço provido pela rede, se auto-cria, descobre outros nós, se inteira de serviços disponíveis e solicita conectividades. Uma vez que se conectou, o dispositivo deve ser capaz de funcionar como remetente, destino e também como roteador para encaminhamento de dados pertencentes a nós com área de transmissão inalcançável pelos dispositivos destinos.

Essa funcionalidade de encaminhamento garante que o roteamento em uma rede MANet seja multisalto. Além de roteamento ser multisalto, as características de uma rede ad hoc móvel podem ser topologia dinâmica, heterogeneidade de dispositivos em uma mesma rede MANet, além dos já mencionados independência e livre de infraestrutura.

Apesar de conhecermos bem a arquitetura de redes com infraestrutura fixa, em especial rede celular, que por todas as métricas tem provado ser a tecnologia mais bem sucedida da última década [TT06], a pesquisa em redes ad hoc sem fio continua porque uma rede desta natureza pode ser rapidamente inicializada com pouca intervenção de usuário; tem a capacidade de se auto-criar, auto-organizar e auto-administrar; não tem dispesas com estações base e cabeamento; e têm várias aplicações.

\section{$2.2 \quad$ Token Ring}

Originalmente, o protocolo Token Ring foi desenvolvido pela IBM no começo dos anos oitenta. E mais tarde, foi padronizado e incluso nas especificações de IEEE sob denominação de IEEE 802.5 [trs98].

De acordo com as especificações em [trs98], a estrutura física de um Token Ring consiste em topologia em estrela, enquanto a sua estrutura lógica é um anel. Na figura 2.2, apresentamos um exemplo de topologia em estrela (b) para representação física, e uma topologia em anel (a) para representação lógica.

Token Ring é formado por estações de trabalho fisicamente conectadas que disputam direito exclusivo e momentâneo para uso de um meio de transmissão de dados. Ter esse direito exclusivo, só é possível se uma determinada estação estiver com token - um controlador de transmissões contido de uma sequência de bits única que circula em meio de transmissões. A circulação de um token pode ser feita em sentido único, ou horário, ou anti-horário. O token passa de estação em 


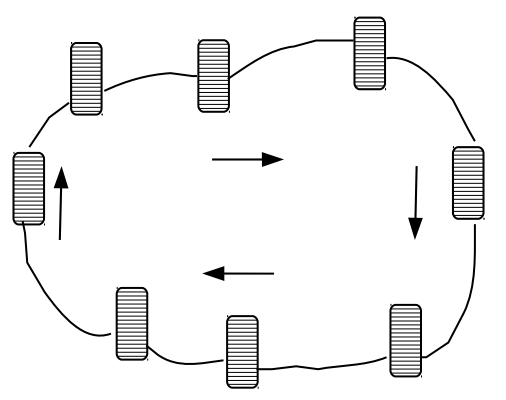

a) Estrutura lógica

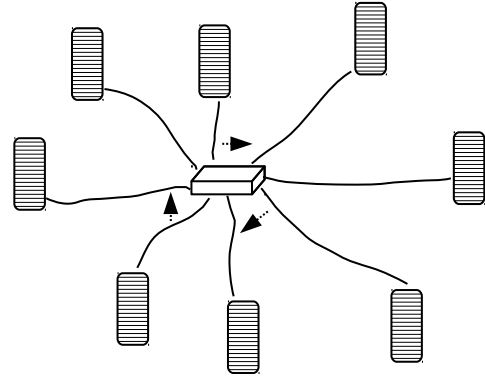

b) Estrutura física

Figura 2.2: Uma rede Token Ring

estação. Na figura 2.2, escolhemos a circulação no sentido horário. Porém, alertamos que o sentido de circulação de token no nosso protocolo Token Ring sem fio é determinado pelo predecessor e o sucessor do primeiro nó disponível.

Quando uma estação detecta o token apropriado, faz as atualizações dependentes do token para depois transmitir os dados e liberar o token. Porém, se uma estação receber um token apropriado e não tiver dados para transmitir, libera o token para que uma outra estação possa utilizar.

De acordo com a especificação [trs98], uma estação pode reter um token até que ela termine de transmitir os pacotes armazenados em uma fila local.

Para cada classe de serviço, por exemplo, voz em tempo real, interatividade, recuperação de rede, é alocada uma prioridade por acordo mútuo entre usuários de rede.

Também, detecção de erros e mecanismos de recuperação de falha são providos para restauração de rede.

Uma rede em Token Ring é classificada como uma LAN e também aplicável a uma rede de área metropolitana (MAN).

De acordo com a nossa pesquisa e levantamento bibliográfico, o último trabalho ([CCH07]) de pesquisa relacionado a Token Ring sem fio, relativamente recente, foi publicado no ano de 2007.

\subsection{Algoritmo de eleição em anel: O algoritmo de Chang \& Roberts}

Este [TS02] algoritmo distribuído supõe que:

- os nós estão dispostos em forma de anel, cada nó executa localmente o mesmo algoritmo e conhece todos os nós no seu anel.

- as mensagens são enviadas em sentido único (sentido horário, no nosso caso)

- cada nó tem um identificador ID diferente dos demais nós 
- qualquer nó pode iniciar uma eleição.

Uma eleição é feita baseada em IDs de nós. E, uma mensagem eleição é do tipo E(ID, participante). Quando algum nó detecta que o líder atual não está presente:

- ele constrói uma mensagem E(ID, participante), e envia essa mensagem para seu sucessor.

- quando um sucessor $s$ receber uma mensagem do tipo eleição, ele compara o ID na mensagem com o ID dele $(s)$.

- se o ID dele $(s)$ for maior que o ID na mensagem recebida, $s$ constrói uma nova mensagem $\mathrm{E}(\mathrm{ID}$ de $s$, participante) e envia para o sucessor dele.

- se o ID dele for menor que o ID na mensagem recebida, ele envia a mensagem recebida para o sucessor dele.

- se um nó receber uma mensagem contendo ID dele, então ele é o novo líder. Logo, ele envia uma mensagem para o sucessor dele informando que ele é o novo líder. Quando essa mensagem voltar a ele termina o processo de eleição.

Note: uma vez que ID de cada nó é único, o nó eleito será único.

\subsubsection{Eleição de coordenador}

Nesta seção explicaremos a nossa versão do algoritmo de eleição (seção 2.3), levando em conta energia dos nós. Neste caso para eleição de um coordenador (ou, proprietário).

Consideremos $I D$ identificador de um nó, $\varepsilon$ energia restante em um nó e um tipo de mensagem $\mu(R A, I D, \varepsilon)$. Onde, $R A$ é o identificador do anel onde ocorre a eleição e $I D$ é identificador do nó, no anel, com maior $\varepsilon$ até o momento atual.

Um nó começa uma eleição gerando uma mensagem $\mu(R A, I D, \varepsilon)$. Onde $R A$ é o identificador do anel onde está ocorrendo eleição. ID é o identificador dele e $\varepsilon$ é a energia restante nele. Após gerar esta mensagem, ele envia-a para o sucessor dele.

Quando um nó receber uma mensagem $\mu(R A, I D, \varepsilon)$, ele verifica se faz parte do anel com endereço $R A$. Se sim, ele compara $\varepsilon$ local com $\varepsilon$ da mensagem. Se $\varepsilon$ local for maior, ele gera uma nova mensagem $\mu(R A, I D, \varepsilon)$ com $I D$ e $\varepsilon$ dele, mesmo $R A$, e envia esta nova mensagem para o sucessor dele. Se $\varepsilon$ local for menor, ele envia a mesma mensagem recebida para o sucessor dele. Se $\varepsilon$ local e $\varepsilon$ na mensagem forem iguais, usam-se $I D s$ como critério de desempate. I.e., se $I D$ local for maior, o nó gera uma nova mensagem e envia-a para o sucessor dele, senão envia a mensagem recebida para o sucessor dele. 


\section{Capítulo 3}

\section{Protocolo Token Ring sem fio}

Nas próximas seções, faremos uma revisão do protocolo Token Ring sem fio (WTRP) [Erg02].

Primeira versão de WTRP foi desenvolvida por uma equipe de pesquisadores da Berkeley [LAP $\left.{ }^{+} 01\right]$ liderada pelo Dr. Duke Lee. O objetivo era apresentar uma solução para sistemas de transportes inteligentes. Sucederam outras versões $\left[\mathrm{LPV}^{+} 02\right]$ no sentido de melhorar o protocolo. Dentre as versões posteriores Dr. Mustafa Ergen produziu a versão que serve de base para o nosso trabalho.

\subsection{Definições}

Os termos (e as suas definições) no [Erg02] que consideramos relevantes para o nosso trabalho são:

1. quadro refere-se a sequência de bits que é passada à camada fisica.

2. As palavras identificador e endereço serão utilizadas indiscriminadamente.

3. nó proprietário de um anel é o nó cujo identificador é também identificador do anel.

4. um nó representa qualquer dispositivo móvel, capaz de detectar, receber e transmitir sinais. As palavras estação, nódo e nó serão utilizados como sinônimos (não só neste capítulo, mas em todo o trabalho).

5. predecessor e sucessor de um nó $\mathrm{X}$ representam os nós de quem $\mathrm{X}$ recebe, e a quem o X passa um token, respectivamente.

6. "anel próprio" refere-se a um anel onde os campos sucessor e predecessor de qualquer nó são identificadores (ID) corretos (vide o trabalho [Erg02] seção 1 do capítulo 10).

7. a capacidade de uma rede é o total da sua largura de banda.

8. Um token é uma sequência de sinal transmitido de nó em nó usado para controlar o acesso a meio [trs98]. As palavras "token" e "token de permissão" serão usadas indiscriminadamente. 


\subsection{Revisão de arquitetura de sistema}

\subsubsection{Controle de acesso ao meio}

Controle de acesso ao meio (MAC) permite várias estações transmitirem no mesmo meio (canal). Mas também é possível utilizar múltiplos canais de forma a reduzir colisões (falaremos desse assunto mais adiante).

Na arquitetura de WTRP, a camada MAC gerencia um anel e tempo de transmissões neste anel.

O gerenciamento de um anel envolve:

1. Certificar que cada anel (podemos ter vários anéis isolados) tem um único identificador.

2. Certificar que existe exatamente um token para um anel.

3. Certificar que o anel é próprio.

4. Executar operações de inclusão e saída de estações.

\subsubsection{Alocador de canal}

Alocador de canal escolhe um canal em que um nó deve transmitir de modo a evitar interferências. No WTRP, cada estação (nó) possui um alocador de canal. Então, cada nó tem capacidade de decidir que canal usar (de forma distribuída) analizando as informações (número de nós e número de sequência, por exemplo) coletadas de token. Um token contém um campo designado a número de nós (NoN) em anel. Se esse NoN alcançar o valor máximo, então é uma indicação que estações fora do anel não podem aderir a este anel. Consequentemente, esses nós devem buscar outros anéis.

\subsubsection{Gerenciador de mobilidade}

Gerenciador de mobilidade decide quando uma estação entra ou sai do anel. O problema que o gerenciador de mobilidade tem a resolver é similar ao problema de hand-off móvel. I.e., quando um nó móvel se afasta de um anel e se aproxima de um outro anel, por um limiar, o gerenciador de mobilidade decide mudar este nó para o anel a qual ele se aproxima.

\subsubsection{Controle de admissão}

Controlador de admissão tem a responsabilidade de limitar o número de estações que podem transmitir em um meio. Isso assegura latência limitada e largura de banda reservada para estações que já têm permissão para transmitir no meio. Existe um controlador de admissão em cada anel. Periodicamente, ele solicita outras estações para participarem do anel, se algum recurso está disponível. E, somente estações que precisam de menos recursos que os disponíveis podem tentar participar do anel [ELSV02].

\subsection{O protocolo Token Ring sem fio}

\subsubsection{Descrição}

Em WTRP, os campos predecessor e sucessor de cada nó definem o anel e a ordem de transmissão. 
Uma estação recebe token do seu predecessor, transmite dados e passa o token para o seu sucessor. A seguir, ilustraremos um quadro de token e passamos a explicar os campos incluídos nele: O campo FC designa tipo de pacote, tais como Token de permissão (o token tradicional),

\begin{tabular}{|l|l|l|l|l|l|l|}
\hline FC & RA & DA & SA & NoN & Gen_Seq & Seq \\
\hline
\end{tabular}

Tabela 3.1: Quadro de Token [Erg02]

Solicit Successor, Set Predecessor, etc. Os campos endereço de origem (SA), endereço destino (DA), identificador de anel (RA), número de sequência (Seq), e o número de geração são incluídos. RA designa o anel a que o token pertence. Seq é inicializado com zero e é incremetado por cada nó que recebe o token. Gen_Seq é inicializado com zero e incrementado cada vez que o proprietário de anel recebe o token. Também, NoN é representado em anel, ele é calculado através de diferença de Seq em uma rotação do token.

Cada nó mantém informações sobre as transmissões feitas no seu anel e nos anéis próximos. Para ajudar nessa tarefa, cada nó constrói e mantém localmente uma lista ordenada de nós no seu anel e uma lista não ordenada e global de nós fora do seu anel, mas dos quais está ouvindo transmissões. Na figura 3.1, a estação D monitora
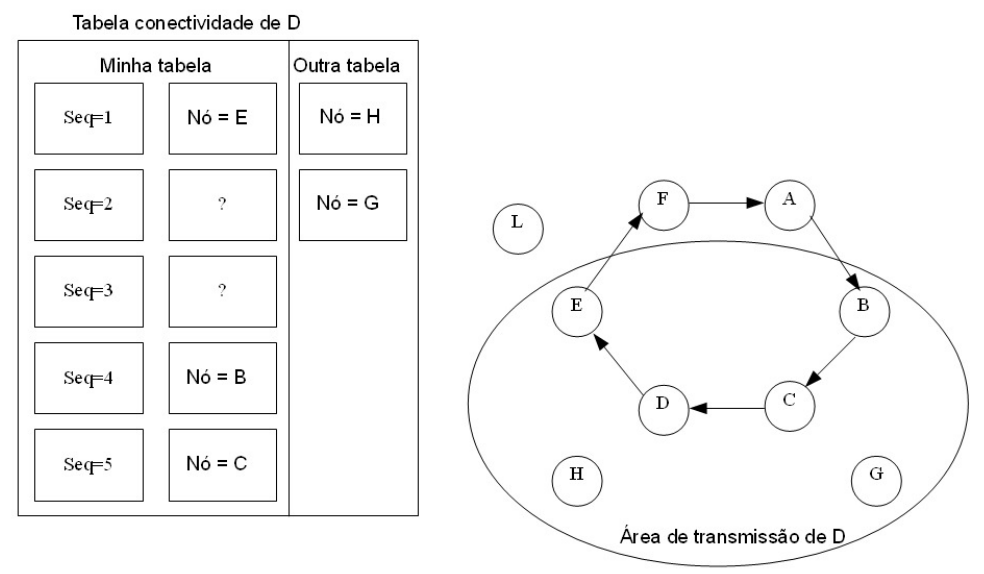

Figura 3.1: Tabela de conectividade [Erg02]

as sucessivas transmissões de token de $\mathrm{E}$ para $\mathrm{F}$ antes que o token volte a ele. No tempo 0 , D transmite o token com sequência número 0; no tempo 1, E transmite o token com sequência 1, e assim a diante. D não escutará as transmissões de $\mathrm{F}$ e A, mas quando ele escutar transmissão de origem no B, D reparará que o número de sequência foi aumentado em 3 ao invés de 1 . Isso indica a D que houveram duas estações que ela não conseguiu escutar entre $\mathrm{E}$ e B.

Proprietário de um anel é a estação cujo endereço MAC é o mesmo que o identificador de anel. Proprietário de um anel pode mudar. Para isso, basta o nó reivindicador mudar o identificador de anel para o seu endereço MAC.

Um nó depende de $A C K$ implícito $(A c k I)$ para monitorar a sua transmissão de token. Quando ele receber AckI, o nó fica ciente que a sua transmissão de token foi bem sucedida. Ou seja, se 
nenhum AckI for escutado então o token não terá sido recebido e se perdeu. Neste caso, o tempo de espera pela transmissão de token expirou. Como consequência, o nó que não escutou o AckI gerará um novo token e auto proclamar-se-á proprietário do token.

Para resolver problema de vários tokens (garantir unicidade), um conceito de prioridade é usado. Gen_Seq e RA definem a prioridade de um token. Um token com Gen_Seq maior tem prioridade mais alta. Quando Gen_Seq de dois tokens são iguais, identificador de anel de cada token é usado para o desempate. A prioridade de um nó é a prioridade do último token que este nó aceitou ou gerou. Quando um nó recebe um token com prioridade menor que a dele, ele elimina o token e notifica o predecessor sem aceitar o token.

O mecanismo de recuperação de anel é invocado quando algum nó que faz monitoramento decide que o seu sucessor não está alcançável. Neste caso, o nó tenta recuperar da falha formando anel novamente. A estratégia de WTRP para reconstruir um anel é tentar excluir o menor número possível de nós. Usando a tabela de conectividade, o nó que faz monitoramento é capaz de rapidamente encontrar (na ordem de transmissão) um nó (no anel) para reconectar o anel enviando uma mensagem de reconexão para o nó escolhido.
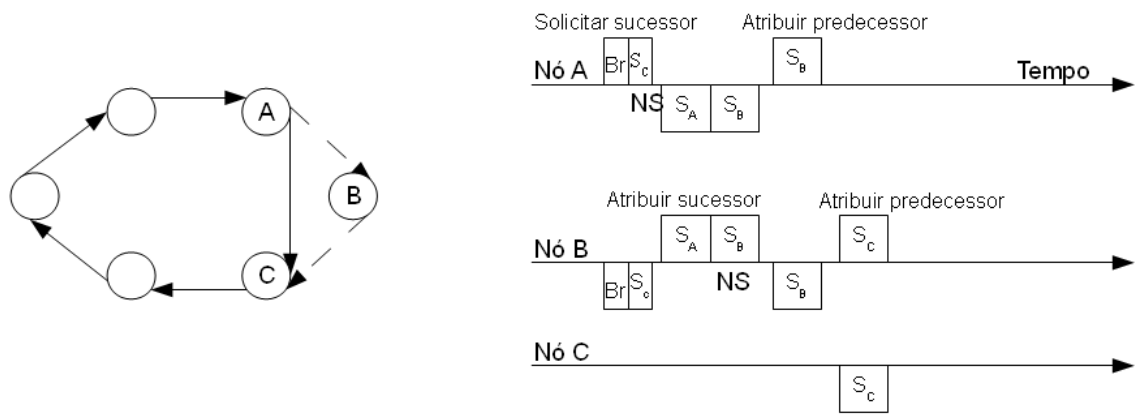

Figura 3.2: Procedimento de entrada [Erg02]

WTRP permite nós aderirem a um anel dinamicamente, um por vez, se o tempo de rotação de token (soma de tempos THT por nó, mais overhead tal como tempos de transmissão de token) não cresça inaceitavelmente com a adição de um novo nó. Suponha que nó B deseja aderir ao anel (figura 3.2). Digamos também que A faz broadcast (Br) da mensagem "Solicitar sucessor" (que inclui sucessor $\mathrm{C}$ de A) para que outros nós possam aderir ao anel. O controlador de admissão no nó A espera pelas respostas de nós interessados por algum tempo antes de decidir qual candidato incluir. Por sua vez, um nó que queira ser incluso no anel, por exemplo B, quando escutar a mensagem "Solicitar sucessor", ele transmite uma mensagem "Atribuir sucessor" para o nó A. Quando o tempo de espera pelas respostas terminar, o nó A pode decidir quem é o vencedor. Suponha que B vença a contenda, então o nó A passa para B a mensagem "Atribuir predecessor", e B passa para nó C a mensagem "Atribuir predecessor". Assim, termina o procedimento de entrada.

Como mostra a figura 3.3, suponhamos que estação B queira deixar o anel. Primeiro, B espera 

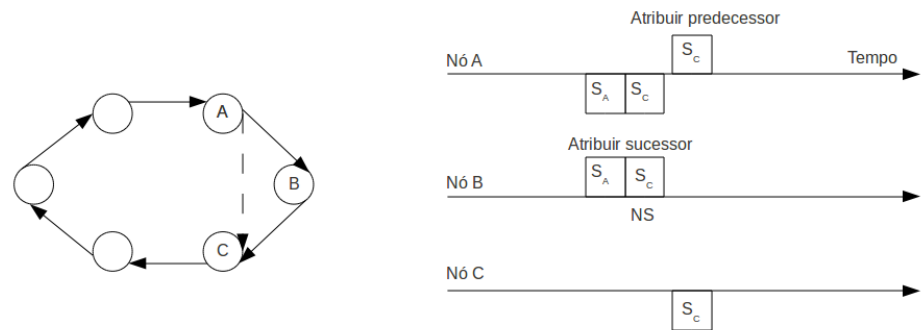

Figura 3.3: Procedimento de saida [Erg02]

chegar a sua vez de transmitir. Uma vez que tenha chegado, B envia um pacote "Atribuir predecessor" com endereço MAC do sucessor de B (no caso, nó C) para o predecessor A. Se A consegue escutar C, ele tenta conectar com C enviando um pacote "Atribuir predecessor". Se A não consegue escutar C, ele buscará (na ordem de transmissão) um nó na tabela de conectividade e que está no mesmo anel, e envia um pacote "Atribuir predecessor" a esse nó.

O protocolo WTRP implementa eliminação de interferências. Para isso, um nó pode ser incluso em qualquer anel se e somente se o anel não atingiu a capacidade máxima (em número de nós NoN). Esse número máximo de nós é global a todos os anéis. Quando um nó deseja fazer parte de um anel, se ele detectar um token, verifica se tem vaga. Se não tiver, ele continuará buscando (através de token detectado) por um anel que ainda tenha vaga. Se o anel detectado ainda tiver vaga, o nó que deseja fazer parte do anel pode aguardar por uma mensagem "Solicitar sucessor" transmitida por um nó no anel.

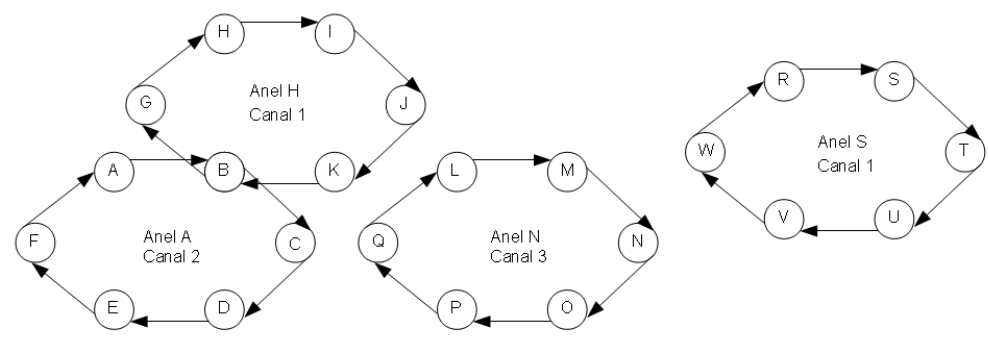

Figura 3.4: Vários anéis [Erg02]

Na figura 3.4, podemos ver que o endereço de qualquer anel é sempre o endereço de algum nó nesse anel. Este nó é chamado de proprietário do anel. No exemplo, o proprietário do anel A é o nó A. Uma vez que supomos que o endereço MAC de um nó é único então endereço de um anel também é único. Esta unicidade de endereço é importante, uma vez que permite a nós distinguirem 
mensagens vindas de diferentes anéis.

Para assegurar que um proprietário está presente em um anel, ele atualiza o Gen_Seq cada vez que receber um token. Quando o proprietário deixa o anel, o sucessor dele vai alterar predecessor, e ficar ciente que endereço do anel não é igual ao identificador do seu predecessor, então ele pode assumir papel de proprietário do anel. Também, caso um proprietário deixe anel dele sem notificar às estações restantes no anel. Nesse caso, para concluir que o proprietário está inalcançável, basta alguma estação receber o token com valor de Gen_Seq desatualizado.

\subsection{Outros trabalhos relacionados}

Vários outros trabalhos foram feitos com foco em Token Ring sem fio. Na verdade, esse protocolo foi inicialmente introduzido pela equipe da Universidade de Califórnia Berkeley liderada por Duke Lee como parte dos projetos de sistema de transporte inteligente, e aeronaves não tripuladas $\left[\mathrm{LAP}^{+} 01, \mathrm{LPV}^{+}\right.$02]. Ainda, Top et al. apresentam uma versão de WTRP para uso em ambientes dinâmicos ad-hoc [TKD]; em [CCH07], uma versão extendida capaz de permitir várias transmissões em simultâneo em WMAN (Rede de área metropolitana sem fio); em [ZYCW04a], Deng et al. analisam o desempenho de WTRP e propõem uma versão com foco em reduzir consumo de energia; e ainda, em [ZYCW04b], Deng et al. propõem uma versão de WTRP de pequena escala com mecanismo de preempção, hibernação e contenção.

Também, para pesquisas em tolerância a falha, controle de acesso ao meio, desafios em redes $a d-h o c$ sem fio, análise de desempenho de redes sem fio em NS [Pre11], estudo de QoS em termos de filas de armazenamento de pacotes em redes sem fio consultamos [KR06, LR09, KTMN05, CCV88, JS03, LHG11]. 


\section{Capítulo 4}

\section{O protocolo}

Neste trabalho desenvolvemos uma variação de protocolo Token Ring sem fio para MANet. Esse protocolo consiste em anel de anéis em que vários anéis se penduram a um anel varal. Um varal é um anel formado por nós coordenadores de todos anéis pendurados a ele.

Este protocolo tem por objetivos:

- prover uma solução para que diferentes anéis pendurados a um mesmo varal possam fazer troca de informações (pacotes). Sem aumentar significativamente o consumo de energia.

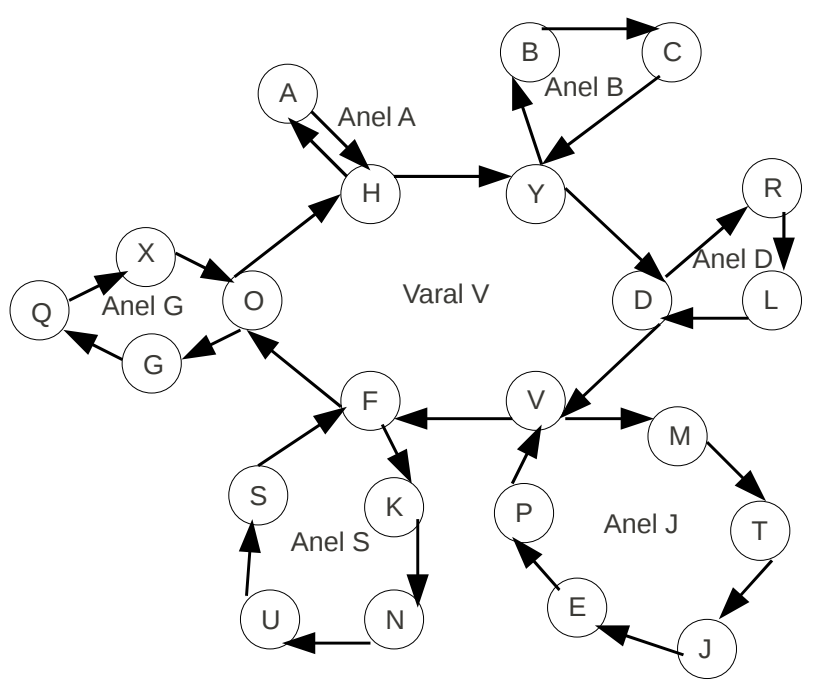

Figura 4.1: Anel de anéis

\subsection{A descrição do protocolo}

Neste protocolo classificamos um nó de seguinte forma: 
- simples - um nó comum, sem privilégios

- proprietário - criador de anel ou eleito para ser dono de anel

- anel unitário - aquele em que um nó é predecessor e sucessor de si mesmo

- varal - é um anel especial onde os anéis comuns se penduram

- coordenador - representante de um anel em um varal

- líder - criador de varal ou eleito para ser proprietário de varal

Em um varal cada coordenador possui um predecessor e um sucessor, ambos coordenadores de dois anéis possivelmente diferentes. Assim, cada coordenador terá dois predecessores e dois sucessores. Por exemplo, o nó Y (coordenador no anel B) na figura 4.1 tem por predecessores o nó C (membro do anel B) e o nó H (também coordenador), e tem por sucessores o nó B (membro do anel B) e o nó D (também coordenador).

Neste protocolo dividimos o roteamento em dois, à saber: roteamento intra-anel e inter-anel. O roteamento intra-anel é o roteamento entre estações que pertencem ao mesmo anel, por exemplo o roteamento no anel S da figura 4.1. E o roteamento entre os coordenadores é denominado roteamento inter-anel.

\subsection{Definições formais}

Sejam

- $R_{X}$ anel do nó $X$

- Pred $_{X}$ predecessor do nó $X$

- $\operatorname{Succ}_{X}$ sucessor do nó $X$

- $L_{I D s}$ lista de identificadores

- $S_{I D s X}$ sequência de IDs (exceto $X$ ) de nós no $R_{X}$

- $x P_{X}$ ex-predecessor do nó $X$

- $x S_{X}$ ex-sucessor do nó $X$

- $T_{R_{X}}$ tabela de conectividade do nó $\mathrm{X}$ associado ao anel $R$

- $T_{V_{X}}$ tabela de conectividade do nó $\mathrm{X}$ associado ao varal $V$

- $L_{X}$ lista de nós que o $X$ consegue escutar, mas que não compartilham anel com $X$

- $L R_{X}$ lista de nós que responderam a uma solicitação de inclusão do $X$

Cada coordenador possui uma $L_{I D s}$ de todos os nós em seu anel. Esses identificadores podem facilitar o encaminhamento de dados entre anéis através de varal. Explicando o conceito com o exemplo da figura 4.1: se o destinatário (por exemplo, nó U) não pertencer ao mesmo anel que o remetente (por exemplo, nó L), os dados são encaminhados do remetente L para o seu coordenador 


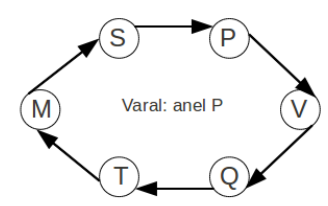

Figura 4.2: Varal construído

$\mathrm{D}$, deste para o coordenador seguinte, e assim sucessivamente até o coordenador $\mathrm{F}$ e deste último para o destinatário U.

Na construção de um anel de anéis, a primeira tarefa é a construção de um anel, que poderá transformar-se em varal, figura 4.2. Para que isso seja possível, ou a capacidade máxima do anel deve ser atingida, através de inclusão de nós; ou ainda, se um nó solicitar inclusão no anel em construção, e não for alcançável por pelo menos dois nós sucessivos no varal, então:

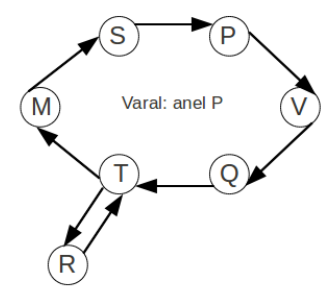

Figura 4.3: Anel $R$ pendurado no varal

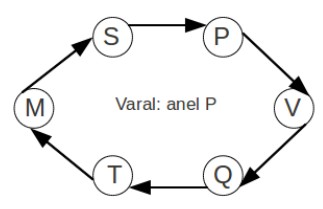

(

Figura 4.4: Anel unitário $R$

- ou esse nó vai pendurar em um nó no varal (caso ele for alcançável por algum nó no varal) formando um anel com dois nós, figura 4.3;

- ou ele forma um anel unitário, figura 4.4;

\subsection{Estrutura de token}

A formação de um anel requer que um token seja criado por algum nó. Em um anel unitário, o token não circulará até que um outro nó junte ao anel.

$\mathrm{Na}$ figura 4.1, ilustramos uma estrutura que representa um anel de anéis com a capacidade fixa em seis estações por anel. Nessa estrutura, o anel V representa o varal - o primeiro anel criado. Na seção 4.7.2, apresentaremos a estratégia de transformar um anel em varal. 


\begin{tabular}{|l|l|l|l|l|l|l|l|}
\hline FC & RA & DA & SA & NoN & Cnt_Gen & Cnt_Coord & Seq \\
\hline
\end{tabular}

Tabela 4.1: Quadro do Token de anel

A estrutura de token padrão no nosso protocolo (tabela 4.1) não difere muito da estrutura de token (tabela 3.1) apresentada na seção 3.3. A seguir, descrevemos os campos de token de permissão:

O campo FC identifica o tipo de token (token de permissão, "Atribuir predecessor", "Atribuir sucessor", etc). O campo RA informa o endereço do anel a que o token pertence, DA é o endereço do nó que vai receber o token; SA é o endereço do nó que envia o token, o campo Seq representa o número de sequência no token, é inicializado em zero e incrementado por cada nó que recebe e passa o token adiante. O campo Cnt_Gen (contador do proprietário de um anel) pode ser lido por um nó qualquer em um anel, porém somente o proprietário desse anel poderá incrementá-lo. O campo Cnt_Coord (contador do coordenador de um anel) pode ser lido por um nó qualquer em um anel, porém somente o coordenador do anel poderá incrementá-lo. Tanto o campo Cnt_Gen como o campo Cnt_Coord são inicializados em zero e o primeiro é incrementado cada vez que o token passa pelo proprietário, ao passo que o segundo é incrementado cada vez que o token passa pelo coordenador. E, o campo NoN é designado a número atual de nós em anel, ele é determinado pela diferença entre Seq atual e Seq anterior. Observação: o token de varal tem a mesma estrutura que o token apresentado na figura 4.1 à exceção do campo Cnt_Coord (que não tem necessidade de existir em varal).

\subsection{Comunicação entre anéis}

Cada nó deve manter uma $L_{I D s}$ de todos os nós no anel (exceto varal) a qual ele faz parte. Para que isso seja possível, quando um nó $X$ entra em $R_{X}$, seja $X$ um coordenador ou nó comum, o $S u c c_{X}$ gera e transmite um aviso de inclusão (com ID do nó $X$ ) para o sucessor dele; deste último para o sucessor dele, e assim sucessivamente até que o aviso chegue ao $\operatorname{Pred}_{X}$. Ademais, $S u c c_{X}$ envia uma $S_{I D s X}$ para o nó $X$. Também, quando um nó $X$ deixa $R_{X}$, seja $X$ um coordenador ou nó comum, $x S_{X}$ gera e transmite um aviso de saída (com ID do nó $X$ ) para o sucessor dele; deste último para o sucessor dele, e assim sucessivamente até que o aviso chegue ao $x P_{X}$.

Se um nó $X$ cair inesperadamente, o $x P_{X}$ procura na tabela de conectividade um nó para fechar o anel. Feito isso, $x P_{X}$ gera e envia um token de reapresentação contendo ID dele para o sucessor. Quando um nó receber um token de reapresentação com identificador ID do seu predecessor, ele registra esse ID na $L_{I D s}$, então retransmite o token de reapresentação recebido, e, gera e envia um token de reapresentação com ID dele para o sucessor dele. Se o token de reapresentação recebido tiver ID de outro nó (diferente de predecessor e dele mesmo), ele registra esse ID na $L_{I D s}$, e retransmite o token de reapresentação recebido. E, se receber um token de reapresentação com ID dele mesmo, ele não retransmite esse token.

\subsection{Gerenciamento de conectividade}

Cada nó possui mecanismos para fazer gerenciamento de conexões. Para gerenciar conexões cada nó mantém tabela(s) de conectividade. Uma tabela de conectividade permite a um determinado nó $X$ registrar as transmissões escutadas com origem em nós que ele consegue escutar. Esses nós podem 

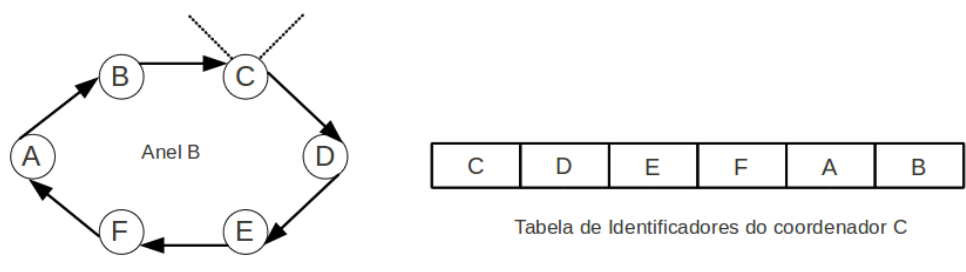

Figura 4.5: Lista de ids em $C$

estar no mesmo anel que ele ou não: para os nós no seu anel, ele mantém uma tabela ordenada $T_{R_{X}}$ ao passo que para os nós fora do seu anel, ele mantém uma tabela não ordenada $L_{X}$. A ordem crescente aplicada às tabelas de conectividade corresponde a número de sequência (Seq) no token. Ademais, salientamos que cada coordenador $X$ possue três tabelas de conectividade, $T_{R_{X}}, T_{V_{X}}$, e $L_{X}$.

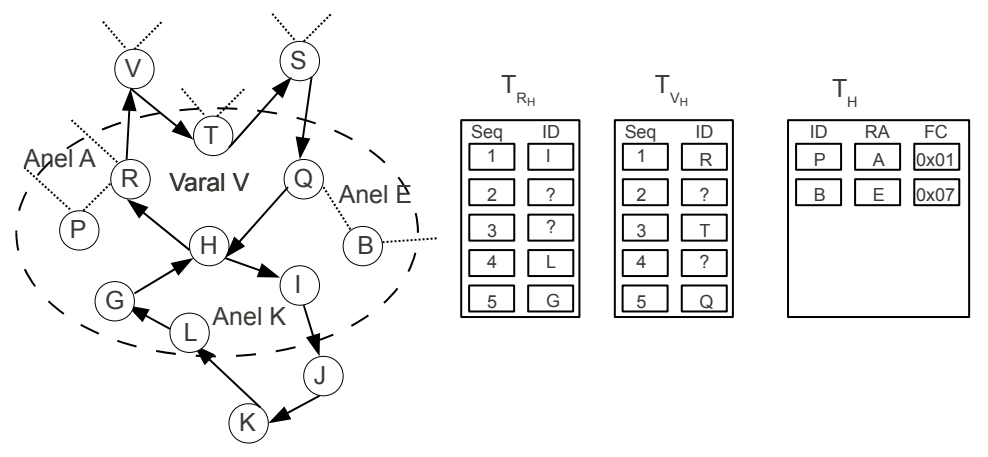

Área de transmissão do nódo $\mathrm{H}$

Figura 4.6: Alcance de sinal e tabelas de conectividade do $H$

Na figura 4.6, apresentamos um exemplo de área de transmissão e tabelas de conectividade de um nó coordenador. Consideremos o varal V (relacionado a tabela $T_{V_{H}}$ ): Quando o token sai do nó $\mathrm{R}$ o Seq vale 1, depois o nó $\mathrm{H}$ vai escutar uma próxima transmissão somente quando o token sair do T, nesse instante Seq valerá 3. Então, H deduzirá que houve uma transmissão entre $\mathrm{R}$ e T que não conseguiu escutar. Quando Q transmitir o token, H verifica que Seq vale 5, então deduzirá que houve uma transmissão entre $\mathrm{T}$ e Q que não conseguiu novamente escutar. Da mesma forma, no anel $\mathrm{K}$ (relacionado a tabela $T_{R_{H}}$ ), H escuta uma transmissão partindo do I com Seq igual a 1, e mais tarde volta a escutar uma transmissão partindo do nó L com Seq valendo 4, então conclui que houve duas transmissões que não conseguiu escutar. Na tabela $L_{H}$, o nó $\mathrm{H}$ registra os nós que consegue escutar ( $\mathrm{P}$ e B), porém estes estão fora dos seus anéis. O nó P está no anel A e o B está no anel E.

Nas redes de telecomunicações é muito importante que uma estação receptora confirme as mensagens. Normalmente, quando uma estação recebe uma mensagem ele transmite uma resposta ao emissor avisando o recebimento da mensagem. No nosso protocolo, seguindo a idéia em [Erg02], adotamos o conceito $A C K$ (resposta de reconhecimento positivo de mensagem [KR06]) implícito 
- AckI. Isto é, o processo em que um nó transmite um token e monitora esse token até que seja retransmitido pelo sucessor dele.

Dividimos as tarefas de gerenciamento de um anel entre o proprietário e o coordenador. O proprietário é a estação cujo identificador é RA, e o coordenador é a estação que representa uma "porta" do anel para um varal e vice-versa. Por exemplo, a estação H é o coordenador do anel K na figura 4.6. Conforme mencionado anteriomente, um proprietário é a estação que cria o seu anel ou, é a estação eleita 2.3.1.

Ao término da construção de varal, cada nó no mesmo, acumula as funções de coordenador e proprietário de um anel unitário. Essas funções somente mudarão para possivelmente dois nós diferentes quando o "proprietário e coordenador" inicial não estiver presente, ou quando houver eleição no anel.

Uma vez que o nosso protocolo implementa vários tokens e qualquer nó pode gerar um token, são necessários procedimentos para eliminar tokens quando não têm mais utilidade. Para lidar com a eliminação de tokens atribuimos prioridades a tokens. Definimos a prioridade de um token como sendo Cnt_Gen desse token. Isto é, quando um token completa a rotação voltando ao proprietário, a sua prioridade é incrementada. Caso dois tokens tenham prioridades iguais, os endereços RA deles são usados para escolher que token eliminar. A prioridade de um nó é a prioridade do último token que este nó aceitou ou gerou. Se um nó receber um token com prioridade inferior a dele, este nó elimina o token sem aceitá-lo e avisa ao seu predecessor. Assim, o predecessor não vai monitorar esse token.

\subsection{Tratamento de falhas}

Um nó simples é considerado em falha, se o predecessor dele não receber um AckI após um determinado número de tentativas de transmissões de token. E, se algum nó, exceto o proprietário, receber um token com o Cnt_Gen igual ao seu Cnt_Gen, então este nó assume que o proprietário está em modo de falha.

O nosso protocolo implementa mecanismos para recuperar as falhas causadas por quedas inesperadas de nós. A seguir, descrevemos as estratégias adotadas:

- se o predecessor de um nó simples identificar a falha do nó, então este predecessor busca na sua tabela de conectividade (em ordem de transmissão de token) um nó para fechar o anel. Essa reconstrução deve ser feita de modo que o anel seja reconstruído reduzindo menor número de nós possível [Erg02].

- a queda inesperada de um coordenador causará rutura em varal e em anel. Neste caso, teremos dois componentes isolados: predecessor no varal do coordenador em falha busca um nó viável para fechar o varal (usando as estratégias explicadas no item anterior); também, o predecessor no anel cujo coordenador falhou busca um nó na sua tabela de conectividade para fechar o anel (usando as estratégias explicadas no item anterior). Um nó N no anel onde o coordenador falhou vai receber o token com Cnt_Coord desatualizado, então ele assume que o coordenador não está presente. Logo, este nó $\mathrm{N}$ verifica se consegue escutar algum nó no varal olhando a sua tabela 3 (veja figura 4.6). Se ele consegue escutar pelo menos um nó no varal, ele vai fazer broadcast solicitando a entrada no varal. E, se for introduzido, ele vai alterar Cnt_Coord e 
assumir o papel de coordenador. Porém, se não for introduzido, ele passa o token a diante e o sucessor dele vai tentar o mesmo procedimento, e assim sucessivamente até que algum nó no anel consiga ser coordenador; ou, até que o varal fique inalcançável para todos os nós no anel isolado.

- se um nó receber token com Cnt_Gen desatualizado, este token assume que o proprietário não está presente. Então, ele inicia as eleições para encontrar um proprietário.

- Se um nó $N$ em um anel R não receber token por um periodo superior ao tempo máximo de rotação de token então $\mathrm{N}$ forma um anel unitário.

\subsection{Procedimentos de entrada e saída}

\subsubsection{Procedimento de entrada}
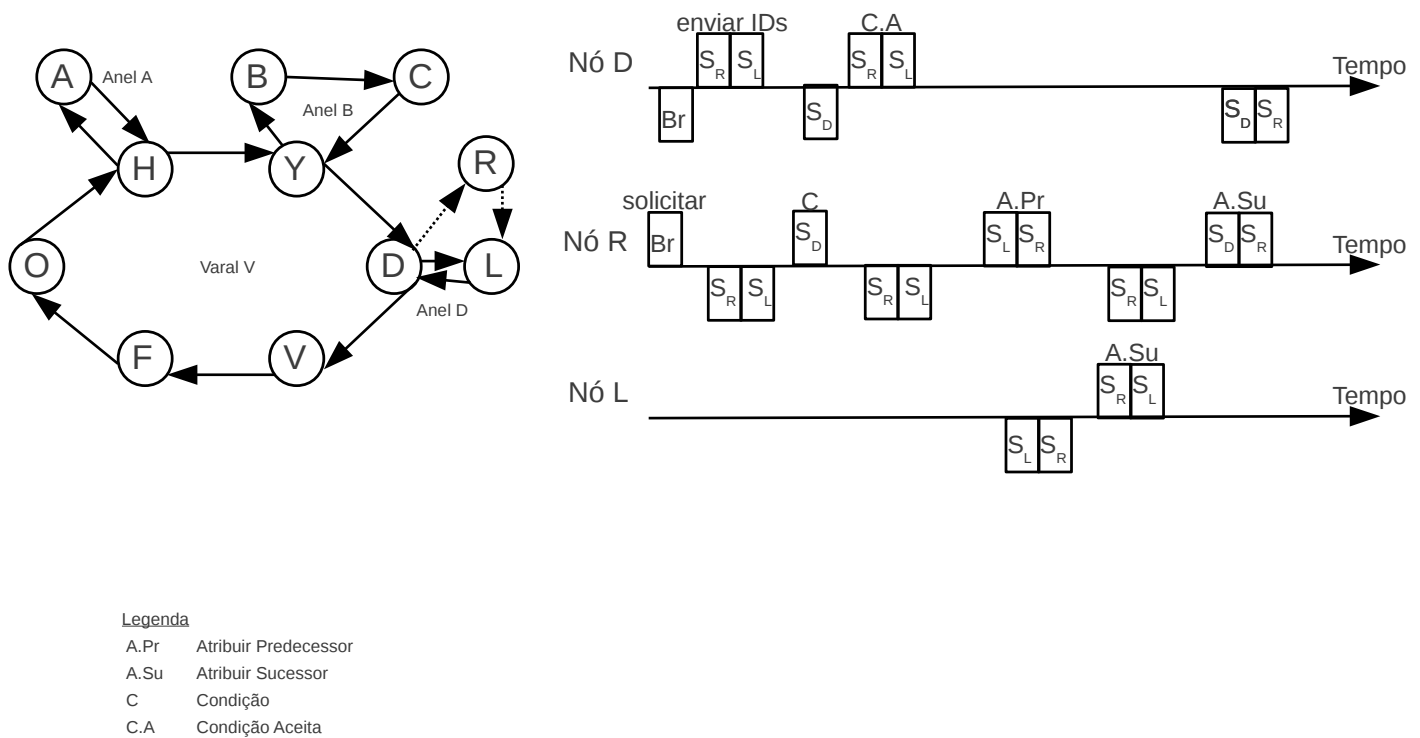

Figura 4.7: Entrada do nó $R$ no anel $D$

Um nó $X$ faz broadcast solicitando entrada em um anel. Para cada nó $Y$ no anel que escutar (o broadcast), espera receber token e verifica se a capacidade máxima do anel não foi atingida, se não foi atingida, então envia uma mensagem contendo ID dele e ID do $S u c c_{Y}$ ao nó $X$, e passa o token para $S u c c_{Y}$. Depois, se o nó $Y$ for selecionado pelo $X$, ele receberá uma mensagem "Condição" deste último, então, espera receber token e envia uma mensagem "Condição Aceita" para $X$ (no entanto, se $X$ não receber "Condição Aceita" até expirar o tempo de espera: ele seleciona outro nó da $L R_{X}$, se houver, e envia "Condição" para este; se não houver, $X$ formará anel unitário). Depois, o nó $Y$ fica aguardando uma mensagem "Atribuir sucessor" vinda do nó $X$. Para que essa mensagem chegue a $Y, X$ terá que enviar "Atribuir predecessor" para $S u c c_{Y}$ e receber deste último "Atribuir sucessor". Quando $Y$ receber "Atribuir sucessor" vinda do $X$, termina o processo de inclusão do $X$ no anel como sucessor do $Y$ e predecessor do $S u c c_{Y}$. No entanto, se $X$ não receber "Atribuir 
sucessor" do $S u c c_{Y}$ até expirar o tempo de espera, ele enviará "Atribuir predecessor" para $Y$. Este último responderá com uma mensagem "Atribuir sucessor", se ainda for possível criar um novo anel. Se não for possível, o nó $Y$ não responderá a $X$, e este último, após o tempo de espera expirar, selecionará outro nó da $L R_{X}$ (se houver) e tentará conexão com esse nó enviando uma mensagem "Condição". Se nenhum nó $Y$ consegue introduzir o nó $X$, ou se o número de tentativas de solicitar entrada (através de broadcast) atingir o máximo, o nó $X$ construirá um anel unitário e aguardará por tempo $\alpha$ antes de executar novamente o procedimento de entrada.

Na figura 4.7, apresentamos um exemplo do procedimento de entrada. Inicialmente, o nó $\mathrm{R}$ faz broadcast solicitando entrada. O nó D no anel D escuta broadcast, então espera receber o token, daí envia o ID dele e ID do sucessor dele (L) ao nó R. Então, R envia uma mensagem "Condição" para D e este último responde com uma mensagem "Condição Aceita". Logo, o nó R envia uma mensagem "Atribuir predecessor" ao L que recebe a mensagem e envia "Atribuir sucessor" para R. Logo que o nó R receber a mensagem do L, ele enviará "Atribuir sucessor" para o D, terminando o procedimento de entrada para $R$.
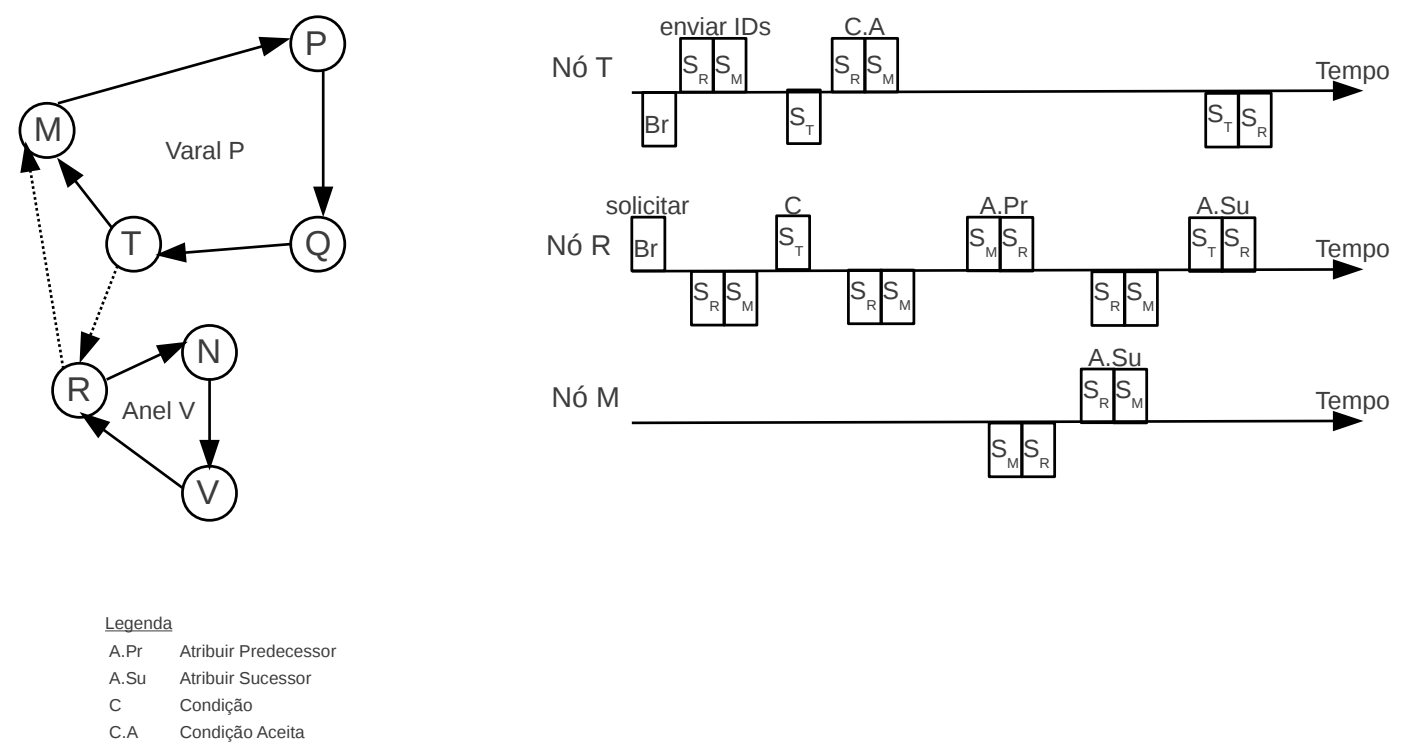

Figura 4.8: Inclusão do anel $V$ ao varal $P$

O procedimento de entrada de um anel em um varal é ligeiramente diferente. Se algum nó $N$ no anel isolado consegue escutar as transmissões feitas em varal, ele espera receber o token, confirma ausência de coordenador (através de Coord_Cnt); então, ele faz broadcast solicitando entrada no varal. Se algum coordenador $Y$ no varal escutar o broadcast, ele espera receber o token do varal, verifica se a capacidade máxima do varal ainda não foi atingida; se ainda houver alguma vaga no varal, então o nó $Y$ envia uma mensagem contendo ID dele e ID do $S u c c_{Y}$ (no varal) para o nó $N$. Depois, se o nó $Y$ for selecionado pelo $N$, ele receberá uma mensagem "Condição" deste último, então, espera receber token e envia uma mensagem "Condição Aceita" para $N$ (no entanto, se $N$ não receber "Condição Aceita" até expirar o tempo de espera: ele seleciona outro nó da $L R_{N}$, se houver, e envia "Condição" para este; se não houver, $N$ aguardará por tempo $\alpha$ antes de executar o procedimento de entrada novamente). 
Quando o nó $N$ receber a mensagem do coordenador $Y$, ele envia uma mensagem "Atribuir predecessor" para $\operatorname{Succ}_{Y}$ (no varal). E, espera receber do sucessor referido uma mensagem "Atribuir sucessor". Depois de receber a mensagem do $S u c c_{Y}$, ele envia uma mensagem "Atribuir sucessor" para o nó $Y$. Daí termina o procedimento de entrada do nó solicitante no varal. Se o nó $N$ não receber resposta do $S u c c_{Y}$, então ele selecionará outro nodo da $L R_{X}$ (se houver) e tentará conexão com esse nó enviando uma mensagem "Condição". Se nenhum nó coordenador em varal consegue introduzir o solicitante $\mathrm{N}$, então este último aguardará por tempo $\alpha$ antes de executar novamente o procedimento de entrada em varal.

Para evitar que dois coordenadores respondam em simultâneo a uma mesma solicitação de entrada, somente o coordenador com token de varal poderá respondem a solicitação.

Um exemplo do procedimento de entrada de um anel em um varal é apresentado na figura 4.8. $\mathrm{O}$ nó $\mathrm{R}$ no anel $\mathrm{V}$ faz broadcast solicitando a entrada no varal $\mathrm{P}$. $\mathrm{O}$ nó $\mathrm{T}$ (atendente) escuta esse broadcast, envia o ID dele e o ID do sucessor dele para R. Este último nó envia uma mensagem "Condição" para nó T e recebe "Condição Aceita" do T. Daí, nó R envia uma mensagem "Atribuir predecessor" para o nó $\mathrm{M}$ (sucessor do atendente no varal). Quando o nó M receber a mensagem do R, ele vai responder enviando "Atribuir sucessor". E, o nó R envia "Atribuir sucessor" para o nó T, após ter recebido a mensagem do nó $\mathrm{M}$.

\section{Critérios de escolha para inclusão de um nó}

Todos os nós $Y$ que escutaram uma solicitação (de nó $X$ ) enviam uma resposta ao $X$. O nó $X$ armazena (até expirar tempo de espera por respostas) as respostas recebidas em uma lista $L R_{X}$. Em seguida, ele escolhe um nó $Y$ e tenta uma inclusão com este último.

Para execução de escolha o nó $X$ ordena $L R_{X}$ por um dos seguintes critérios:

- número de nós no anel de $Y$

- energia do pacote de resposta recebido de $Y$

- primeira resposta recebida

\subsubsection{Procedimento de saída}

\section{Nó simples}

O nó cessante $X$ envia um pacote "Atribuir sucessor" com identificador do $\operatorname{Succ}_{X}$ para o Pred $_{X}$. Se Pred $_{X}$ consegue escutar o $S u c c_{X}$, então $\operatorname{Pred}_{X}$ tenta conectar ao $S u c c_{X}$ enviando "Atribuir predecessor". Se não consegue escutar o sucessor, então busca na sua tabela de conectividade um nó e envia um pacote "Atribuir predecessor" para este nó.

A figura 4.9 ilustra uma situação em que o nó A inicia o procedimento de saída enviando uma mensagem "Atribuir sucessor" contendo identificador de S ao nó R. E, o nó R envia uma mensagem "Atribuir predecessor" contendo identificador dele para S.

\section{Nó proprietário}

Um nó proprietário cessante $X$, não coordenador, executa o mesmo procedimento de saída explicado acima. Porém, primeiro nó que receber o token e detectar que Cnt_Gen (em token) não foi atualizado convoca eleições. 


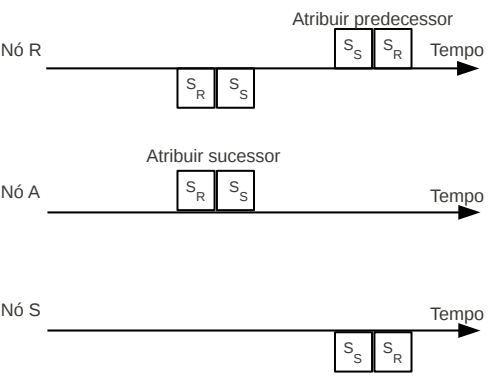

Figura 4.9: Saída do nó $A$ do anel $R$ e coordenador $T$

\section{Nó coordenador}

O coordenador cessante $E$ faz broadcast da mensagem de saída de um coordenador. Essa mensagem conterá ID do $S u c c_{E}$ no $R_{E}$, ID do $S u c c_{E}$ e do $\operatorname{Pred}_{E}$ no $V_{E}$. Quando um nó $Y$ escutar essa transmissão:

- se $Y$ for $\operatorname{Pred}_{E}$ no $R_{E}$ então envia "Atribuir predecessor" para $S u c c_{E}$. Se não consegue alcançar $S u c c_{E}$ procura outro nó na sua tabela de conectividade para fechar o anel.

- se $Y$ for $\operatorname{Pred}_{E}$ no $V_{E}$ então envia "Atribuir predecessor" para $S u c c_{E}$ no $V_{E}$.

- se $Y$ for um nó no $R_{E}$ e consegue escutar (verificando na $L_{Y}$ ) $\operatorname{Pred}_{E}$ no $V_{E}$ então espera receber token e executa o procedimento de entrada de um anel em um varal 4.8
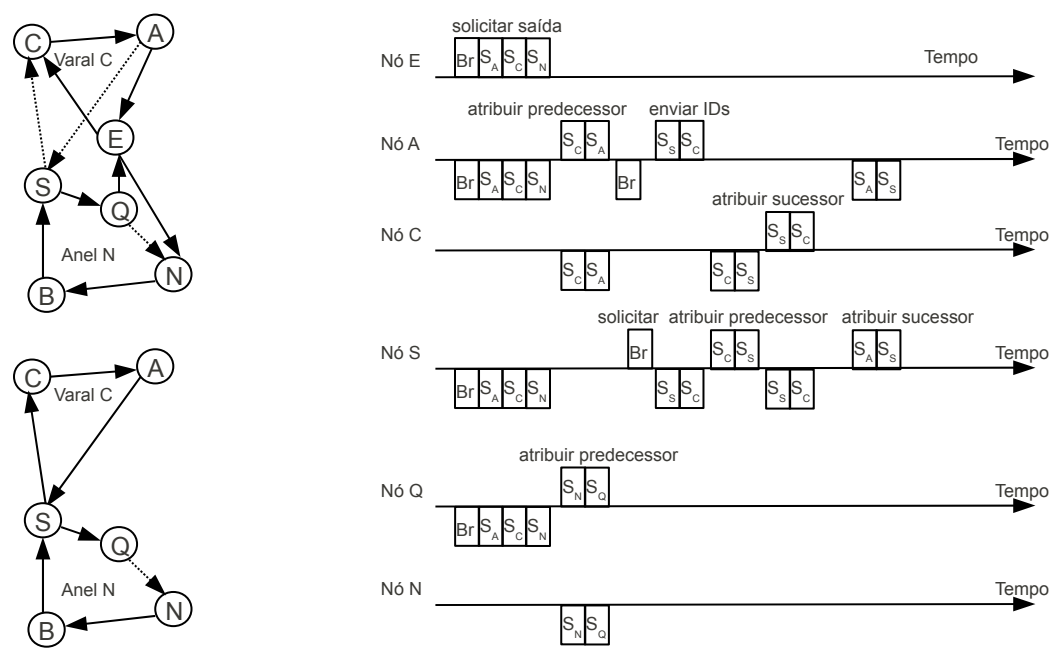

Figura 4.10: Saída do coordenador $E$

\section{Nó proprietário de varal}

O nó proprietário cessante espera receber o token e convoca as eleições enviando uma mensagem para o sucessor dele no varal. Todos os nós no varal vão participar das eleições para encontrar um novo proprietário do varal. Uma vez encontrado um novo proprietário, este 
atribui o endereço dele ao campo RA do varal. A mudança de papel do nó cessante de proprietário do varal para um coordenador, permite a ele executar o procedimento de saída para um coordenador explicado no item 2.
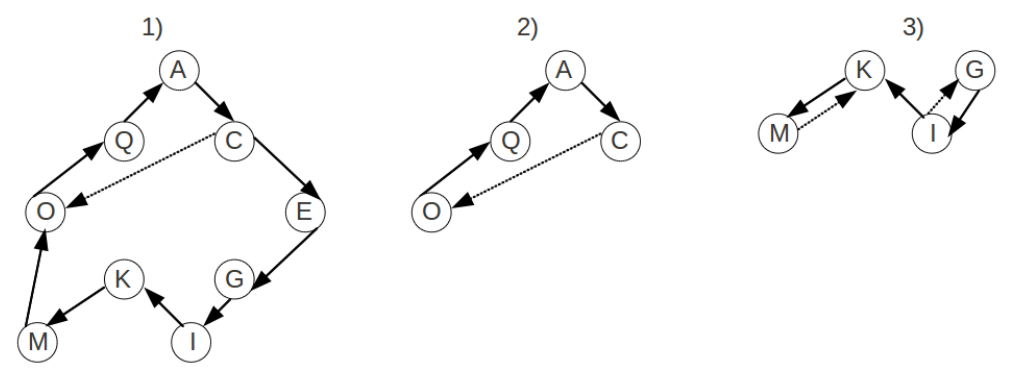

Figura 4.11: Reconexão do anel após a saída do nó E

Importante: O processo de fechar um anel requer tratamento de um caso particular. Para explicar esse caso e apresentar a solução adotada por nós, usamos o exemplo da figura 4.11. Imagine que o nó E decida sair. Ele envia uma mensagem "Atribuir sucessor" para C. Então, o nó C busca na tabela de conectividade um nó para fechar o anel. Uma vez que o nó C não consegue escutar os nós G, I, K e M, e consegue escutar o nó $\mathrm{O}$, então ele vai fechar o anel com este nó O figura 4.112 2). $\mathrm{O}$ trecho que vai do nó $\mathrm{G}$ a $\mathrm{M}$ fica fora do anel. Após algum tempo, o nó G constata que não está recebendo o token, então solicita o sucessor I para formarem um anel. Consequentemente, o nó I deixa de ser predecessor do K. Por sua vez, o K também verifica que não está recebendo o token, então solicita o sucessor M para formarem um outro anel 3). Se o trecho tivesse um número ímpar de nós, último nó desse trecho formaria um anel unitário. Essa solução é aplicada sempre que um nó sai de anel ou falha.

\section{Transformação de um anel em varal}

Como já tinhamos referido anteriormente. Para que um anel se transforme em varal, ele tem que atingir a capacidade máxima, ou então, um nó s neste anel tem que começar um novo anel pendurado a ele (s). Em baixo, passaremos a explicar com mais detalhes.

Se um nó não coordenador em um anel não unitário receber uma solicitação para formar um novo anel, ele espera receber token (T), forma o novo anel, e assume papel de coordenador e proprietário no mesmo. Antes de passar o token (T), verifica se este último já foi transformado em token de varal:

- Se sim, ele executa outras tarefas necessárias com token (T) e passa para o sucessor dele

- Se não, ele transforma o token $(\mathrm{T})$ em token de varal e assume o papel de proprietário

Se por outro lado, o proprietário de um anel não unitário receber token e verificar que a capacidade máxima do mesmo foi atingida, ele transforma o token em token de varal e continua sendo proprietário.

Observação: Por simplicidade, se o número de nós em um varal diminuir até 1, esse varal é transformado em anel. 


\section{Capítulo 5}

\section{Implementação}

Neste capítulo apresentamos algumas particularidades da implementação da "prova de conceito" de acordo com o simulador utilizado, tais como: descrição de tipos de mensagens, parâmetros e constantes, transmissão de token de permissão e relacionamento entre módulos implementados.

Nesta seção apresentamos algumas particularidades de como foi feita a implementação considerando o ambiente utilizado para teste.

\subsection{Descrição dos pacotes do projeto}

Os tokens especiais utilizados no nosso protocolo são mensagens representadas por pacotes em NS. Algumas dessa mensagens podem ser transmitidas para um destinatário específico - unicast, outras podem ser transmitidas para todos os nós ao alcance do emissor - broadcast. Na tabela 5.1, descrevemos de uma forma breve tipos de mensagens especificadas e implementadas no evWTRP. Também, podemos distinguí-las através do formato de quandro de cada uma (veja apêndice A).

Na figura 5.1 apresentamos a estrutura de dados "union" utilizada para armazenar na memória os pacotes correspondentes as mensagens. Cada mensagem tem formato de quadro igual para anel e para varal. Porém, o reconhecimento de um quadro pertencer a um anel ou varal é através do campo FC (control de quandro) veja apêndice A.

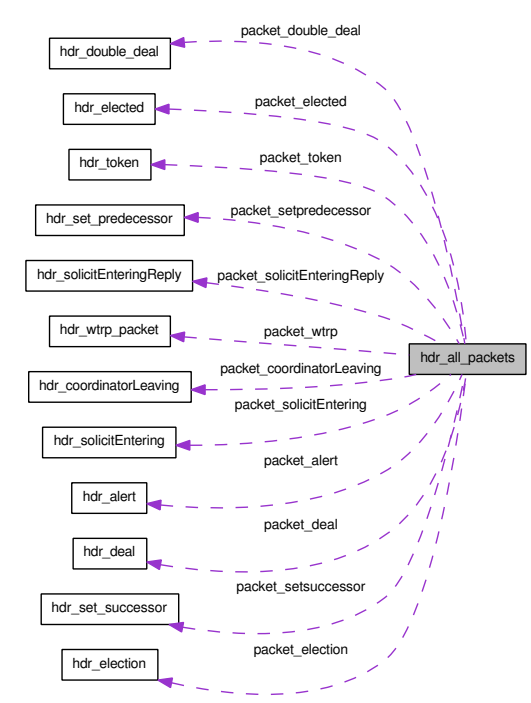

Figura 5.1: union com cabeçalho de todas as mensagens 


\begin{tabular}{|c|c|}
\hline Tipo de token & Descrição \\
\hline de eliminação & $\begin{array}{l}\text { mensagem eliminada. Não implementamos } \\
\text { porque NS implementa os seus mecanismos de } \\
\text { eliminar mensagens. }\end{array}$ \\
\hline de permissão & $\begin{array}{l}\text { é o token normal. Permite a um nó utilizar } \\
\text { recursos críticos, seja em anel ou varal. }\end{array}$ \\
\hline da eleição de proprietário & $\begin{array}{l}\text { criado e transmitido durante execução de uma } \\
\text { eleição. }\end{array}$ \\
\hline de proprietário eleito & adverte que um nóvo proprietário foi eleito. \\
\hline de atribuir predecessor & $\begin{array}{l}\text { ao receber esta mensagem, o nó receptor define } \\
\text { emissor como predecessor. }\end{array}$ \\
\hline de atribuir successor & $\begin{array}{l}\text { ao receber esta mensagem, o nó receptor de- } \\
\text { fine sucessor especificado na mensagem como } \\
\text { sucessor. }\end{array}$ \\
\hline de selecionado & $\begin{array}{l}\text { nó solicitante envia uma mensagem deste tipo } \\
\text { ao nó escolhido (dentre os nós que respon- } \\
\text { deram a solicitação de entrada). }\end{array}$ \\
\hline de resposta de um selecionado & $\begin{array}{l}\text { transmitido do nó respondedor para nó solici- } \\
\text { tante de entrada. }\end{array}$ \\
\hline de aviso de entrada & $\begin{array}{l}\text { transmitido e retransmitido, de um nó para } \\
\text { sucessor dele, quando um novo nó for detec- } \\
\text { tado em um anel. }\end{array}$ \\
\hline de aviso de saída & $\begin{array}{l}\text { transmitido e retransmitido, de um nó para } \\
\text { sucessor dele, quando um nó deixar um anel. }\end{array}$ \\
\hline de reentrada & $\begin{array}{l}\text { transmitido e retransmitido, de um nó para } \\
\text { sucessor dele, quando um nó reentrar em um } \\
\text { anel. }\end{array}$ \\
\hline de solicitação de entrada & $\begin{array}{l}\text { transmitido (por broadcast) de um nó solici- } \\
\text { tante para todos os que o escutam. }\end{array}$ \\
\hline de resposta a solicitação & $\begin{array}{l}\text { transmitido em resposta a uma solicitação de } \\
\text { entrada escutada. }\end{array}$ \\
\hline de saída de um coordenador & adverte saída de um coordenador. \\
\hline
\end{tabular}

Tabela 5.1: Tabela de tokens 


\subsection{Definições e constantes}

- max_Node_number - Número máximo de nó em todo o cenário. Realizamos os testes com MAX_NODE_NUMBER $=150$

- MAX_NODE_PER_RING - Número de nó por anel. Realizamos os testes com MAX_NODE_PER_RING $=64$

- solicit_Ring_timeout - Tempo de espera antes de solicitar novamente entrada. Realizamos os testes com SOlicit_RING_timeOut $==5.2$ segundos.

- solicit_try_max_num - Número de tentativa de solicitação de entrada. Para os testes realizados, um nó solicita entrada no máximo 3 vezes.

- RePly_timeout - Tempo que um solicitante espera para receber maior número de respostas possível. Testado com valor de 5 segundos.

- min_token_holding_time - Tempo normal de apreensão de token. Nas simulações feitas, cada nó tem meio segundo com token.

- token_holding_time - Tempo normal de apreensão de token em varal. Nas simulações, cada coordenador pode ter token de varal por um periodo de 1 segundo; de forma a evitar colisões nas recepções de token de anel e de varal.

- monitoring_iaCk_timeout - Tempo de monitoramento de token. monitoring_iack_timeout $=$ TOKEN_HOLDING_Time $+1.5 \mathrm{~s}$. Utilizado por temporizadores que monitoram token em anel e varal.

- max_token_pass_try - Número de tentativa de passar token. Nos testes, permitimos que a tentativa de passar token seja no máximo 3.

- token_Rotation_timeout - Tempo que um nó espera para receber token antes de assumir que a rede caiu. TOKEN_ROTATION_tIMEOUt é definido por TOKEN_HOLDING_TIME $\times$ MAX_NODE_PER_RING

- DeAl_RePly_timeout - Tempo de espera por uma mensagem "Condição Aceita". Esse parâmetro é dado por tempo de simulação dividido por número total de nós na presente simulação.

- PRint_info_timeout - Tempo que um nó espera para informar a sua posição e energia gasta por ele. No teste do consumo de energia, cada nó imprime a posição dele e energia total gasta por ele a cada segundo.

\subsection{Transmissão de Token}

Como já tinhamos mencionado, para evitar transmissão de ACK, cada vez que um nó recebe token, executa tarefas que dependem deste, e o transmite por broadcast. A seguir, ilustramos como é feito transmissão de token.

Na figura 5.2, apresentamos a estratégia implementada para transmissão de token por broadcast. A estação 1 (coordenadora e proprietária do anel 1) transmite pacote de token para estação 4 no 
anel 1. Essa transmissão é também recebida pela estação 8 (coordenadora e sucessora da 1 no varal), pela estação 2 (sucessora da 4) que registra-a na tabela de conectividade e pela estação 3 (predecessora da 1 no anel 1) que aguardava AckI (monitoramento).

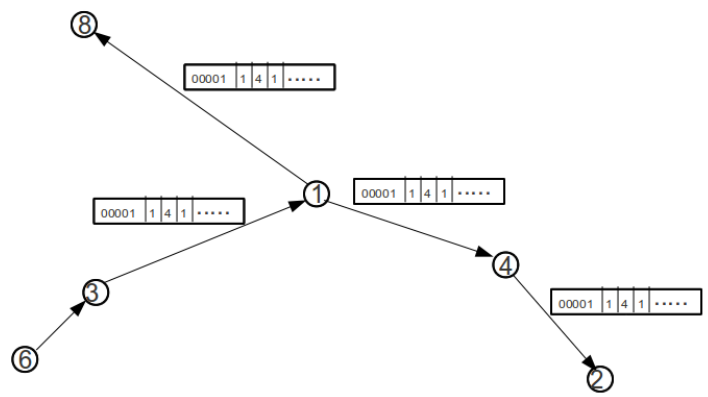

Figura 5.2: Representação de transmissão de token por broadcast

Dessa forma, com uma transmissão por broadcast, garantimos a sobrevivência do nó transmissor na estrutura a que está inserido.

Nota: No NS2 quando um nó deseja fazer broadcast ele manda uma mensagem para endereço -1 .

\subsection{Relação entre módulos}

A nossa implementação ${ }^{1}$ no NS foi dividida em módulos de forma a evitar que ela seja intitulada de muito complexa. Nós procuramos aplicar algumas práticas comuns de engenharia de software, tais como: evitar acomplamento, facilidade de manutenção, legibilidade e reuso; tudo através de modularização.

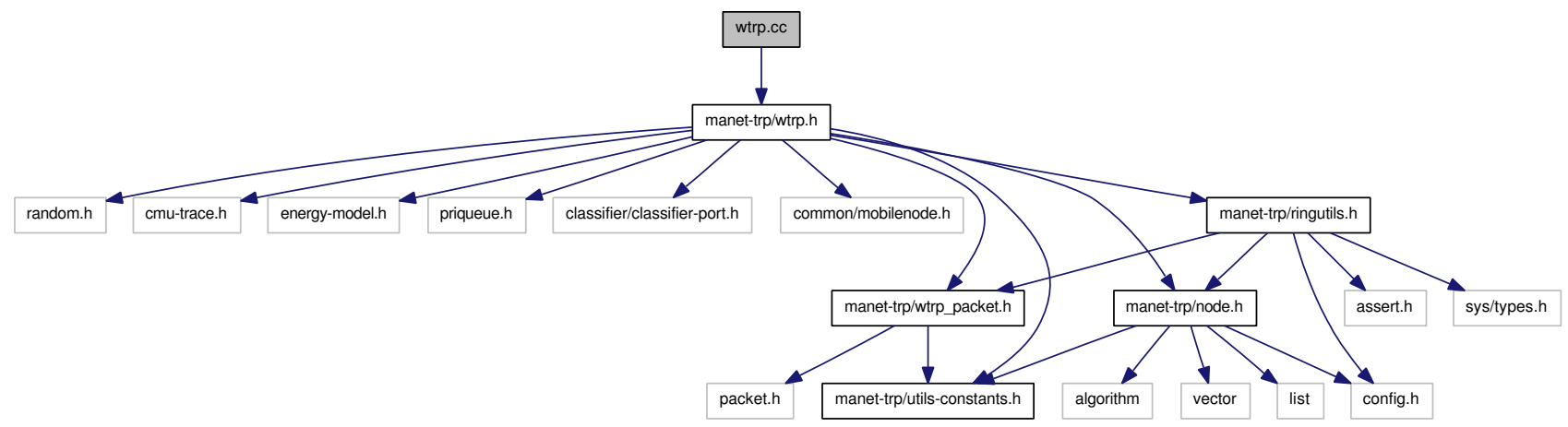

Figura 5.3: estrutura dos arquivos incluidos

Na figura 5.3, apresentamos árvore de inclusão de arquivos. O módulo wTRP é o módulo principal. A sua classe principal é o agente wtrp. Este último utiliza as funcionalidades do NS para ligação com OTcl, envio e recepção de pacotes entre agentes (estes representam estações), controle de temporizadores e gerenciamento de energia. Esse módulo delega as tarefas de criar, ler, atualizar e deletar pacotes e estruturas de dados para módulo RINGUTiLs. Este último módulo provê funcionalidades auxiliares e não depende de mecanimos do NS, além de utilização do endereço broadcast fornecido pelo simulador. O módulo NoDE é uma entidade, representa o conceito de um

\footnotetext{
${ }^{1}$ Acesse:http://code.google.com/p/ns2-wtr-routing-protocol/source/browse/
} 
nó como entidade. O WTRP_PACKET contém declarações e definições de tipo de pacotes, estrutura de dados para gerenciamento desses pacotes na memória e funções de acesso aos mesmos. Por último, o UTILS-CONSTANTS contém constantes e parâmetros utilizados durante as simulações. Os demais, são funcionalidades do simulador. 


\section{Capítulo 6}

\section{Resultados experimentais}

O protocolo evWTRP, como já foi dito, é uma extensão do protocolo WTRP. É uma alternativa a este último. Como tal, evWTRP deve ter características vantajosas (em certas situações) que incentivem o seu uso. Nesse sentido realizamos alguns experimentos com simulações, e chegamos a interessantes conclusões.

Neste capítulo apresentamos os experimentos realizados e discutimos os resultados obtidos. As métricas utilizadas são: tempo médio de rotação de token (TRT), taxa de transferência de dados, atraso médio ponto a ponto, teste de configuração e consumo de energia (estudo preliminar).

Imaginamos um cenário de conferência em que participantes necessitam trocar dados entre si, por exemplo, arquivos de contatos ou uma pequena gravação de voz.

Todos os experimentos foram realizados no ambiente de simulação do NS. Onde cada estação pode deslocar-se para uma área onde haja sinal de alguma rede, e permaneça estática enquanto executa os procedimentos implementados em evWTRP. As redes podem ser formadas por estações em uma estrutura de anel único ou em uma estrutura de um anel de anéis (varal). De acordo com o nosso planejamento todas as estações utilizam mesmo canal de comunicação. À excessão dos nós que iniciam uma simulação, atribuimos velocidades, no intervalo entre $50 \mathrm{~m} / \mathrm{s}$ a $250 \mathrm{~m} / \mathrm{s}$, às estações que fazem parte de uma rede. E, configuramos as estações para que possam escutar-se entre si em uma distância de até 250 metros em uma área com relevos. Aliás, salientamos que nem todas as estações conseguem escutar todas as transmissões que ocorrem na rede a que ela faz parte.

\subsection{Ambiente de experimentos}

Como tinhamos dito, os experimentos foram realizados no simulador NS, i.e. o tempo foi simulado. Portanto, não vamos fazer uma descrição das máquinas utilizadas nos experimentos.

\subsection{Ambiente de simulação}

Para que seja possível executar simulações de redes sem fio em um ambiente de NS, é necessário configurar arquivo(s) TCL (veja seção B.3.1, apêndice B) com alguns parâmetros importantes. Na tabela 6.1 apresentamos os parâmetros comuns a todas as simulações realizadas. O modelo de propagação utilizada é TwoRayGround. Este em conjunto com raio de alcance desejado, determinam um limiar de recepção de sinal (determinante para configuração de raio de comunicação). Para as nossas simulações consideramos raio de alcance de 250 metros, consequentemente o calculador de 
limiar de recepção de sinal do NS produziu um valor de 3.65262e-10. O raio de comunicação depende do modelo de propagação de sinal [Ke]. Por padrão TTL no NS é de 32 saltos, alteramos esse valor

\begin{tabular}{|c|c|}
\hline Parâmetros & Valores \\
\hline Frequência & $9.14 \mathrm{e}+08$ \\
\hline Taxa de transmissão & $11 \mathrm{Mb}$ \\
\hline Energia de transmissão & 0.281838 \\
\hline Limiar da energia de recepção & $3.65262 \mathrm{e}-10$ \\
\hline Tipo de canal & WirelessChannel \\
\hline Tipo de propagação & TwoRayGround \\
\hline Tipo de interface de rede & WirelessPhy \\
\hline Tipo de MAC & $802 \_11$ \\
\hline Tipo de interface de fila & Droptail com prioridade \\
\hline Tipo de camada de enlace & LL \\
\hline Modelo de antena & OmniAntenna \\
\hline Número máximo de pacotes na fila & 200 \\
\hline Tempo de Vida (TTL) & 100 (padrão 32 NS) \\
\hline Número de nós & Varia \\
\hline Protocolo & WTRP \\
\hline Área de simulação & $1311 \mathrm{~m} \times 943 \mathrm{~m}$ \\
\hline Tempo de simulação & Varia \\
\hline Tipo de aplicação & CBR \\
\hline Tamanho de pacotes & Varia \\
\hline Modelo de energia & EnergyModel \\
\hline
\end{tabular}

Tabela 6.1: Tabela de parâmetros de simulação

para que seja de 100 saltos, em virtude de contrução e teste com anéis de até 50 nós. O protocolo utilizado em todos as simulações é o nosso evWTRP. Os cenários imaginados são áreas de 1311 metros x 943 metros com relevos, o que levou-nos a utilizar o modelo de propagação mencionado anteriormente. Uma vez que os nossos experimentos não visam diretamente camada de aplicação, os testes utilizando pacotes de dados CBR foram suficientes. E, para ter informações relacionadas ao consumo de energia durante as simulações utilizamos o modelo ENERGYMODEL, onde cada estação começa com uma energia de 100 Joules.

\subsection{Experimentos e resultados}

\subsubsection{Tempo de rotação de token}

O tempo de rotação de token (TRT) de um nó $x$ é a diferença entre o tempo de transmissão de token $T$ e o tempo de recepção desse mesmo token. Como dissemos anteriormente, token permite que uma determinada estação possa utilizar os recursos compartilhados em uma rede. A reutilização deste token pode ser mais assídua ou menos assídua dependendo da estrutura de rede ser em um anel ou em varal. O experimento de TRT nos permitirá saber o quanto demora para uma determinada estação voltar a reutilizar um recurso compartilhado em uma estrutura de rede em anel, e também em uma estrutura de rede em varal.

Para calcular TRT utilizando os mecanismos do simulador, consideramos a diferença entre o tempo $\Delta$ tev que um nó em uma rede leva para enviar $\theta$ e e receber $\theta \mathrm{r}$ token. Onde, $\Delta$ tev $=\theta \mathrm{r}-\theta$ e. 
Nesse cômputo estão inclusos os atrasos produzidos pelo processamento na fila e pela transmissão de pacotes intra camadas do simulador. Este experimento foi realizado no simulador, utilizamos quantidade igual de nós para ambas as estruturas de rede.

Para discutir os resultados, utilizamos as estruturas apresentadas na figura 6.8, e outras formadas por 30 nós (em um anel) e por 30 nós em varal (com 8 no varal). Simulamos evWTRP durante 330 segundos, com estrutura de rede completamente estável, coletamos os tempos de transmissão e recepção de pacote de token na camada RTR (roteamento) para um coordenador(figura 6.1 nó 0) e para últimos nós comuns inclusos (figura 6.1 nó 11 estruturas R12 e N12V4, e nó 29 estruturas R30 e N30V8).

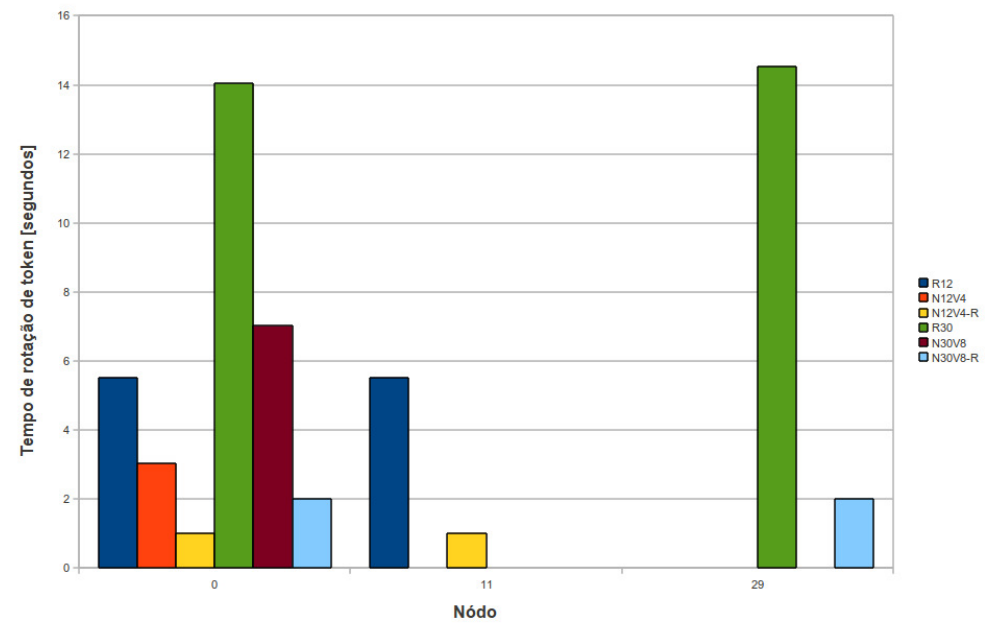

Figura 6.1: Gráfico de TRT

Na figura 6.1 apresentamos os resultados dos cálculos de TRT. Como pode ser visto: a soma dos TRT do nó coordenador 0 (no anel e varal na estrutura N12V4) é inferior a TRT na estrutura R12; também, TRT na N12V4 é inferior a TRT na R12 para nó 11; do mesmo jeito, a soma dos TRT do nó coordenador 0 (no anel e varal na estrutura N30V8) é inferior a TRT na estrutura R30; e também, TRT na N30V8 é inferior a TRT na R30 para nó 29; Estas observações levam-nos a concluir que, com a mesma quantidade de nós, um nó leva menos tempo para ter possibilidade de reutilizar token em estrutura com varal do que em uma estrutura com um anel. I.e, estrutura em varal permite mais reutilização dos recursos compartilhados do que estrutura em um anel.

\subsubsection{Resultado de experimento de taxa de transferência de dados}

Diz-se que a taxa de transferência de dados é o número de pacotes entregue por total de tempo de simulação. Matematicamente, pode ser definida por: $\frac{\text { nbits }}{1000}$, onde nbits representa quantidade de bits entregue a destinatários com sucesso [RDD13]. Sabemos que taxa de transferência de dados cresce à medida que conectividade melhora [RDD13].

Para ter uma indicação desta vazão em estruturas com varal, utilizamos o simulador para analisar transmissões de pacotes de dados (de 100, 200 e 512Kilobytes) CBR (taxa constante de Bits) sob UDP (protocolo de transmissão de dados) de 2 em 2 segundos durante 10 segundos. Para tal, construimos alguns cenários formados por varais de 10, 30 e 50 nós e outros formados por anéis com 10, 30 e 50 nós. Os resultado estão disponíveis no gráfico a seguir. 


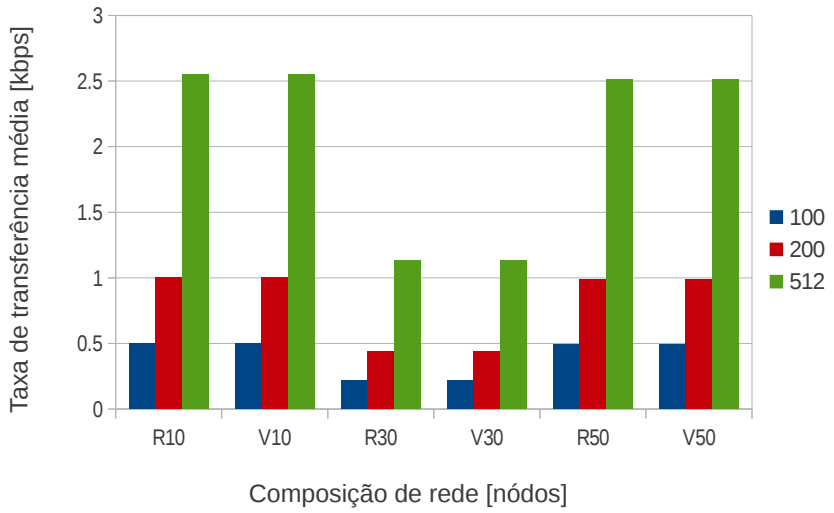

Figura 6.2: Gráficos de taxa de transferência média em redes com 10, 30 e 50 nós

Se observarmos a figura 6.2, concluimos que as taxas de transferência de dados em estruturas com varal e em estruturas com um anel são iguais, para (R10 e V10), (R30 e V30) e (R50 e V50). Em outras palavras, a mudança de topologia de anel para varal com vários anéis não prejudica a quantidade de pacotes de dados entregue.

\subsubsection{Atraso médio ponto a ponto}

De uma forma sucinta, definimos atraso ponto a ponto como sendo o tempo médio que um pacote de dados leva para alcançar o destino. Isso inclui todos os atrasos possíveis causados por buffering durante a descoberta de rota e enfileiramento na interface de fila [RDD13]. O atraso ponto a ponto é calculado através de subtração do tempo em que um pacote de dados $p$ é enviado do tempo em que esse pacote $p$ chega ao destino. O cômputo prático usual para esta métrica é $\frac{\sum \Delta \mathrm{t}}{\text { npacote }}$, i.e a razão do somatório dos atrasos $\Delta$ t pelo npacote (quantidade recebida de pacotes de dados).

No nosso trabalho fizemos experimentos de forma que seja possível comparar o atraso médio ponto a ponto observado em uma rede de estrutura Token Ring sem fio (abordagem tradicional WTRP), e o atraso observado em uma rede de estrutura em varal (evWTRP).

Com este experimento queremos deixar indicação que o atraso de entrega de dados no protocolo evWTRP é menor que o atraso de entrega de dados no protocolo WTRP. Isto é, o atraso de entrega de dados é proporcional ao número de saltos entre origem e destinatário.

Seja $n$ quantidade de nós em uma MANet, construimos redes WTRP de tamanho $n$, e redes evWTRP também de tamanho $n$ com $\left\lceil\frac{n}{4}\right\rceil$ nós em varal e os demais em subanéis; enviamos pacotes de dados CBR (taxa constante de bit) de tamanhos 100KB, 200KB e 512KB. Para cada rede WTRP ou evWTRP, e para cada tamanho de pacote de dados CBR; durante 10 segundos enviamos (com intervalo de 2 segundos) dados de um nó para outro nó através de roteamento feito por WTRP e por evWTRP e observamos os resultados apresentados a seguir.

Na figura 6.3 apresentamos os resultados das simulações mencionadas. Como podemos ver, o 


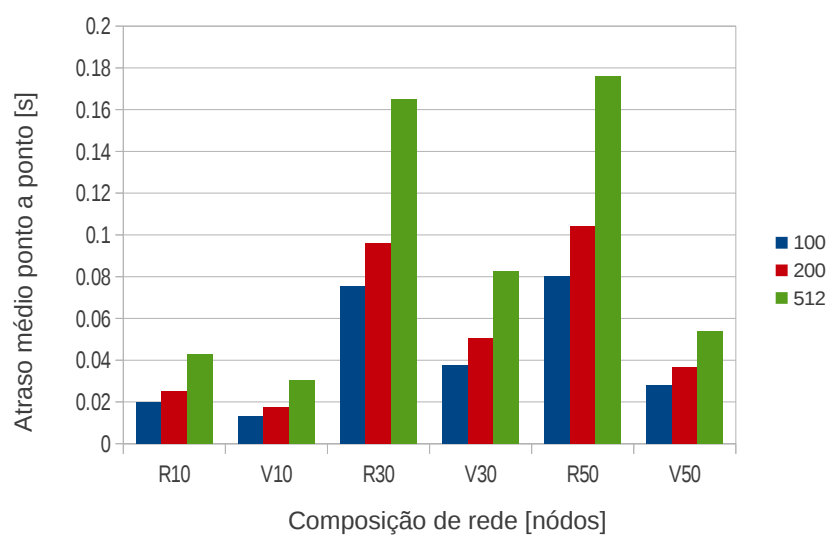

Figura 6.3: Gráficos de atraso médio ponto a ponto

atraso é proporcional ao tamanho de pacote CBR. I.e, atrasos médios para entregar pacotes de tamanho $512 \mathrm{~KB}$ é maior que atrasos médios para entregar pacotes de 200KB, e atrasos médios deste último é maior que atrasos médios para 100KB, independentemente da estrutura de rede em causa. Mas também, analisando o gráfico da referida figura, esta indica-nos que: o atraso na entrega de dados é menor em redes com estrutura em varal (protocolo evWTRP) em relação às redes com estrutura em um anel (protocolo WTRP), se considerarmos mesma quantidade de estações e pacotes de dados do mesmo tamanho. Ademais está indicação diz-nos que a latência em varal é menor que a latência em anel.

\subsubsection{Configuração para simulação com posicionamento aleatório}

Nesta seção explicaremos como é formada configuração para cada arquivo TCL (com posicionamento aleatório de nós) utilizado na simulação.

Sejam

- $n \geq 1, n \in N$ número total de nós

- $t \geq 1, t \in N$ quantidade de componentes não-conexos.

- $m_{i} \geq 1, m_{i} \in N$ quantidade de anéis pendurados ao i-ésimo componente, com $1 \leq i \leq t$

- $r_{k}^{m_{i}}$ k-ésimo anel do i-ésimo componente. Em um componente $m_{i}$, o anel pendurado ao proprietário de um varal é o primeiro anel $r_{1}^{m_{i}}$, anel pendurado ao sucessor do proprietário do varal é o segundo $r_{2}^{m_{i}}$, assim sucessivamente até o anel pendurado ao predecessor do proprietário do varal é o último anel do componente $m_{i}$.

Definimos uma configuração $\mathcal{C}$, para o resultado de uma simulação de arquivo TCL, como sendo $\mathcal{C}=m_{1}: r_{1}^{m_{1}}, r_{2}^{m_{1}}, \ldots, r_{m_{1}}^{m_{1}} ; m_{2}: r_{1}^{m_{2}}, r_{2}^{m_{2}}, \ldots, r_{m_{2}}^{m_{2}} ; \ldots ; m_{t}: r_{1}^{m_{t}}, r_{2}^{m_{t}}, \ldots, r_{m_{t}}^{m_{t}}$. 


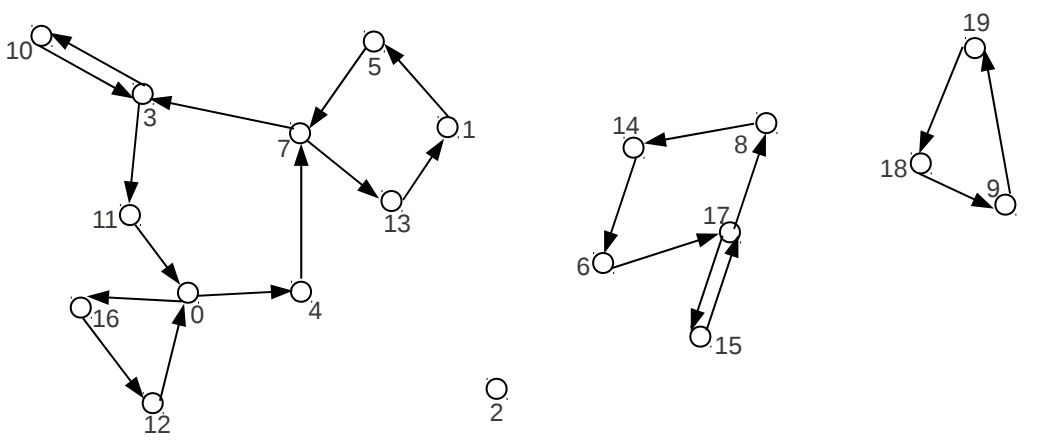

Configuração do cenário $=5: 3,1,4,2,1 ; 1 ; 4: 1,2,1,1 ; 3$

Figura 6.4: Exemplo de cenário e a sua configuração

Na figura 6.4 apresentamos um exemplo de cenário resultante da simulação para 20 nós e a configuração encontrada para esse cenário. Identificando da esquerda para direita, temos o primeiro componente (varal) com 5 nós; consideramos o nó 0 proprietário do varal, então o primeiro anel tem 3 nós, o segundo tem um nó, o terceiro anel tem 4 nós, quarto e quinto têm 2 e 1 nós, respectivamente;o segundo componente contém um anel simples; no terceiro componente (varal) com 4 nós, consideramos o nó 6 proprietário do varal, então o primeiro anel desse componete contém 1 nó, o segundo contém 2 nós, e terceiro e quarto anéis contêm 1 nó cada; e o quarto componente é um anel formado por 3 nós.

\subsubsection{Resultados de teste de configuração}

Teste de configuração consiste em gerar um dado número de nós, posicioná-los aleatoriamente, executar evWTRP para cada nó e verificar qual configuração 6.3.4 teve mais frequência. Para executar este teste, fizemos os seguintes procedimentos:

1. Escrevemos um código em Perl que: para cada critério de entrada 4.7.1, gera 5000 arquivos TCL com 25 nós em cada arquivo, posiciona aleatoriamente cada nó e cada nó executa evWTRP.

2. Depois, escrevemos um outro programa em Perl que analiza as mensagens impressas por cada nó e constrói uma configuração 6.3 .4 coerente com execução do protocolo evWTRP.

3. Por fim, escrevemos um outro código em Perl que conta o número de ocorrência de uma determinada configuração em cada arquivo TCL simulado.

Nas figuras 6.5, 6.6 e 6.7 apresentamos os resultados dos testes de configurações para os três critérios de entrada 4.7.1. Esses resultados mostram que as configurações mais frequentes foram anéis simples e anéis com duas estações. As ocorrências dessas configurações foram largamente discrepantes, uma situação que se aceita se levarmos em conta as adversidades como posicionamento 


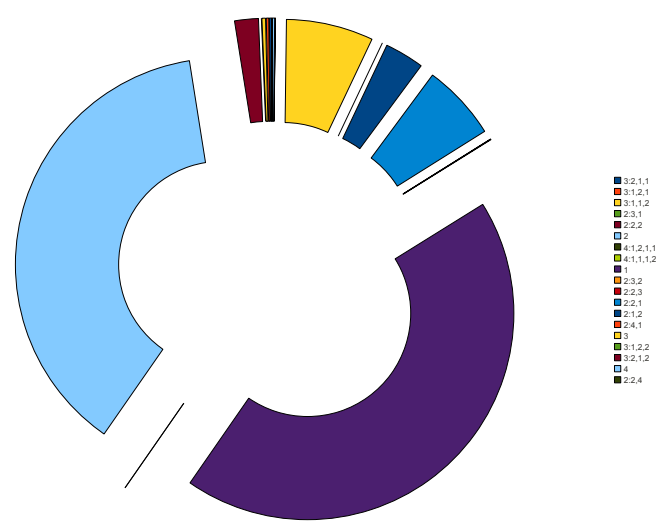

Figura 6.5: Configurações e ocorrências pelo critério PRPC

e alcance. Dentre os varais formados o mais frequente foi um varal de dois nós com um anel de dois nós e outro simples pendurados.

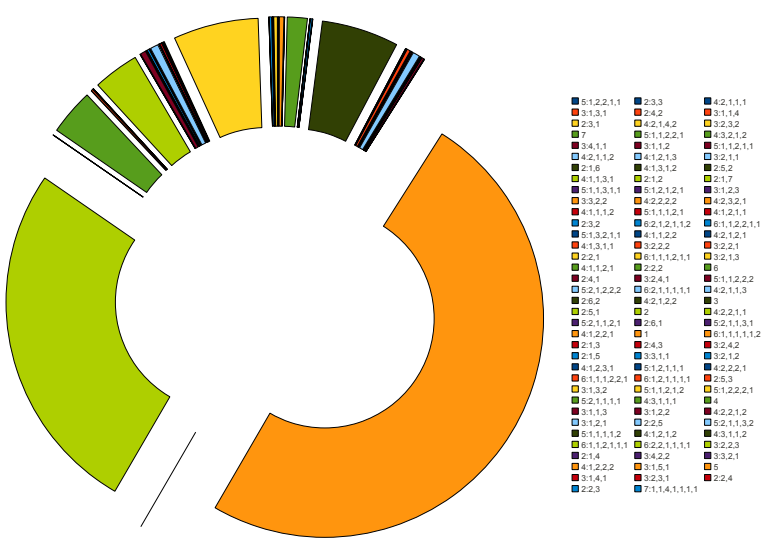

Figura 6.6: Configurações e ocorrências pelo critério número de nós

Todos os critérios de entrada implementam heurística de direcionar estação solicitante para uma estrutura em varal, se este existir. Porém, o critério de entrada por número de nós produziu mais variedades de varais nos testes realizados. Esta conclusão é justa, uma vez que este critério direciona as estações solicitantes para anéis com maior quantidade de estações.

Se considerarmos os fatores posicionamento aleatório das estações, alcance limitado, tempo que um nó solicitante pode esperar por respostas e espera por permissão (token) para responder a uma solicitação de entrada; chegamos a conclusão de que, é menos provável formar uma única estrutura conexa no protocolo evWTRP, independentemente da heurística de entrada aplicada. O que não quer dizer que evWTRP seja inútil a concepção de uma rede ad-hoc.

OBS: As tabelas com as configurações e as ocorrências estão disponíveis no apêndice E. 


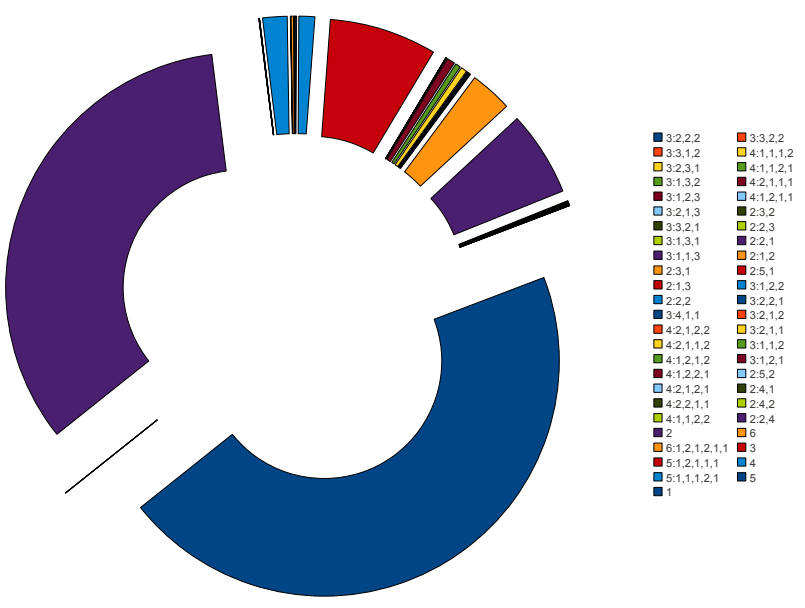

Figura 6.7: Configurações e ocorrências pelo critério sinal de recebimento de pacote

\subsubsection{Experimento do consumo de energia}

Atualmente, o estudo do consumo de energia é um assunto importante em tecnologias de redes sem fio, uma vez que terminais em redes dessa natureza possuem quantidade limitada de energia [TT06]. Por isso, aproveitamos para realizar um estudo preliminar sobre consumo de energia. Para tal, construimos dois cenários representados na figura 6.8. Onde a) representa uma estrutura em anel simples com quantidade $n$ de nós e b) representa um pior caso para uma estrutura em varal com os mesmos $n$ nós. Fizemos a simulação de evWTRP no NS durante 110 segundos com estações passando token entre si, sendo que nos últimos 10 segundos, simulamos transmissão de dados CBR de um nó origem para um nó destino. Com isso, coletamos energia gasta com transmissões e recepções de pacotes, por nó, em ambas estruturas.

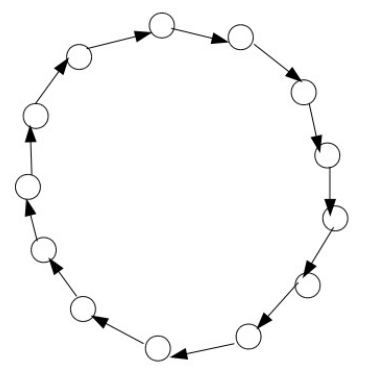

a)

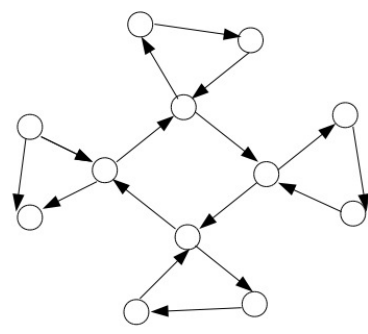

b)

Figura 6.8: Cenário para o teste do consumo de energia

Nos experimentos realizados, tanto na estrutura em varal assim como na estrutura em anel simples, um determinado nó começa com energia de 100 Joules, solicita entrada em um mesmo instânte (em ambas estruturas) e executa os demais procedimentos do protocolo evWTRP.

De uma forma precipitada, podemos ser induzidos a acreditar que uma estrutura em varal 


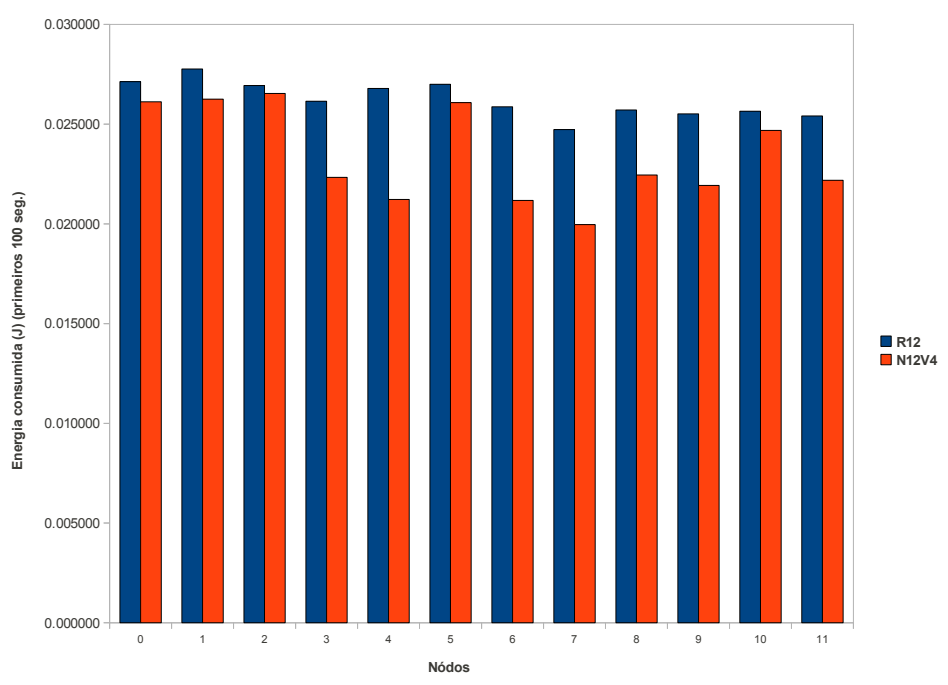

Figura 6.9: Resultados do consumo de energia nos 100 segundos iniciais

sempre consumirá mais energia que uma estrutura em um anel. Pois, o primeiro tem mais tokens circulando (realização de transmissões e recepções), e também TRT é menor, considerando mesmo tempo de simulação. Porém, nem sempre é verdade.

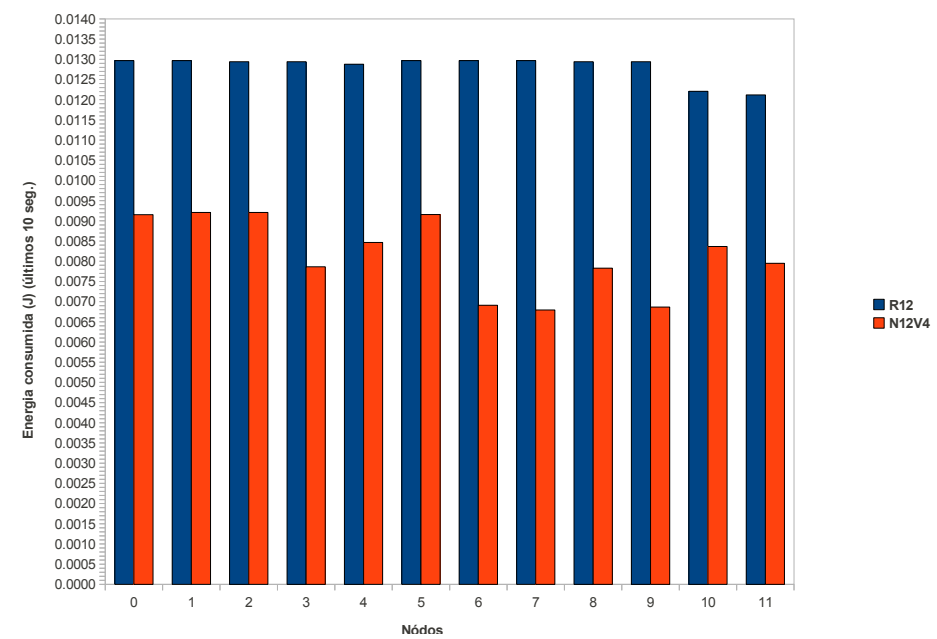

Figura 6.10: Resultados do consumo de energia nos 10 segundos finais

Na figura 6.9, apresentamos o consumo de energia por nó nos primeiros 100 segundos, em que os nós executam exclusivamente procedimentos na camada de roteamento com evWTRP. Como pode ser visto, todos os nós consumiram menos energia na N12V4 (em relação à R12); ou seja, o consumo de energia na estrutura N12V4 é menor que o consumo de energia na estrutura R12.

Uma vez que em estrutura de varal pacotes de dados (CBR no caso) tendem a fazer um caminho 
mais curto para chegar ao destino, é esperado que o consumo de energia durante transmissões de pacotes CBR não seja superior ao consumo de energia em uma estrutura de anel único, durante o mesmo periodo. Na figura 6.10, apresentamos os resultados do consumo de energia nos últimos 10 segundos com transmissões de pacotes CBR. Também, o consumo de energia na N12V4 é inferior ao consumo de energia na R12, comparando um nó na N12V4 com o análogo na R12. Repare que aqui o consumo de energia em estrutura de varal decresceu ainda mais em relação a estrutura de anel único.

Um fator importante para que o consumo de energia na N12V4 seja menor que na R12 é o posicionamento de nós. Digamos que um pacote (token) transmitido relevante é aquele que é recebido do sucessor (no anel e varal), predecessor (no anel e varal). Na estrutura N12V4, os nós estão mais afastados, daí recebem menos pacotes (token) não relevantes, então gastam menos energia com recepção de pacotes. E, na estrutura R12, tem nós mais próximos entre si, então gastam mais energia com recepção de pacotes (inclusive os não relevantes). Contudo, deste experimento preliminar, concluímos que uma estrutura em varal nem sempre consumirá mais energia que uma estrutura em anel. 


\section{Capítulo 7}

\section{Conclusões}

As redes de telefonia celular (arquitetura infraestruturada) têm prestado serviços imprescindíveis a humanidade permitindo comunicações entre dispositivos pessoal móveis. Porém, o surgimento de novas tecnologias e novos dispositivos móveis com serviços de rádio transmissão e recepção requer uma nova alternativa para comunicação móvel, em que terminais móveis sejam capazes de se criarem, se organizarem e se administrarem na ausência de infraestrutura formando uma nova abordagem de rede sem fio. Esta nova abordagem chama-se redes Ad-hoc sem fio - MANet.

Redes $A d-h o c$ sem fio não é um conceito novo. No começo dos anos setenta, já existiam publicações nessa área e, na época, a única aplicação envisionada era comunicação militar. Porém, a sua pesquisa voltou a ganhar interesse nos meados dos anos noventa com a chegada de tecnologias móveis [TT06]. A perda de interesse em pesquisa até meados dos anos noventa deveu-se a desafios, tais como: tempo de vida de bateria em dispositivos móveis muito limitado, topologias complicadas que requerem algoritmos sofisticados para controle de acesso a meio e roteamento, por exemplos aplicação em comunicação militar não justificava.

Protocolo de roteamento Token Ring sem fio (WTRP) trouxe uma alternativa a política de acesso a meio. Ele é um protocolo distribuído de MAC que oferece qualidade de serviços em termos de uso com exclusividade de largura de banda e controle limitado de latência. Originalmente, esse protocolo foi desenvolvido na Universidade de Califórnia - Berkeley (aplicação em sistema de transporte inteligente). Os estudos continuaram com a tese de mestrado do Mustafa Ergen sob o título de protocolo Token Ring sem fio. As suas aplicações vão de redes de veículos aéreos não tripulados (VANTs) até aplicações multimédia.

Um número considerável de trabalhos de pesquisa foram apresentados seguindo WTRP. Nós embarcamos nesse assunto propondo evWTRP.

O protocolo que propomos (evWTRP) é uma extensão do protocolo Token Ring sem fio (WTRP - proposto pelo Mustafa Ergen) com abordagem de roteamento diferente. O protocolo evWTRP organiza uma coleção de nós sem fio em uma estrutura de anel de anéis. Os nós são organizados em varal - um anel formado por nós coordenadores de anéis (com roteamento inter-anel), e anéis (com roteamento intra-anel) pendurados a este varal. Com esta organização, uma estrutura em anel de anéis pode incluir maior número de nós com menos saltos do que seria em uma estrutura (anel) de WTRP. O que facilita encaminhamento de dados. Uma vez que WTRP visa redução de latência em entrega de dados e uso seletivo de largura de banda, a nossa abordagem também procurou manter essa filosofia.

Para saber se é viável implementar um protocolo dessa natureza, desenvolvemos um programa 
para simulador NS e testamos estruturas que representam varal e outros que representam um anel.

Com os testes realizados, vimos que a nossa versão do protocolo, evWTRP, tende a ter uma latência mais reduzida do que no protocolo WTRP, no que diz respeito a entrega de dados, e considerando o atraso médio ponto a ponto; por tempo de execução do protocolo, ele também, permite a cada estação na estrutura reutilizar mais vezes o token de permissão do que WTRP, através de menor tempo de rotação de token, consequentemente, cada estação terá mais oportunidade de reutilizar os recursos críticos compartilhados; apesar de ser um protocolo que utiliza protocolo UDP para transporte de dados, no experimento realizado, temos a indicação que evWTRP não perde para WTRP no que diz respeito a quantidade de dados entregue no destinatário; e, quanto ao consumo de energia, vimos que em algumas situações evWTRP consumirá menos energia que WTRP, apesar de uma estação em evWTRP (re)utilizar mais vezes token.

Os experimentos realizados e as análises feitas encorajam-nos em investir esforços de pesquisa em protocolos de roteamento para redes improvisados móveis sem fio, em especial protocolo Token Ring.

\subsection{Considerações Finais}

Neste trabalho concebemos procedimentos de inclusão, exclusão, comunicação e controle de nós em um protocolo de roteamento para redes móveis sem fio para causas emergenciais e breves.

Implementamos os conceitos usando simulador NS, discutimos os resultados obtidos. Para tal comparamos a nossa abordagem evWTRP a WTRP [Erg02] utilizando parâmetros TRT e Taxa de transferência.

\subsection{Sugestões para Pesquisas Futuras}

Existem alternativas de pesquisa para anel de anéis voltado a redes $a d$-hoc móveis sem fio. Nesta seção apresentamos algumas possíveis direções de pesquisa em Token Ring sem fio.

\subsubsection{Alcançabilidade}

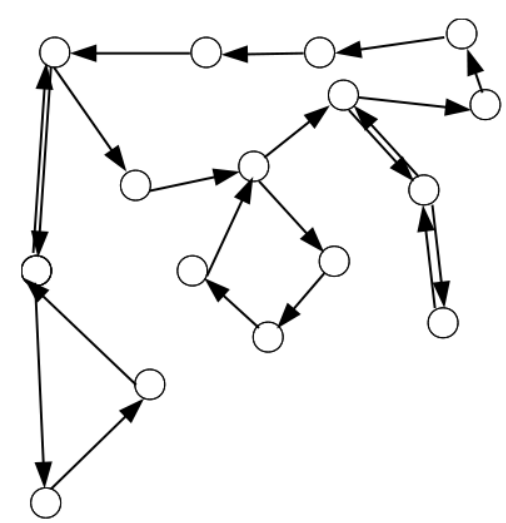

Figura 7.1: Exemplo de uma estrutura para maior alcançabilidade

Uma única estrutura conexa 7.1 em que as estações executam os roteamentos interno e externo. Nesta abordagem, cada vez que um novo anel (por exemplo, anel 10 na figura 7.2) é criado, o anel 
imediatamente superior (por exemplo, anel 2 transforma em varal 2, na figura 7.2) passa a ser varal. Esta abordagem permite que todos os nós alcançáveis possam enviar e receber dados.

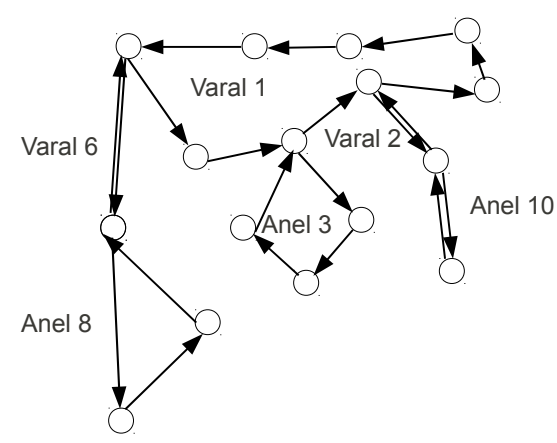

Figura 7.2: Transformação de anel em varal

\subsubsection{Consumo de energia}

Na seção 6.3.6, apresentamos um experimento preliminar sobre o consumo de energia. Esse experimento indicou que vale a pena despender esforço com estudo do consumo de energia no evWTRP. Alguns dos ítens que podem ser levados em conta no estudo do consumo de energia no protocolo de anel de anéis, são: otimização do tempo que um nó segura token de permissão; ajustamento em recepção de transmissões não relevantes (transmissões recebidas de nós sem relacionamento direto); e, utilização de token só para controle de conectividade. 
CONCLUSÕES 


\section{Apêndice A}

\section{Especificação}

Neste capítulo especificamos os quadros que representam os formatos das mensagens (tokens de permissão e especiais, trocados entre nós).

\section{A.1 Especificação dos quadros de tokens}

1. Token Deletado

Para evitar que um token (em um varal ou anel) seja recuperado, o valor 00000000 é atribuído ao campo FC de um token.

2. Token Normal

\begin{tabular}{|c|c|c|c|c|c|c|c|}
\hline 00000001 & RA & DA & SA & NoN & Gen_Seq & Coord_Seq & Seq \\
\hline 1 & 2 & 2 & 2 & 8 & 8 & 8 & 8
\end{tabular}

Permite ao nó portador utilizar com exclusividade os recursos compartilhados e disponíveis no anel com RA.

3. Token de eleição

\begin{tabular}{|c|c|c|c|c|c|c|}
\hline 00000010 & RA & DA & SA & MAX_POWER & MAX_ID & participantes \\
\hline 1 & 2 & 2 & 2 & 8 & 2 & 8
\end{tabular}

Permite eleger proprietário de um anel. O nó que contém ID igual a MAX_ID é eleito proprietário.

4. Aviso de proprietário eleito

\begin{tabular}{|c|c|c|c|c|}
\hline 00000011 & RA & DA & SA & ELECTED \\
\hline 1 & 2 & 2 & 2 & 2 \\
\hline
\end{tabular}

Passa de nó em nó anunciando que o nó cujo ID é igual a ELECTED, foi eleito proprietário ou coordenador do anel.

5. Atribuição de predecessor

\begin{tabular}{|c|c|c|c|c|c|c|}
\hline 00000100 & RA & DA & SA & NoN & Gen_Seq & Seq \\
\hline 1 & 2 & 2 & 2 & 8 & 8 & 8
\end{tabular}

Permite que o nó com DA possa ser sucessor do nó com SA. É utilizado para inclusão e saída de um nó em um anel. 
6. Atribuição de sucessor

\begin{tabular}{|c|c|c|c|c|}
\hline 00000101 & SA & RA & SA & NS \\
\hline 1 & 2 & 2 & 2 & 2 \\
\hline
\end{tabular}

Permite que o nó com DA possa ser predecessor do nó com NS (futuro sucessor).É usado para inclusão e saída de um nó em um anel.

7. Adverte selecionado

\begin{tabular}{|l|l|l|l|}
\hline 00000110 & SA & RA & NS \\
\hline
\end{tabular}

Representa o tipo de pacote enviado do nó (com endereço SA) que deseja entrar em um anel para o nó que ele selecionou dentre os que responderam.

8. Token de varal

\begin{tabular}{|c|c|c|c|c|c|c|}
\hline 00000111 & RA & DA & SA & NoN & Gen_Seq & Seq \\
\hline 1 & 2 & 2 & 2 & 8 & 8 & 8
\end{tabular}

Permite ao coordenador portador utilizar com exclusividade os recursos compartilhados e disponíveis no anel com RA.

9. Token de eleição em um varal

\begin{tabular}{|c|c|c|c|c|c|c|}
\hline 00001000 & RA & DA & SA & MAX_POWER & MAX_ID & participantes \\
\hline 1 & 2 & 2 & 2 & 8 & 2 & 8 \\
\hline
\end{tabular}

Permite eleger um novo proprietário de varal e passa de nó em nó até voltar ao nó que o gerou.

10. Aviso de proprietário eleito em um varal

\begin{tabular}{|c|c|c|c|c|}
\hline 00001001 & RA & DA & SA & ELECTED \\
\hline 1 & 2 & 2 & 2 & 2 \\
\hline
\end{tabular}

Passa de nó em nó anunciando que o nó cujo ID igual a ELECTED, foi eleito proprietário do varal.

11. Atribuição de predecessor em um varal

\begin{tabular}{|c|c|c|c|c|c|c|}
\hline 00001010 & RA & DA & SA & NoN & Gen_Seq & Seq \\
\hline 1 & 2 & 2 & 2 & 8 & 8 & 8
\end{tabular}

Permite que o nó com DA possa ser sucessor do nó com SA. É utilizado para inclusão e saída de um nó em um varal.

12. Atribuição de sucessor em um varal

\begin{tabular}{|c|c|c|c|c|}
\hline 00001011 & RA & DA & SA & NS \\
\hline 1 & 2 & 2 & 2 & 2 \\
\hline
\end{tabular}

Permite que o nó com DA possa ser predecessor do nó com NS (futuro sucessor). É utilizado para inclusão e saída de um nó em um varal. 
13. Token de aviso de entrada

\begin{tabular}{|c|c|c|c|c|}
\hline 00001101 & RA & DA & SA & ID \\
\hline 1 & 2 & 2 & 2 & 2
\end{tabular}

Este token é utilizado para avisar que o nó $\mathrm{N}$ acabou de entrar no anel cujo endereço é RA. Ele transita de sucessor em sucessor até o predecessor do nó com identificador ID.

14. Token de aviso de saída

\begin{tabular}{|c|c|c|c|c|}
\hline 00001110 & RA & DA & SA & ID \\
\hline 1 & 2 & 2 & 2 & 2 \\
\hline
\end{tabular}

Este token é utilizado para avisar que o nó cujo identificador igual a ID saiu do anel de endereço RA. Ele transita de sucessor em sucessor até o predecessor do nó com identificador ID.

15. Token de reentrada

\begin{tabular}{|c|c|c|c|c|}
\hline 00001111 & RA & DA & SA & ID \\
\hline 1 & 2 & 2 & 2 & 2
\end{tabular}

Este token é utilizado quando um nó quer enviar ID dele para o sucessor. Sempre que houver queda inesperada em um anel, este token é enviado e recebido entre os nós restantes no anel.

16. Token de solicitação de entrada em um anel

\begin{tabular}{c|c|c|c|}
\hline 00010000 & RA & Br. & SA \\
\hline 1 & 2 & 2 & 2
\end{tabular}

Um nó utiliza este token para solicitar entrada em um anel. O campo RA é ID desse nó, se esse nó chegou a formar um anel unitário. Senão, RA é um campo com valor inválido (definido).

17. Token de solicitação de entrada em um varal

\begin{tabular}{|c|c|c|c|}
\hline 00010001 & RA & Br. & SA \\
\hline 1 & 2 & 2 & 2
\end{tabular}

Um nó utiliza este token para solicitar entrada em um varal. O campo RA é endereço do anel a qual o nó pertence.

18. Resposta a mensagem adverte selecionado

\begin{tabular}{c|c|c|c|}
\hline 00010010 & DA & SA & SUCC \\
\hline 1 & 2 & 2 & 2
\end{tabular}

Representa pacote de mensagem de resposta do nó selecionado (com endereço SA) à advertência enviada pelo nó que deseja ser incluso.

19. Token de resposta a solicitação de entrada em um anel

\begin{tabular}{cc|c|c|}
\hline 00010100 & DA & SA & MY_SUCC \\
\hline 1 & 2 & 2 & 2
\end{tabular}

Esse token é enviado em resposta a solicitação de entrada do nó com endereço DA em um anel. 
20. Token de resposta a solicitação de entrada em um varal

\begin{tabular}{|c|c|c|c|}
\hline 00010101 & DA & SA & MY_SUCC \\
\hline 1 & 2 & 2 & 2
\end{tabular}

Esse token é enviado em resposta a solicitação de entrada feita pelo nó com endereço DA em um anel.

21. Token de alerta de saída de um coordenador

\begin{tabular}{|c|c|c|c|c|c|c|}
\hline 00010110 & RA & Br. & SA & PRED_V & SUCC_V & SUCC \\
\hline 1 & 2 & 2 & 2 & 2 & 2 & 2 \\
\hline
\end{tabular}

Um coordenador cessante, que possui sucessor SUCC no anel RA, predecessor PRED_V e sucessor SUCC_V no varal, faz um broadcast desse token avisando a sua saída. 


\section{Apêndice B}

\section{Alguns detalhes da implementação do protocolo}

Neste capítulo falaremos de principais funcionalidades implementadas no protocolo e na última seção B.3 falaremos um pouco do simulador de rede - NS.

O protocolo foi implementado em $\mathrm{C}++$ e criamos cenários para simulação usando OTcl. Para tal, instalamos o NS; criamos um diretório (manet-trp) onde colocamos todos os arquivos criados para o nosso protocolo.

Para explicar principais funcionalidades do processo de desenvolvimento, primeiro vamos explicar os arquivos de código fonte $(\mathrm{em} \mathrm{C}++$ ) criados; depois, arquivos de código fonte $(\mathrm{em} \mathrm{C}++\mathrm{e}$ OTcl) alterados.

\section{B.1 Descrição dos arquivos criados}

\section{B.1.1 wtrp.h}

Este arquivo contém definição de temporizadores e definição da classe principal (WTRP) do protocolo (trecho de código B.1). A classe Generic_timer é uma classe genérica que implementa os mecanismos necessários para que, ao expirar, um temporizador possa executar alguma ação. A classe WTRP herda da classe Agent, e contém todos os atributos e comportamentos necessários para representar um nó (estação) em uma rede ad-hoc sem fio.

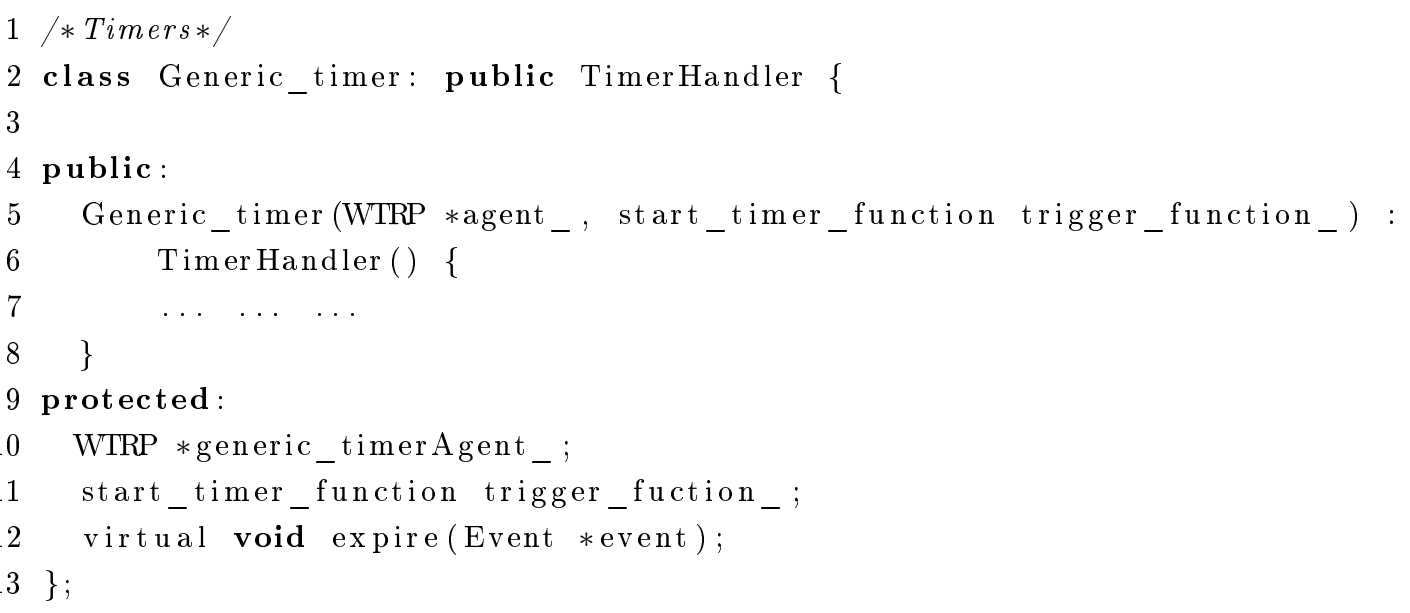


15 class WTRP: public Agent \{

16

17 protected :

$18 / /$ Timers types

19 Generic_timer solicitEntering_timer_;

20

21

22 public:

$23 \operatorname{WTRP}($ nsaddr_t ID ) ;

24

25 void recv(Packet * packet, Handler *);

26 int command(int, const char $*$ const $*$ );

27 ;

Listing B.1: Classes em wtrp.h

\section{B.1.2 wtrp.cc}

wtrp.cc é o arquivo principal da nossa implementação. Ele contém as funções que provêm mecanismos para ligação com OTcl, execução do protocolo inclusive recepção e envio de dados.

1

2 int hdr_wtrp_packet: : offset_;

3 static class WTRPHeaderClass: public PacketHeaderClass \{

4 public:

5 WTRPHeaderClass () :

6 PacketHeaderClass ("PacketHeader/WTRP", sizeof (hdr_all_packets) \{

$7 \quad$ bind_offset (\&hdr_wtrp_packet : : offset_ $)$;

$8\}$

9 \} class_wtrp_hdr;

10

11 static class WTRPclass: public TclClass \{

12 public:

13 WTRPclass () :

14 TclClass ("Agent/WTRP") \{

$15\}$

16 TclObject $*$ create (int argc, const char $*$ const $*$ argv $)\{$

17 assert $(\operatorname{argc}==5)$;

18 return (new $\operatorname{WTRP}\left(\left(\right.\right.$ nsaddr_t$\left._{-}\right)$Address : : instance ()$\left.\left.\cdot \operatorname{str} 2 \operatorname{addr}(\operatorname{argv}[4])\right)\right)$;

$19\}$

$20\}$ class_wtrp;

21

22 WTRP: :WTRP( nsaddr_t ID ) :

23 Agent (PT_WTRP), resetstate_timer_(this, \&WTRP: : clean_dataStructures), offlinestate_timer_(

this, \&WTRP:: do_offline_timeout), solicitEntering_timer_(this , \&WTRP: : solicit_joinRing), collecting_repliers_timer_(this , \&WTRP: : contact_replier), solicit_setPredecessor_timer_(this, \&WTRP: : do_waitFor_predecessor_expired), release_token_timer_( this, \&WTRP: : transmitting_token), monitoringstate_timer_(this, \&WTRP: : transmitting_token), release_vtoken_timer_(this, \&WTRP: : transmitting_varal_token), vmonitoringstate_timer_(this, \&WTRP: : transmitting_varal_token ), packetControlQueue () \{ 


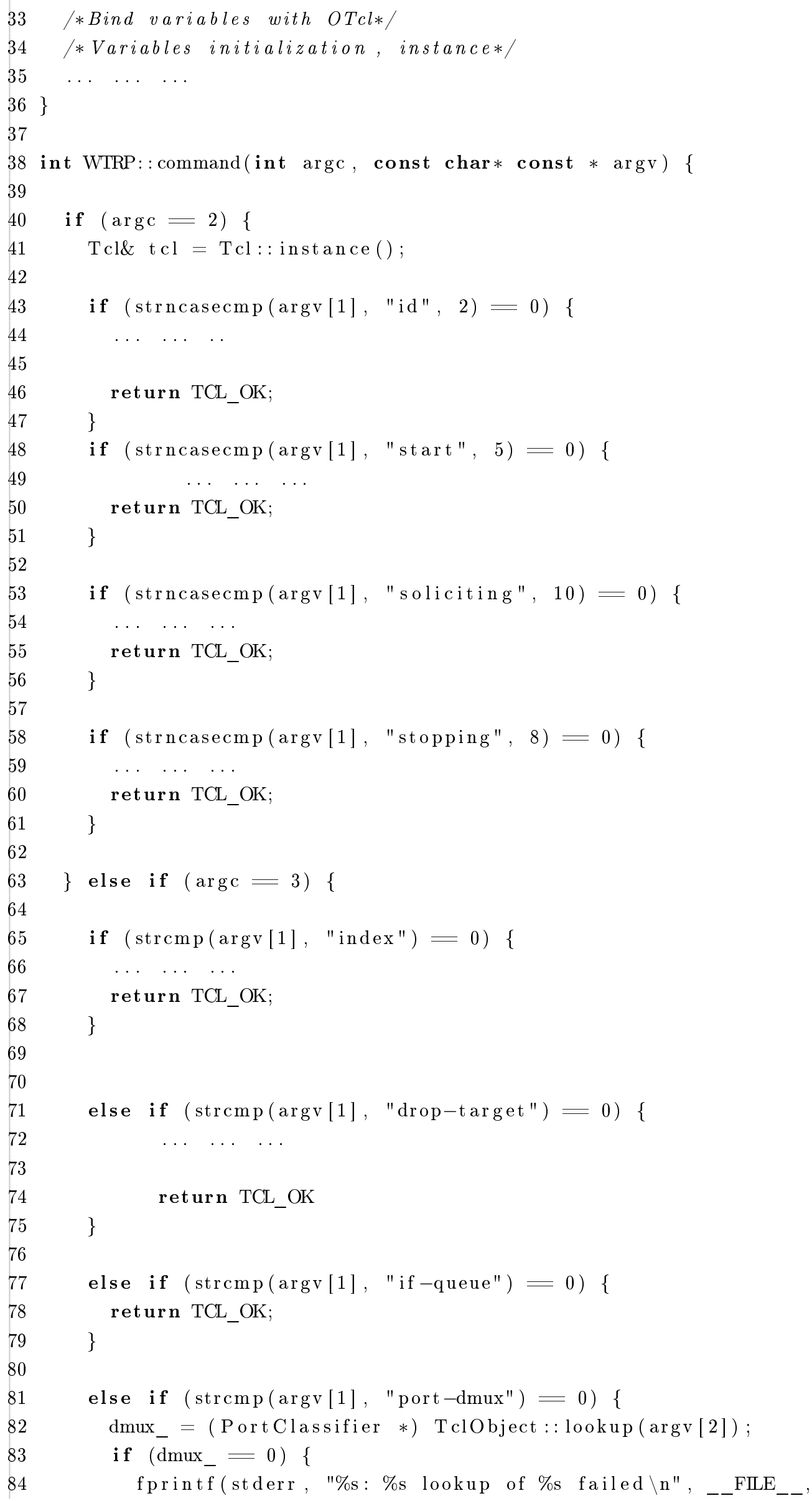




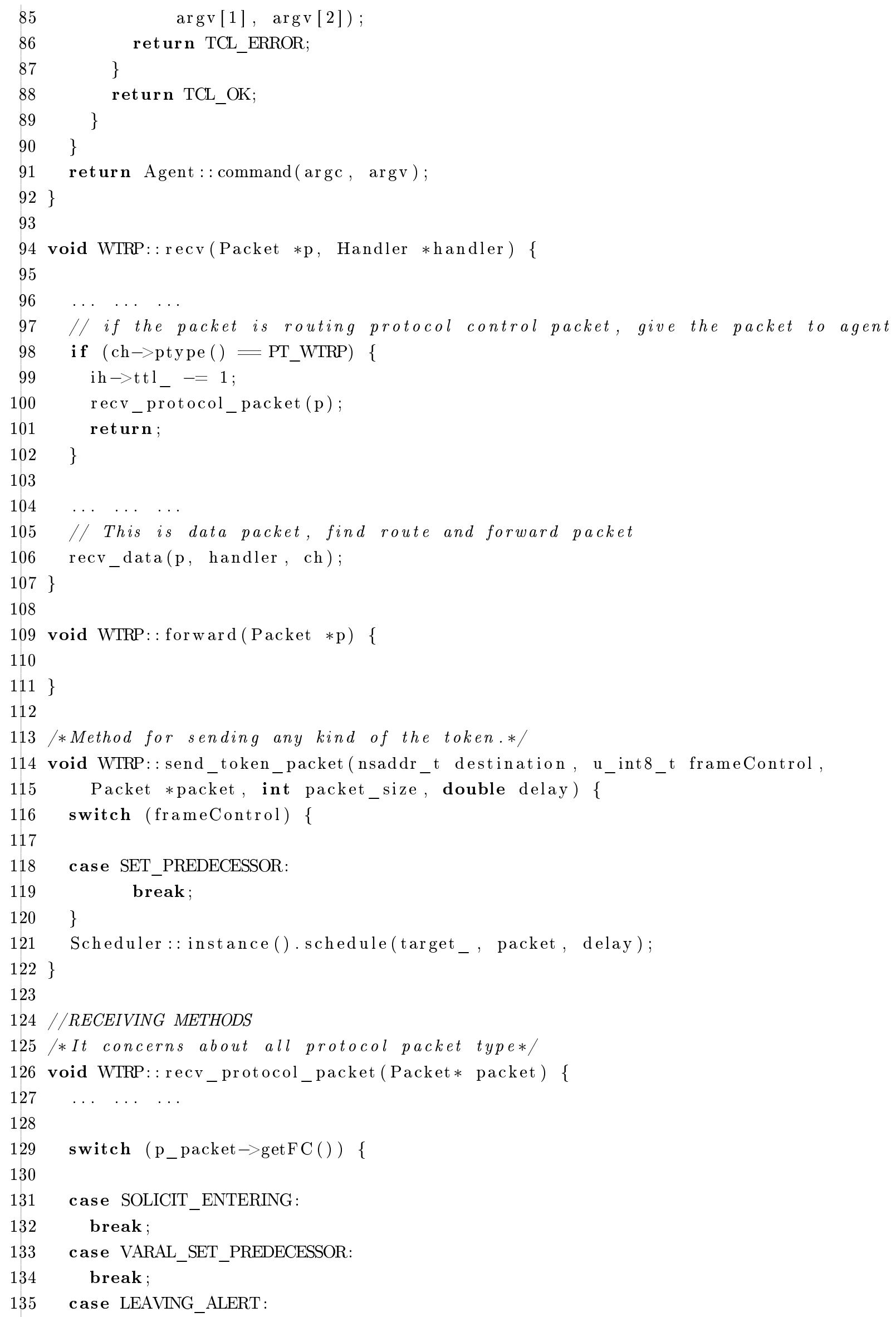




\section{Listing B.2: Classes em wtrp.cc}

No trecho de código B.2, as duas primeiras classes implementam a ligação entre interface Tcl com cabeçalho de pacote e agente WTRP, respectivamente. No construtor de agente WTRP destacamos o argumento PT_WTRP da classe Agent. Este argumento identifica qualquer pacote pertencente a um agente WTRP dentro do ambiente NS2. O nosso agente herda o método command da classe Agent; argv[0] armazena o nome do método a ser invocado, argv[1] armazena as instruções obrigatórias (por exemplo "start") e também armazena as instruções que desejamos executar a partir do Tcl. Por exemplo, um nó solicitar entrada, e um nó deixar anel - "soliciting" e "stopping", respectivamente.

O método recv() é invocado sempre que um agente de roteamento receber um pacote. A partir desse método conferimos se o pacote é para encaminhar para camada de Agente, se é pacote de dados, ou se o pacote é de controle (roteamento). Se for este último, o pacote é entregue a recv_protocol_packet(Packet* packet) para processar de acordo com tipo de pacote (SOLICIT_ENTERING, NORMAL_TOKEN, etc).

A função send_token_packet(nsaddr_t destination, $u_{-}$int8_t frameControl, Packet * packet, int packet_size, double delay) agenda (para delay) envio de pacote de tamanho packet_size, do tipo frameControl para o destinatário destination.

\section{B.1.3 wtrp_packet.h}

O arquivo wtrp_packet.h contém definições de estruturas de tabela de conectividade, lista de nós escutados, lista de identificadores em um anel. Também contém descrição de estados em que um nó pode se encontrar.

\section{B.1.4 node.h}

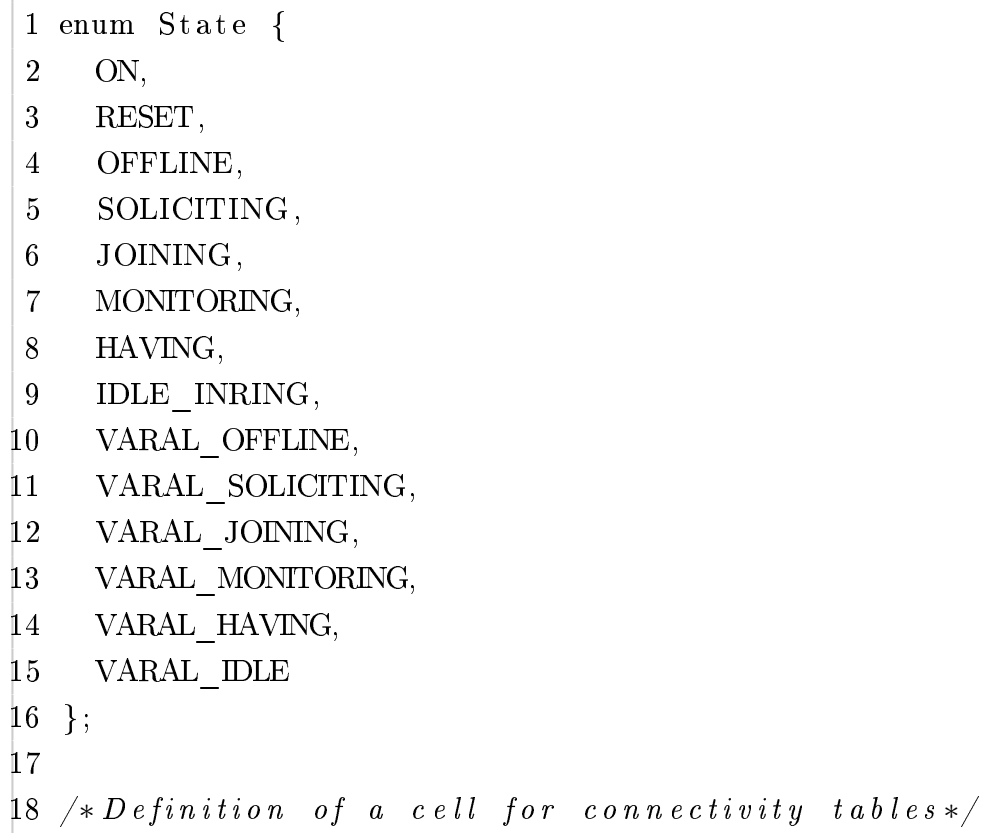




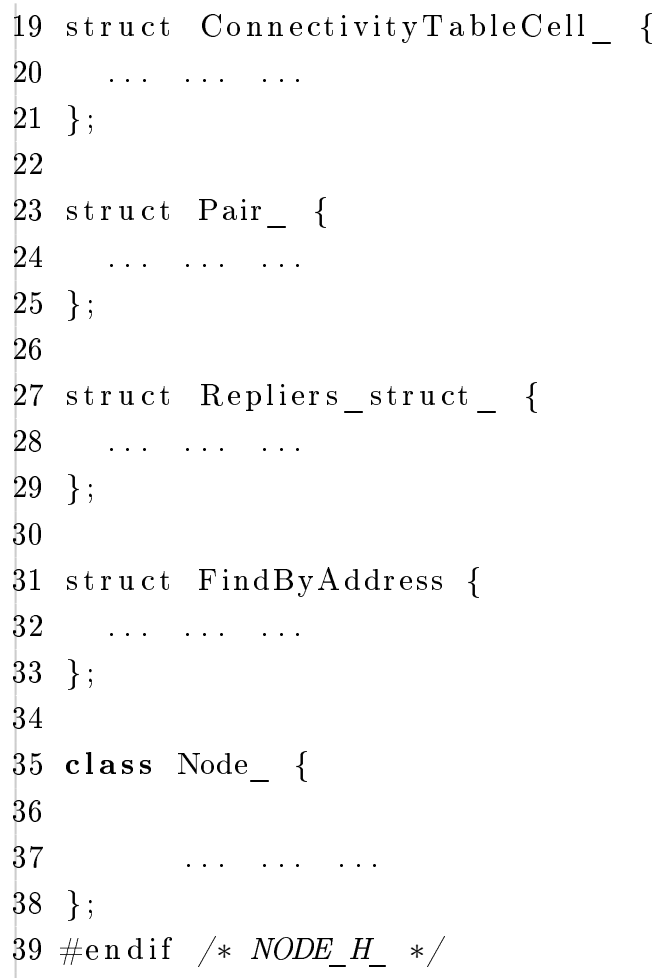

Listing B.3: node.h

O node.h (trecho B.3) contém uma enumeração (State) que define os possíveis estados de um nó; as estruturas que definem campos das tabelas e listas de um nó; e a classe Node_ que define todos os atributos inerentes a um nó dentro e fora de um anel.

\section{B.1.5 ringutils.h e ringutils.cc}

Esses dois arquivos contêm funções que auxiliam o nó no preparo de recepção e transmissão de pacotes.

\section{B.1.6 utils-constants.h}

Contém definições das constantes usadas em temporizadores e em inicializações de atributos de nós.

\section{B.2 Arquivos alterados}

Nesta seção apresentaremos os arquivos que fazem parte da ferramenta NS2 e que tivemos que alterar para ter o nosso protocolo funcionando.

\section{B.2.1 Arquivos em $\mathrm{C}++$ e o Makefile}

- Makefile

1 manet-trp/wtrp.o manet-trp/ringutils.o

Listing B.4: Ligação de objetos do protocolo no Makefile

- packet.h no diretório ns-2.35/common 


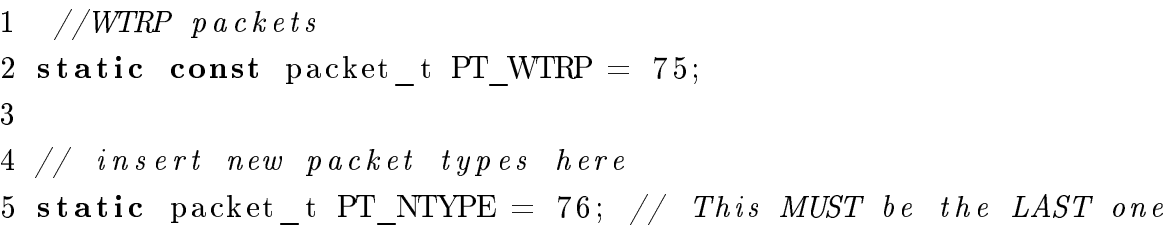

Listing B.5: Definição de tipo de pacote

No arquivo packet.h adicionamos um tipo de pacote (B.5) que permite NS2 reconhecer pacotes do nosso protocolo. Ademais, dentro da classe Packet, adicionamos uma variável received_power_ (B.6) para armazenar energia recebida com um pacote.

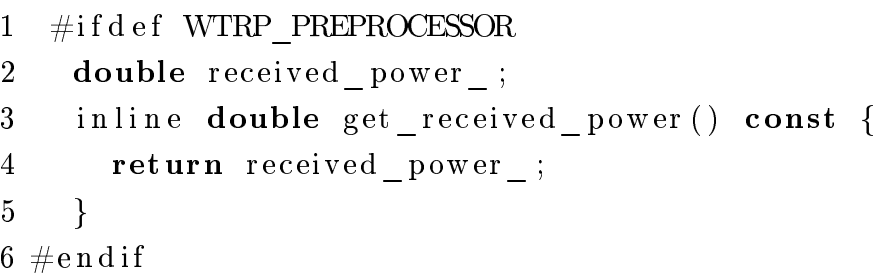

Listing B.6: Armazenamento de energia recebida

- priqueue.cc O tipo de fila implementado no arquivo trata pacotes de roteamento do protocolo WTRP como de alta prioridade. Para tal precisamos avisar a classe Priqueue que pacotes de WTRP são pacotes de roteamento.

- cmu-trace.h e cmu-trace.cc Nos arquivos cmu-trace e cmu-trace.cc criamos uma função para impressão de conteúdo entre camadas de um nó, e também para impressão de conteúdo trocados entre nós.

- wireless-phy.cc no diretório /mac

1 \# i f d e f WTRP_PREPROCESSOR

$2 \quad \mathrm{p} \rightarrow$ received_power_ $=\operatorname{Pr}$;

3 \#endif

Listing B.7: Atribuição de energia recebida com um pacote

Para fazer energia recebida chegar a agente WTRP, além das alterações (declarações) feita no arquivo packet.h tivemos que atribuir valor calculado $(\operatorname{Pr}$ para pacote $p)$ através do método sendUp() da classe WirelessPhy

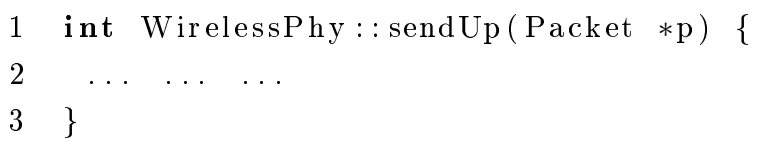

Listing B.8: Protótipo do método sendUp

do arquivo wireless-phy.cc 


\section{B.2.2 Arquivos em OTcl}

- agent.tcl no diretório /tcl/lib/

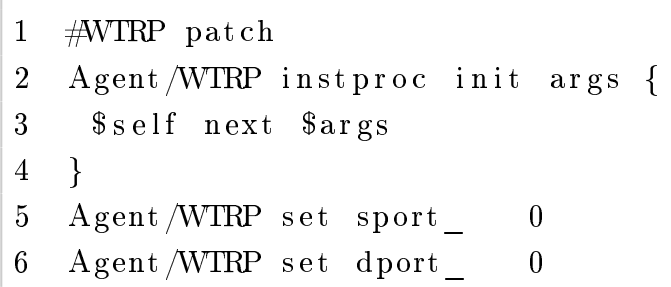

Listing B.9: Atribuição de portas em arquivo tcl

O trecho acima ilustra a atribuição de portas a agente de roteamento, onde sport é a porta de origem e dport é a porta destino.

- ns-default.tcl no diretório /tcl/lib/

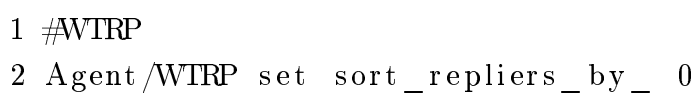

Listing B.10: Atribuição de valor padrão a variável em arquivo tcl

Neste arquivo atribuimos valores padrão a variáveis que podem ser inicializadas (com valores mais adequados) em script tcl e usadas em arquivos $\mathrm{c}++$.

- ns-lib.tcl no diretório /tcl/lib/

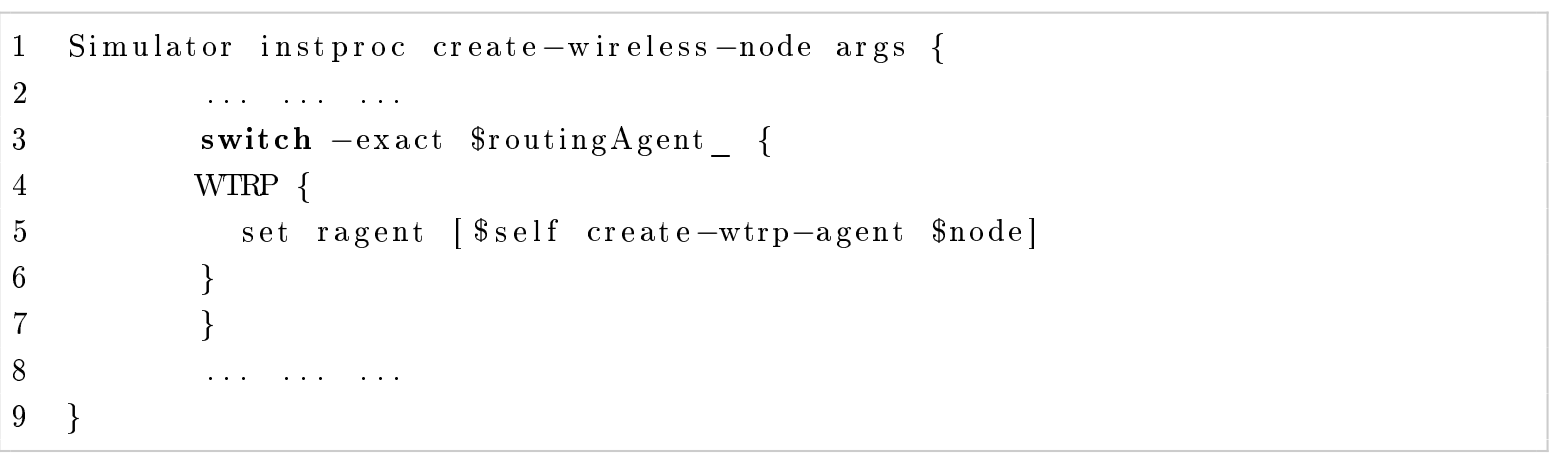

Listing B.11: Procedimento para criar um nó em arquivo tcl

O trecho apresentado em B.11 permite que um nó criado seja atachado a um agente de roteamento para o protocolo WTRP.

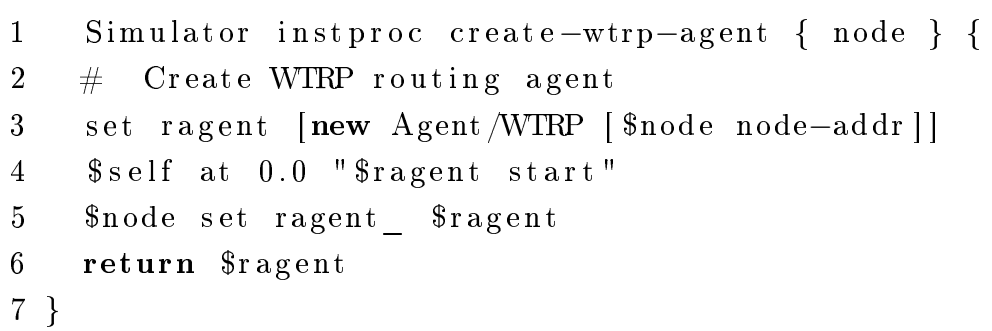

Listing B.12: Cria um agente WTRP

Em B.12 criamos um agente WTRP com endereço node-addr de um nó. Esse agente é agendado para começar no instante 0.0 de simulação, e é atribuido como agente de roteamento para um nó [RR04]. 
- ns-packet.tcl no diretório /tcl/lib/

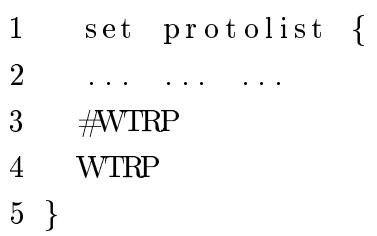

Listing B.13: Definição de nome do protocolo em arquivo tcl

Na definição da lista protolist definimos um nome "WTRP" para o protocolo.

\section{B.3 Simulador de rede}

O simulador de rede (NS versão 2) [DAR11], mais conhecido por ns2, é uma ferramenta de simulação que se baseia em evento discreto.

Simulador NS é composto principalmente por duas linguagens de programação: $\mathrm{C}++$ e OTcl (TCL orientado a objeto) [IH02]. Nas linhas que se seguem apresentaremos arquitetura básica e estrutura de diretórios do NS.

\section{B.3.1 Exemplo de um arquivo TCL}

Nesta seção apresentamos um exemplo de arquivo TCL configurado para simular execução do nosso protocolo WTRP com 5 nós.

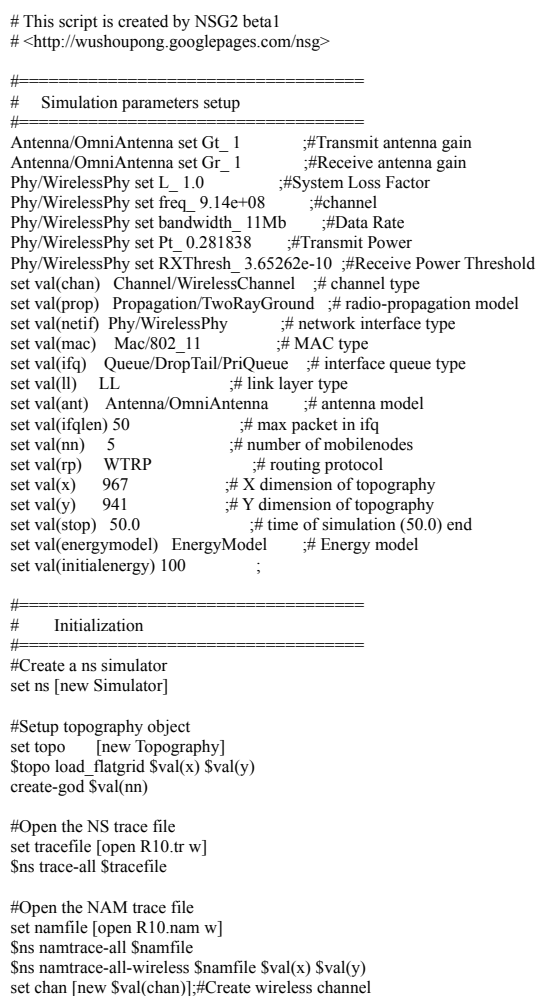

Figura B.1: Exemplo de um arquivo TCL 


\section{B.3.2 Revisão do conceito}

De um lado, simulações detalhadas de protocolos requerem que uma linguagem de programação possa eficientemente manipular bytes, cabeçalhos de pacotes, e implementar algoritmos que funcionam sobre um grande conjunto de dados. Essas tarefas requerem eficiência em tempo de execução. Por outro lado, uma grande parte de pesquisa em redes envolve configurações, diferentes alterações de parâmetros e cenários, sem a necessidade de re-compilar a implementação de um protocolo. Para essas situações é importante a eficiência em tempo de alteração de parâmetros e cenários. Para solucionar esses problemas NS usa duas linguagens de programação, a saber:

- $\mathrm{C}++$ é eficiente quanto ao tempo de execução e nem tanto quanto as alterações para recompilação.

- OTcl é ineficiente quanto a execução, mas eficiente quanto as alterações de cenários para simulação.

Depois de simulações, NS2 gera resultado de simulação (em texto) e (animação). Para interpretar esses resultados graficamente e interativamente, ferramentas como NAM (animador de rede) e Xgraph são usadas. Para analisar um comportamento de rede em particular, usuários podem extrair um subconjunto relevante de dados de texto e transformá-lo em uma apresentação mais concisa.

\section{B.3.3 Estrutura do diretório NS}

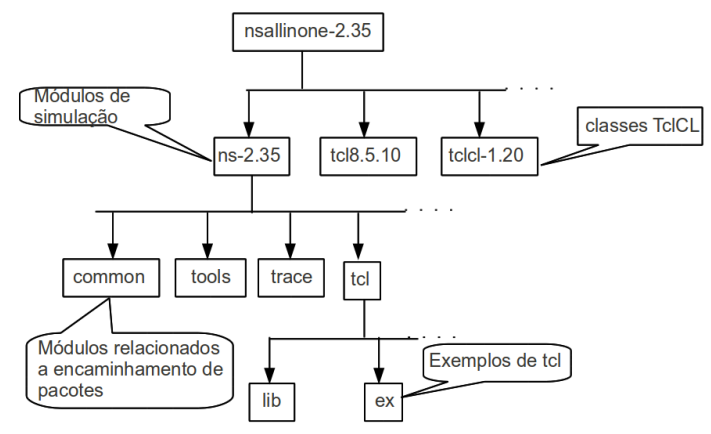

Figura B.2: Estrutura principal do NS

Na figura B.2 apresentamos a estrutura principal do diretório do NS (versão 2-35) após a instalação. No diretório ns-2.35 encontram-se todos os módulos necessários para executar simulações, no tcltc-1.20 estão as classes que permitem ligação objetos e variáveis, em ambas as linguagens $(\mathrm{C}++$ e $\mathrm{OTcl})$; no diretório common colocam-se os arquivos que permitem encaminhamento de pacotes criados para um novo protocolo ou para um protocolo já existente.

Após instalação do NS, usuário tem a sua disposição alguns protocolos de roteamento préinstalados (por exemplo, AODV [RDS09]). O usuário pode alterar esses protocolos ou adicionar um novo. O Protoname [RR04] é uma boa referência para aprender como adicionar um novo protocolo. 


\section{Apêndice C}

\section{Os problemas de terminal oculto e terminal exposto}

Neste capítulo introduzimos dois dos notáveis problemas em redes de natureza sem fio.

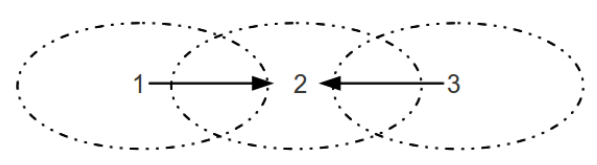

Figura C.1: O problema de terminal oculto

O protocolo MAC CSMA (Carrier Sense Multiple Access - vide Kleinrock, Tobagi 1975) que é utilizado em tecnologias 802.11, é simples e intuitivo [TT06]. Porém, este protocolo sofre do problema de terminal (nó) oculto e do problema de terminal exposto.

Para explicar o problema de terminal oculto, consideremos a figura C.1. Os terminais 1 e 3 não escutam as transmissões entre si. Se ambos utilizam CSMA e transmitirem sinais para o terminal 2 simultaneamente, poderá ocorrem colisão de sinais, e estes se auto-destruírem.

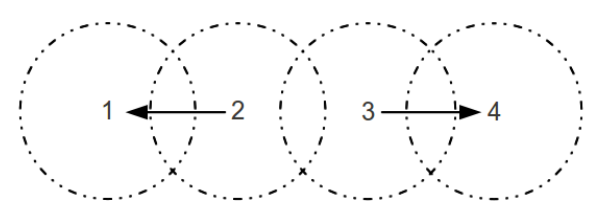

Figura C.2: $O$ problema de terminal exposto

No problema de terminal exposto um terminal não transmite sinais se ele perceber que algum terminal na sua vizinhança está transmitindo. Para explicar melhor o problema de terminal exposto, vamos considerar a figura C.2. Consideremos que o terminal 3 está usando o CSMA como protocolo MAC, e o terminal 2 está transmitindo pacotes para o terminal 1. Como terminal 2 escuta as transmissões do terminal 3 e vice-versa. Se o terminal 3 tiver pacotes para o terminal 4 , então enquanto o terminal 2 transmite para o terminal 1, o terminal 3 não transmitirá pacotes para o nó 4. Consequentemente, o terminal 3 vai provocar disperdício de largura de banda. 
APÊNDICE C 


\section{Apêndice D}

\section{Implementação de energia recebida com um pacote no NS}

Quando um nó recebe um determinado pacote, ele recebe também a energia $\operatorname{Pr}$ com a qual esse pacote foi transmitido. Como desejávamos uma opção que permitisse organizar os pacotes de resposta, a cada solicitação de entra, por energia de recebimento, então aproveitamos para implementar essa característica no nosso protocolo de seguinte modo: quando um nó $X$ solicita entrada em um anel $R$, ele ordena (de forma decrescente em uma lista) os pacotes recebidos em resposta a solicitação de entrada segundo $\operatorname{Pr}$. Para que seja possível obter o $\operatorname{Pr}$ na camada de roteamento adicionamos as seguintes alterações:

- Adicionamos um campo extra

1 received_power_

no arquivo packet.h conforme explicado em B.6.

- Atribuimos o valor $\operatorname{Pr}$ ao

1 received_power_

no arquivo wireless-phy.cc ao adicionar a instrução

1 \#i ifd ef WTRP_PREPROCESSOR

$2 \quad \mathrm{p} \rightarrow$ received_power_ $=\operatorname{Pr}$;

3 \# endif

no método

1 int WirelessPhy: : sendUp (Packet $* \mathrm{p})\{$

$2 \quad \ldots \quad \ldots \quad \ldots$

$3\}$

- No arquivo wtrp.cc conseguimos ler o valor de $\operatorname{Pr}$ uma vez que

1 received_power_

está armazenada no pacote recebido.

Assim foi possível ter (no arquivo wtrp.cc) o valor de $\operatorname{Pr}$ associado a um pacote sem quebrar a arquitetura do NS2. 
64 APÊNDICE D 


\section{Apêndice E}

\section{As configurações}

Neste apêndice apresentamos uma pequena amostra das configurações encontradas por cada um dos três critérios de entrada. Cada linha representa uma configuração - resultado de um experimento. As configurações encontradas estão disponíveis no endereço especificado em 5.4.

\section{E.1 Amostra do Resultado de simulações pelo critério conexão com primeira resposta}

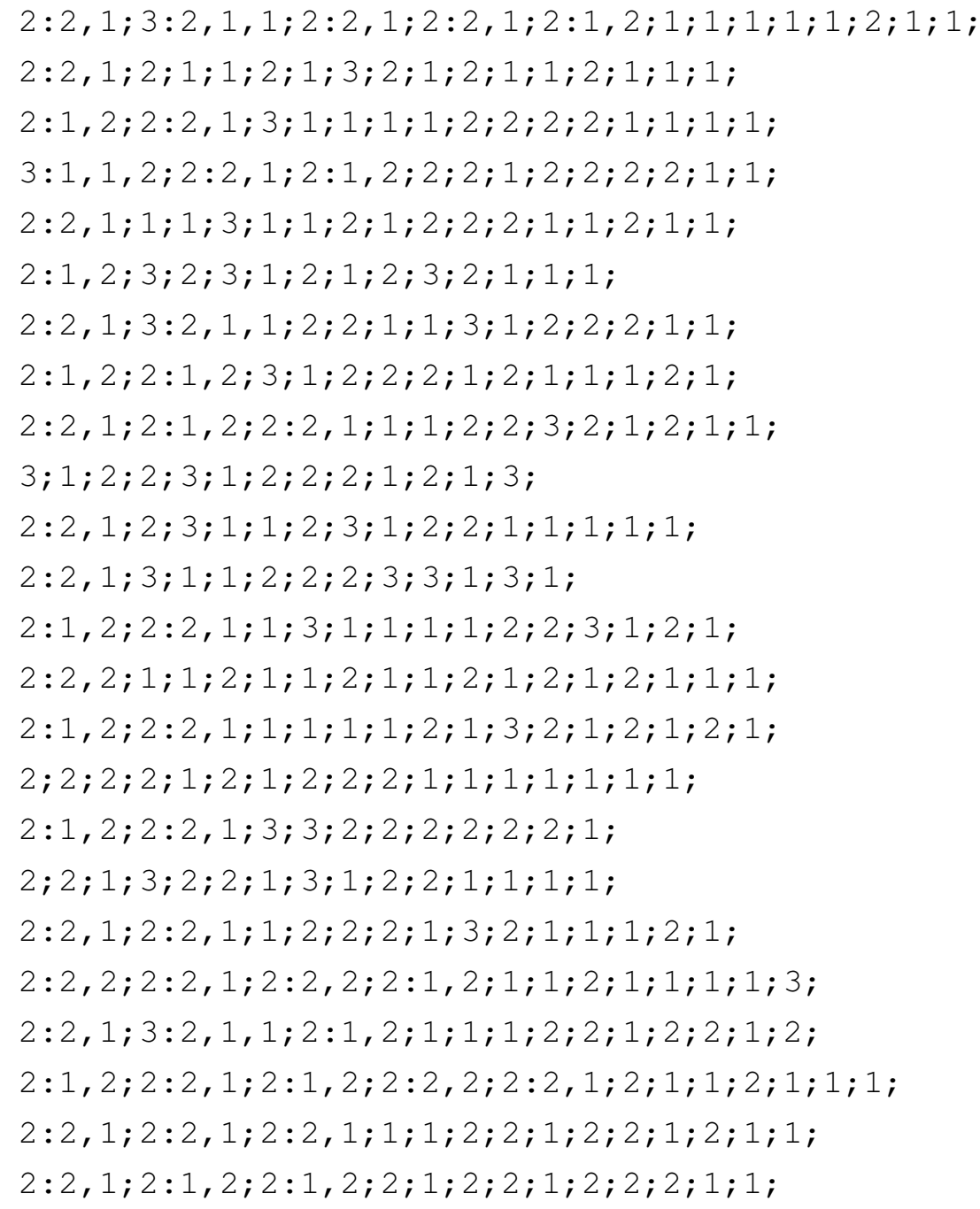




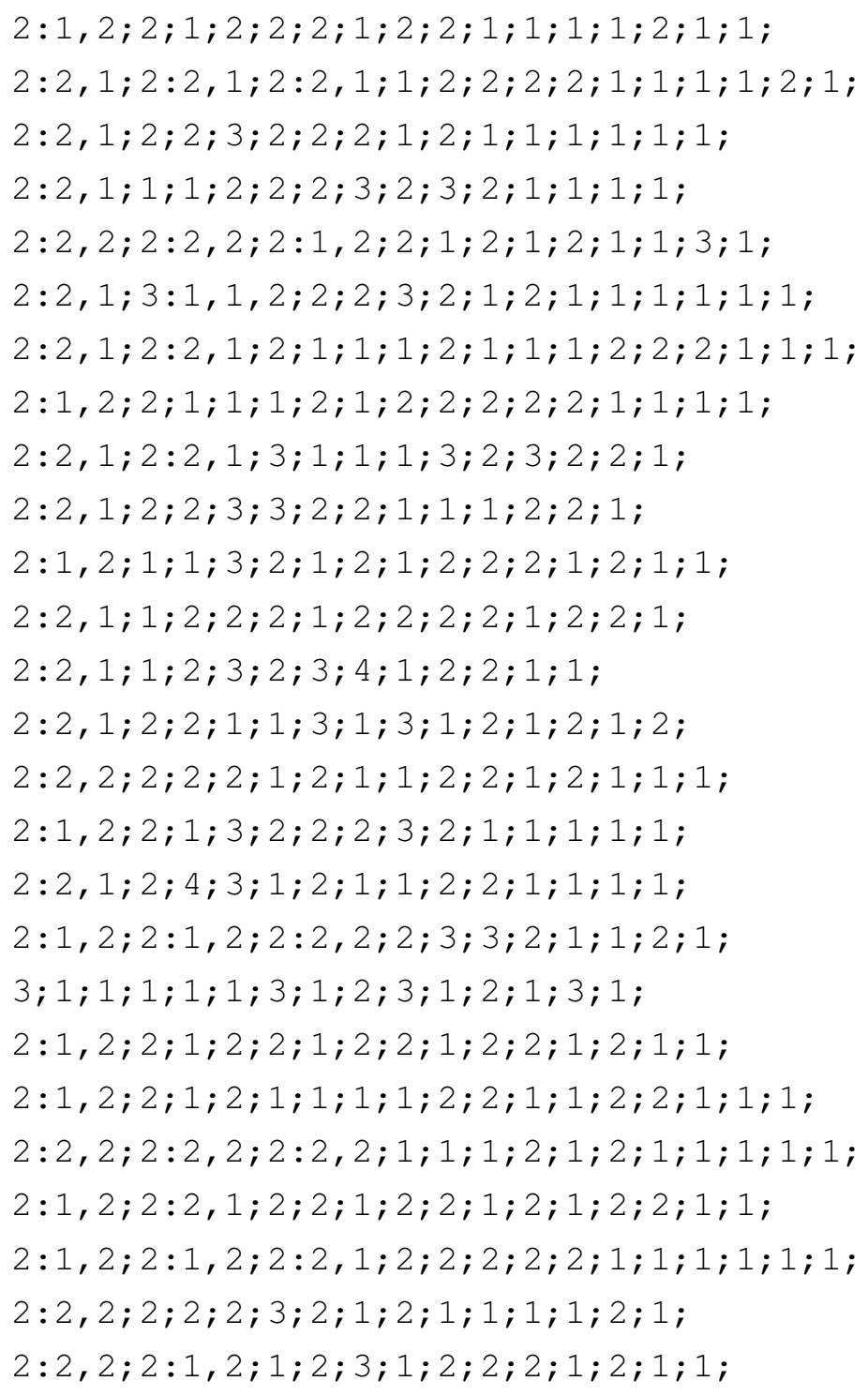

\section{E.2 Resultado de simulações pelo critério número de nós}

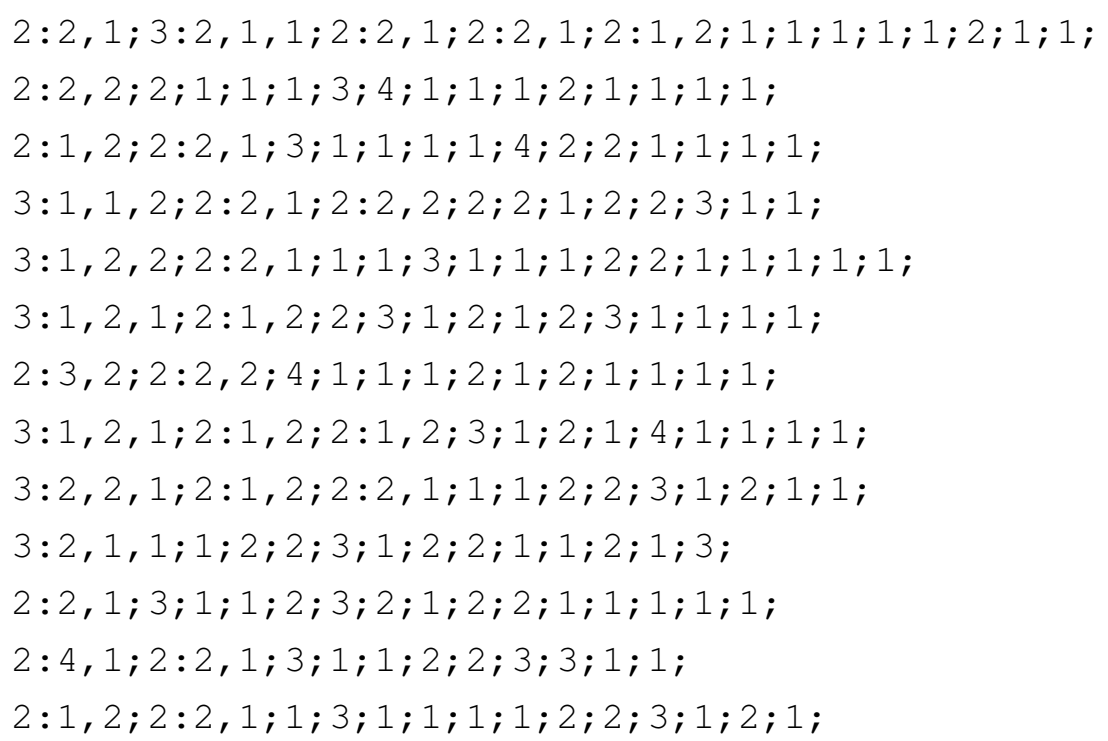




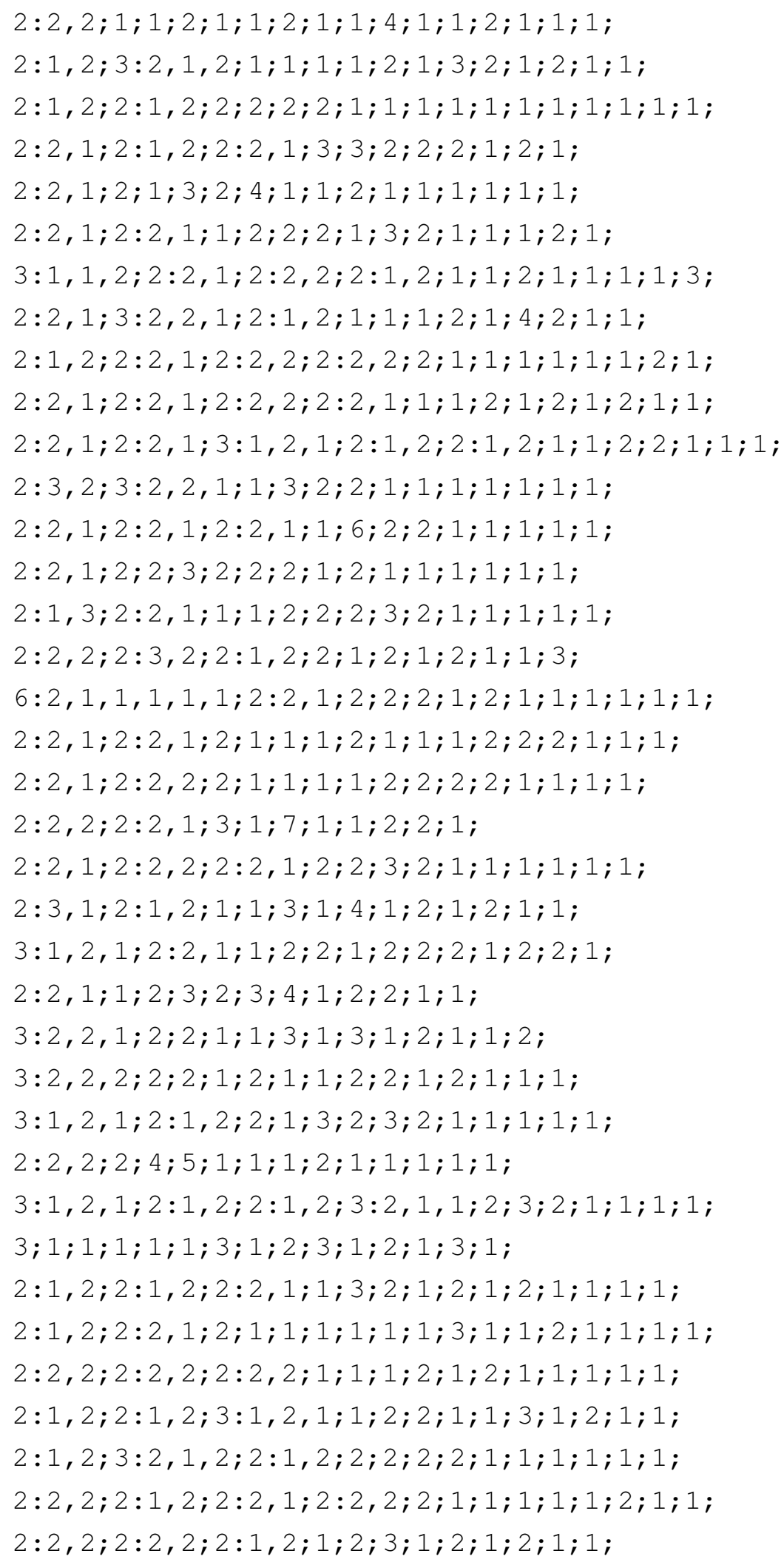

\section{E.3 Resultado de simulações pelo critério sinal de recebimento de pacote}

$2: 2,1 ; 2: 2,2 ; 2: 2,1 ; 2: 2,1 ; 2: 1,2 ; 1 ; 1 ; 1 ; 1 ; 1 ; 2 ; 1 ; 1$ $2: 1,2 ; 2 ; 1 ; 1 ; 2 ; 1 ; 3 ; 4 ; 1 ; 1 ; 1 ; 2 ; 1 ; 1 ; 1 ;$ 
$2: 1,2 ; 2: 2,1 ; 3 ; 1 ; 1 ; 1 ; 1 ; 4 ; 2 ; 2 ; 1 ; 1 ; 1 ; 1 ;$

$2: 1,3 ; 2: 2,1 ; 2: 2,2 ; 2 ; 2 ; 1 ; 2 ; 2 ; 3 ; 1 ; 1$;

$2: 2,1 ; 1 ; 1 ; 3 ; 1 ; 1 ; 4 ; 1 ; 2 ; 2 ; 1 ; 1 ; 2 ; 1 ; 1$;

$2: 1,2 ; 3 ; 2 ; 3 ; 1 ; 2 ; 1 ; 2 ; 3 ; 2 ; 1 ; 1 ; 1 ;$

$5: 1,2,1,1,1 ; 2: 2,2 ; 1 ; 1 ; 4 ; 1 ; 2 ; 2 ; 2 ; 1 ; 1 ;$

$3: 1,2,1 ; 2: 1,2 ; 2: 1,2 ; 3 ; 1 ; 2 ; 1 ; 4 ; 1 ; 1 ; 1 ; 1 ;$

$2: 1,2 ; 2: 2,1 ; 2 ; 1 ; 1 ; 2 ; 2 ; 3 ; 3 ; 1 ; 2 ; 1 ; 1$;

$3 ; 1 ; 2 ; 2 ; 3 ; 1 ; 2 ; 2 ; 2 ; 1 ; 2 ; 1 ; 3$;

$2: 2,1 ; 2 ; 3 ; 1 ; 1 ; 2 ; 3 ; 1 ; 2 ; 2 ; 1 ; 1 ; 1 ; 1 ; 1$;

$2: 2,1 ; 3 ; 1 ; 1 ; 2 ; 2 ; 2 ; 3 ; 3 ; 1 ; 3 ; 1 ;$

$2: 1,2 ; 2: 2,1 ; 1 ; 3 ; 1 ; 1 ; 1 ; 1 ; 2 ; 2 ; 3 ; 2 ; 1 ; 1$;

$2: 2,3 ; 1 ; 1 ; 2 ; 1 ; 1 ; 2 ; 1 ; 4 ; 1 ; 1 ; 2 ; 1 ; 1 ; 1 ;$

$2: 1,2 ; 2: 1,2 ; 1 ; 1 ; 1 ; 1 ; 2 ; 1 ; 2 ; 1 ; 2 ; 1 ; 2 ; 2 ; 1 ; 1$;

$2: 1,2 ; 2: 2,2 ; 2 ; 2 ; 2 ; 2 ; 1 ; 1 ; 1 ; 1 ; 1 ; 1 ; 1 ; 1 ; 1 ; 1$;

$2: 1,2 ; 2: 2,1 ; 2: 2,2 ; 2 ; 2 ; 2 ; 2 ; 2 ; 2 ; 2 ; 1$;

$2 ; 2 ; 1 ; 3 ; 2 ; 4 ; 1 ; 3 ; 1 ; 2 ; 1 ; 1 ; 1 ; 1 ;$

$2: 2,1 ; 3: 2,1,1 ; 2: 2,1 ; 1 ; 1 ; 3 ; 2 ; 1 ; 1 ; 3 ; 1 ; 1 ; 1$;

$2: 2,2 ; 2: 2,1 ; 2: 1,2 ; 1 ; 1 ; 2 ; 2 ; 1 ; 1 ; 1 ; 2 ; 1 ; 3$;

$2: 2,1 ; 2: 2,1 ; 2: 1,2 ; 1 ; 1 ; 1 ; 3 ; 2 ; 1 ; 2 ; 2 ; 1 ; 2$;

$2: 1,2 ; 2: 2,1 ; 2: 1,2 ; 2: 2,2 ; 2: 2,1 ; 2 ; 1 ; 1 ; 1 ; 1 ; 1 ; 1 ; 1$;

$2: 2,1 ; 2: 2,1 ; 2: 2,1 ; 1 ; 1 ; 2 ; 2 ; 1 ; 2 ; 2 ; 1 ; 2 ; 1 ; 1$;

$2: 2,1 ; 2: 1,2 ; 2: 1,2 ; 2 ; 1 ; 4 ; 1 ; 2 ; 2 ; 2 ; 1 ; 1$;

$4: 1,1,2,1 ; 3 ; 1 ; 3 ; 2 ; 2 ; 3 ; 1 ; 1 ; 1 ; 1 ; 1 ; 1$;

$2: 2,1 ; 2: 2,1 ; 2: 2,1 ; 1 ; 3 ; 2 ; 2 ; 1 ; 1 ; 1 ; 1 ; 3 ; 1$;

$2: 2,1 ; 2 ; 2 ; 3 ; 2 ; 2 ; 2 ; 1 ; 2 ; 1 ; 1 ; 1 ; 1 ; 1 ; 1$;

$2: 2,1 ; 1 ; 1 ; 2 ; 2 ; 3 ; 2 ; 2 ; 3 ; 2 ; 1 ; 1 ; 1 ; 1$;

$2: 3,2 ; 2: 1,2 ; 2 ; 2 ; 1 ; 2 ; 1 ; 2 ; 2 ; 1 ; 1 ; 3$;

$4: 1,1,2,1 ; 2: 2,1 ; 2 ; 2 ; 2 ; 1 ; 2 ; 1 ; 1 ; 1 ; 1 ; 1 ; 2 ; 1$;

$2: 2,1 ; 2: 2,1 ; 2 ; 1 ; 1 ; 1 ; 2 ; 1 ; 1 ; 1 ; 2 ; 2 ; 2 ; 1 ; 1 ; 1$;

$2: 2,1 ; 2: 2,2 ; 3 ; 1 ; 1 ; 1 ; 1 ; 1 ; 2 ; 2 ; 2 ; 1 ; 1 ; 1 ; 1$;

$2: 2,2 ; 2: 2,1 ; 3 ; 1 ; 3 ; 1 ; 1 ; 2 ; 2 ; 2 ; 2 ; 1$;

$2: 2,1 ; 3: 1,2,1 ; 2 ; 2 ; 3 ; 3 ; 2 ; 2 ; 1 ; 1 ; 1 ; 1 ;$

$2: 1,2 ; 1 ; 1 ; 3 ; 2 ; 1 ; 2 ; 1 ; 2 ; 2 ; 2 ; 1 ; 2 ; 1 ; 1$;

$2: 2,1 ; 1 ; 2 ; 3 ; 2 ; 1 ; 2 ; 2 ; 2 ; 1 ; 3 ; 2 ; 1 ;$

$2: 2,1 ; 2: 2,2 ; 1 ; 2 ; 3 ; 2 ; 3 ; 1 ; 2 ; 2 ; 1 ; 1$;

$3: 2,2,1 ; 2 ; 2 ; 1 ; 1 ; 3 ; 1 ; 3 ; 1 ; 2 ; 1 ; 1 ; 2$;

$3: 1,2,1 ; 2 ; 2 ; 3 ; 1 ; 2 ; 1 ; 1 ; 2 ; 2 ; 2 ; 1 ; 1 ; 1$;

$2: 2,1 ; 3: 1,2,1 ; 2: 1,2 ; 2 ; 3 ; 3 ; 2 ; 1 ; 1 ; 1 ; 1 ; 1$;

$2: 2,2 ; 2 ; 4 ; 3 ; 1 ; 1 ; 1 ; 2 ; 1 ; 1 ; 2 ; 1 ; 1 ; 1$;

$2: 1,2 ; 2: 1,2 ; 2 ; 3 ; 3 ; 2 ; 1 ; 2 ; 2 ; 1 ; 2 ; 1$;

$3 ; 1 ; 1 ; 1 ; 1 ; 1 ; 3 ; 1 ; 2 ; 3 ; 1 ; 2 ; 1 ; 3 ; 1$;

$2: 2,2 ; 2: 1,2 ; 1 ; 2 ; 2 ; 1 ; 2 ; 2 ; 1 ; 2 ; 1 ; 2 ; 1 ; 1$;

$2: 1,2 ; 2 ; 1 ; 2 ; 1 ; 1 ; 1 ; 1 ; 4 ; 1 ; 1 ; 2 ; 2 ; 1 ; 1 ; 1$; 
$3: 1,2,1 ; 2: 2,2 ; 2 ; 1 ; 1 ; 1 ; 2 ; 1 ; 2 ; 2 ; 1 ; 1 ; 1 ; 1 ; 1 ;$

$2: 1,2 ; 3: 1,2,1 ; 3 ; 1 ; 2 ; 2 ; 1 ; 1 ; 2 ; 1 ; 1 ; 2 ; 1 ; 1$;

$2: 1,2 ; 2: 1,2 ; 3 ; 2 ; 2 ; 2 ; 2 ; 2 ; 1 ; 1 ; 1 ; 1 ; 1 ; 1 ;$

$2: 1,2 ; 2: 1,2 ; 2: 2,2 ; 2 ; 2 ; 1 ; 1 ; 2 ; 1 ; 1 ; 1 ; 2 ; 1 ; 1$;

$2: 2,2 ; 2: 1,2 ; 1 ; 2 ; 3 ; 1 ; 2 ; 2 ; 2 ; 1 ; 2 ; 1 ; 1 ;$ 
APÊNDICE E 


\section{Referências Bibliográficas}

[CCH07] R.G. Cheng, R.I. Chang e K.L. Hua. IWTRP: Spatial-reuse Enhancement of the Wireless Token Ring Protocol. Communications Letters, IEEE, 11:701-703, Agosto 2007. 7,14

[CCV88] S. Casale, V. Catania e L. Vita. Fault Tolerance Increasing In Token Ring LANs. Local Computer Networks. páginas 446-452, Outubro 1988. 14

[DAR11] DARPA. Network simulator ns2. Online, Novembro 2011. VINT project at LBL, Xerox PARC, UCB, and USC/ISI. 59

[ELSV02] Mustafa Ergen, Duke Lee, Raja Sengupta e Pravin Varaiya. WTRP-Wireless Token Ring Protocol. IEEE Transaction on Vehicular Technology, 2002. 10

[Erg02] Mustafa Ergen. WTRP-Wireless Token Ring Protocol. Dissertação de Mestrado, Electrical Engineering and Computer Science, Graduate Division, University of California, USA, 2002. iii, v, xv, xvii, 1, 2, 3, 9, 11, 12, 13, 19, 20, 44

[HMDD04] Jeroen Hoebeke, Ingrid Moerman, Bart Dhoedt e Piet Demeester. An Overview of Mobile Ad Hoc Networks: Applications and Challenges. Journal of the Communications Network, 3:60-66, July 2004. 1, 6

[IEE07] IEEE Group. Wireless LAN Medium Access Control (MAC) and Physical Layer (PHY) Specifications, 2007. IEEE Standard 802.11v 2007. 2

[IH02] Teerawat Issariyakul e Ekram Hossain. Introduction to Network Simulator NS2. Springer, 2002. 59

[JS03] J. Jun e M. Sichitiu. Fairness and QoS in Multihop Wireless Networks. Vehicular Technology Conference, 5:2936-2940, Outubro 2003. 14

[Ke] Chih-Heng Ke. Ns2 learning guide. Online (acessado: 17/10/2013). 34

[KR06] James F. Kurose e Keith W. Ross. Redes de computadores e a Internet: uma abordagem top-down. Pearson Education Inc, 3 edição, 2006. 14, 19

[KTMN05] H. Kawahigashi, Y. Terashima, N. Miyauchi e T. Nakakawaji. Designing Fault Tolerance Ad Hoc Wireless Networks. Military Communications Conference, 3:1360-1367, Outubro 2005. 14

$\left[\mathrm{LAP}^{+} 01\right]$ Duke Lee, Roberto Attias, Anuj Puri, Raja Sengupta, Stavros Tripakis e Pravin Varaiya. A wireless token ring protocol for intelligent transportation systems. páginas 1152-1157, august 2001. 3, 9, 14

[LHG11] L.C. Llewellyn, K.M. Hopkinson e S.R. Graham. Distributed Fault-Tolerant Quality of Wireless Networks. Mobile Computing, IEEE Transactions, 10:175-190, Fevereiro 2011. 14 
$\left[\mathrm{LPV}^{+}\right.$02] Duke Lee, Anuj Puri, Pravin Varaiya, Raja Sengupta, Roberto Attias e Stavros Tripakis. Wireless token ring protocol for ad-hoc networks. IEEE Aerospace Conference Proceedings, 3:1219-1228, Março 2002. 9, 14

[LR09] A.P. Lauf e W.H. Robinson. Fault Tolerance in MANETs Using a Task-to-Resource Reallocation Framework. Computational Science and Engineering, 2:753-758, Agosto 2009. 14

[Pre11] Ligia Rodrigues Prete. Análise e desempenho de redes de acesso sem fio. Dissertação de Mestrado, UNIVERSIDADE ESTADUAL PAULISTA FACULDADE DE ENGENHARIA DE ILHA SOLTEIRA PROGRAMA DE PÓS-GRADUAÇÃO EM ENGENHARIA ELÉTRICA, Abril 2011. 14

[RDD13] Pankaj Rohal, Ruchika Dahiya e Prashant Dahiya. Study and analysis of throughput, delay and packet delivery ratio in manet for topology based routing protocols (aodv, $\mathrm{dsr}$ and dsdv). INTERNATIONAL JOURNAL FOR ADVANCE RESEARCH IN ENGINEERING AND TECHNOLOGY, 1, Março 2013. 35, 36

[RDS09] Mubashir Husain Rehmani, Sidney Doria e Mustapha Reda Senouci. A Tutorial on the implementation of Ad-hoc On Demand Distance Vector (AODV) protocol in Network Simulator (NS-2). Relatório técnico, June 2009. 60

[RR04] Francisco J. Ros e Pedro M. Ruiz. Implementing a new Manet Unicast Routing in ns2. 2004. 58, 60

[TKD] F. Top, V. Kohlhepp e F. Dowla. A Token Ring Protocol for Dynamic Ad-hoc Wireless Environments. 14

[trs98] Information technology - Telecommunications and information exchange between systems - Local and metropolitan area networks - Specific requirements - Part 5: Token ring access method and Physical Layer specifications, 1998. 3, 6, 7, 9

[TS02] Andrew Tanenbaum e Maarten Van Steen. Distributed systems, volume 2. Prentice Hall, 2002. 3, 7

[TT06] S. Toumpis e D. Toumpakaris. Wireless ad hoc networks and related topologies: applications and research challenges. Elektrotechnik and Informationstechnik, páginas 232-241, Fevereiro 2006. 5, 6, 40, 43, 61

[ZYCW04a] Deng Z., Lu Y., Wang C. e Wang W. E²WTRP: an energy-efficient wireless token ring protocol. Personal, Indoor and Mobile Radio Communications, 15th IEEE International Symposium, 1:574-578, Setembro 2004. 14

[ZYCW04b] Deng Z., Lu Y., Wang C. e Wang W. Ewtrp: Enhanced wireless token ring protocol for small-scale wireless ad hoc networks. Communications, Circuits and Systems, 1:398401, Junho 2004. 14 